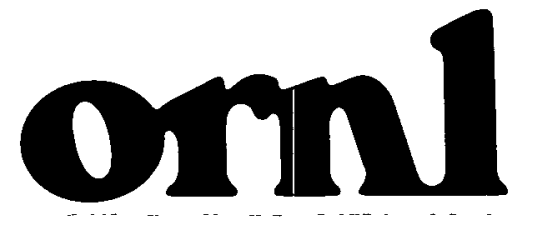

OAK RIDGE NATIOINAL LABORATORY

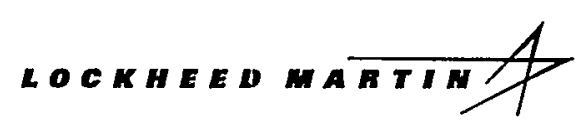

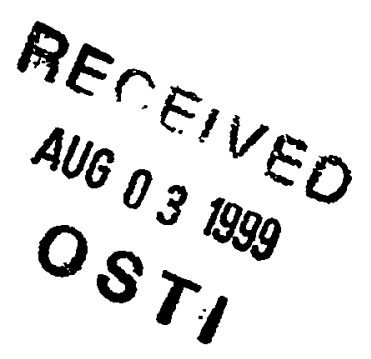

\title{
Recommended Minimum Test Requirements and Test Methods for Assessing Durability of Random-Glass-Fiber Composites
}

\author{
J. M. Corum \\ R. L. Battiste \\ W. Ren \\ M. B. Ruggles
}


This report has been reproduced directly from the best available copy.

Available to DOE and DOE contractors from the Office of Scientific and Technical Information, P.O. Box 62, Oak Ridge, TN 37831; prices available from (423) 576-8401.

Available to the public from the National Technical Information Service, U.S. Department of Commerce, 5285 Port Royal Rd., Springfield, VA 22161.

This report was prepared as an account of work sponsored by an agency of the United States Government. Neither the United States Government nor any agency thereof, nor any of their employees, makes any warranty, express or implied, or assumes any legal liability or responsibility for the accuracy, completeness, or usefulness of any information, apparatus, product, or process disclosed, or represents that its use would not infringe privately owned rights. Reference herein to any specific commercial product, process, or service by trade name, trademark, manufacturer, or otherwise, does not necessarily constitute or imply its endorsement, recommendation, or favoring by the United States Government or any agency thereof. The views and opinions of authors expressed herein do not necessarily state or reflect those of the United States Govemment or any agency thereof. 


\section{DISCLAIMER}

Portions of this document may be illegible in electronic image products. Images are produced from the best available original document. 


\title{
RECOMMENDED MINIMUM TEST REQUIREMENTS AND TEST METHODS FOR ASSESSING DURABULTY OF RANDOM-GLASS-FIBER COMPOSITES
}

\author{
J. M. Corum \\ R. L. Battiste \\ W. Ren \\ M. B. Ruggles
}

June 1999

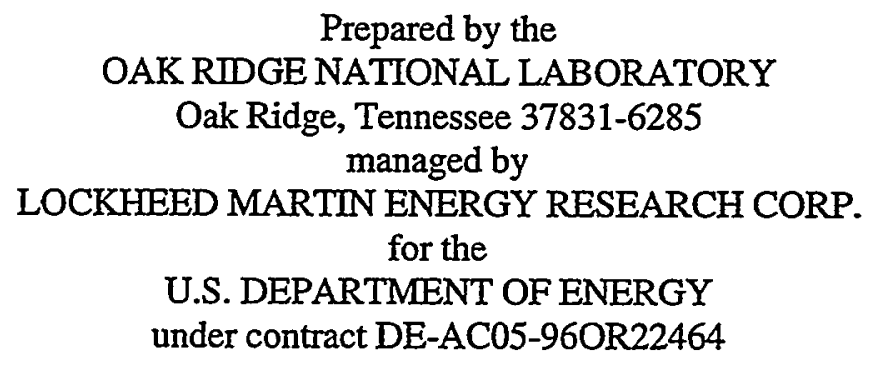




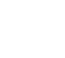




\section{CONTENTS}

CONVERSION FACTORS

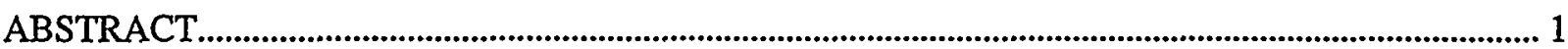

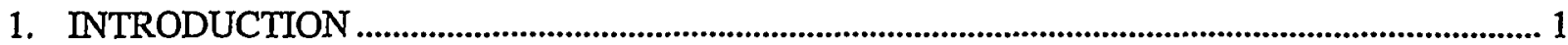

1.1 BACKGROUND ............................................................................................................. 1

1.2 OVERVIEW OF PART 1: MINIMUM TEST REQUIREMENTS ……........................................ 2

1.3 OVERVIEW OF PART 2: TEST METHODS …………............................................................... 3

PART 1: MINIMUM TEST REQUIREMENTS ................................................................................... 5

2. MINIMUM TEST REQUIREMENTS ...................................................................................... 7

2.1 INTRODUCTION ........................................................................................................... 7

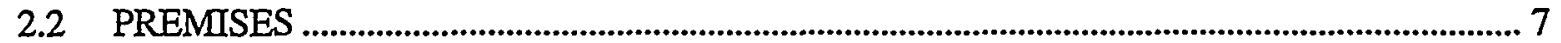

2.3 TENSILE, COMPRESSIVE, AND SHEAR TESTS........................................................................ 7

2.3.1 Tensile Tests .....................................................................................................................

2.3.2 Compression Tests................................................................................................... 8

2.3.3 Iosipescu Shear Tests ............................................................................................................ 8

2.4 FATIGUE TESTS ............................................................................................

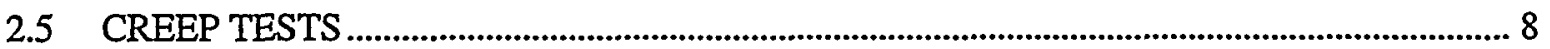

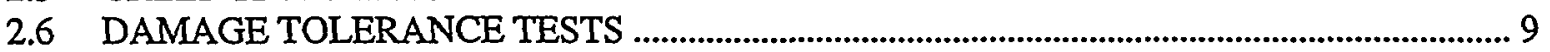

2.7 SUMMARY OF TEST REQUIREMENTS .............................................................................10

PART 2: TEST METHODS..............................................................................................................................11

3. SPECIMEN CONFIGURATIONS ......................................................................................................13

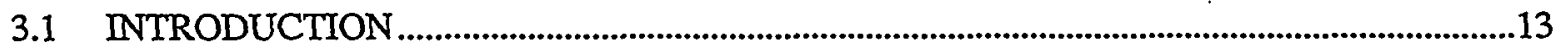

3.2 TENSLE .............................................................................................................................................13

3.3 COMPRESSION ..........................................................................................................................

3.4 SHEAR ……...............................................................................................................................13

3.5 FLEXURE ...........................................................................................................................13

3.6 BIAXIAL FLEXURE ..............................................................................................................13

3.7 REVERSED FATIGUE .............................................................................................................17

3.8 COMPRESSIVE CREEP ..............................................................................................................17

3.9 IMPACT …..................................................................................................................

3.10 SPECIMENS FROM HAT SECTIONS...............................................................................20

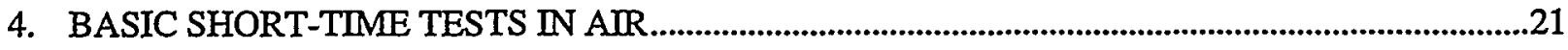

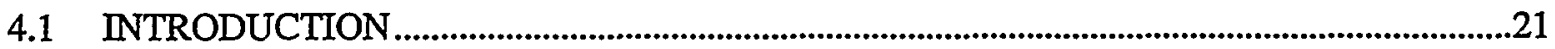

4.2 TENSחE ..................................................................................................................................21

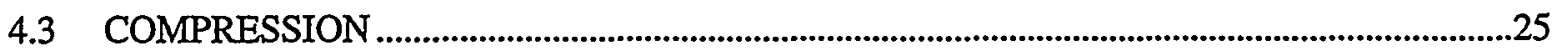

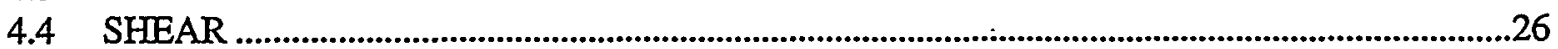

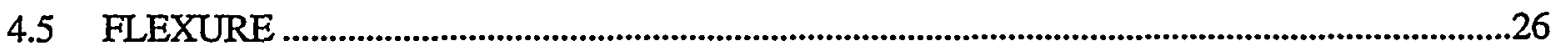

4.6 BIAXIAL FLEXURE...............................................................................................26

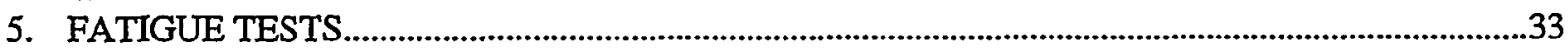

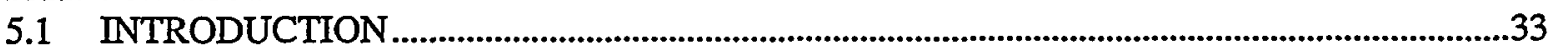

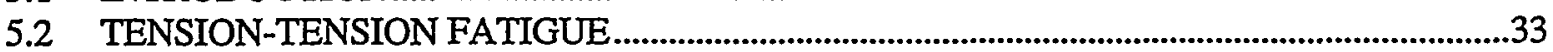

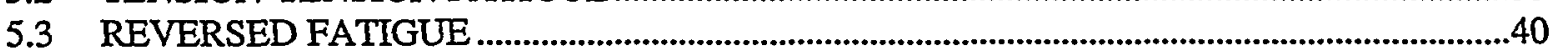

6. CREEP AND CREEP-RUPTURE TESTS..............................................................................41

6.1 INTRODUCTION ......................................................................................................................

6.2 TENSILE CREEP ................................................................................................................

6.2.1 Test Details ...........................................................................................................................4

6.2:2 Simulated Automotive Service Environments ..................................................................4

6.3 COMPRESSIVE CREEP.......................................................................................51

7. LOW-ENERGY IMPACT TESTS FOR DAMAGE TOLERANCE CHARACTERIZATION.............53 


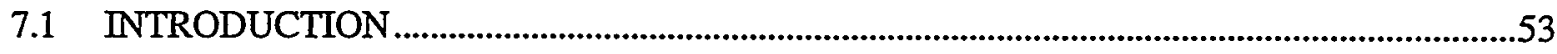

7.2 SPECIMEN SUPPORT STRUCTURE

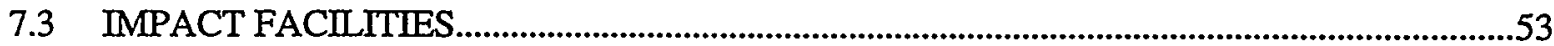

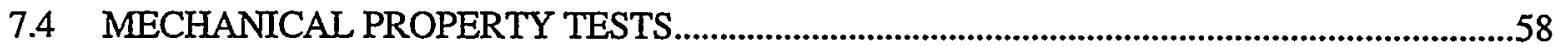

8. TESTS OF SPECIMENS FROM HAT SECTIONS

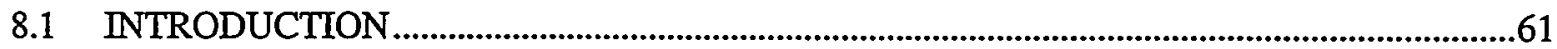

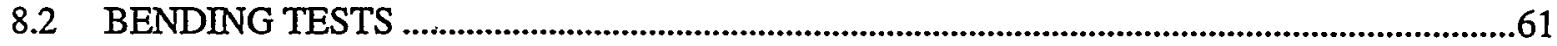

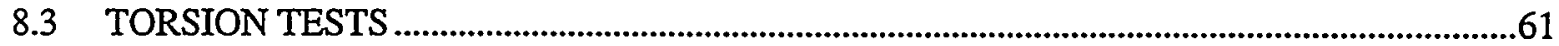

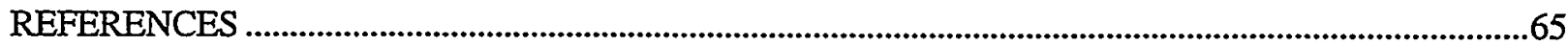

Appendix. TEST FIXTURE FOR HAT-SECTION TORSION SPECIMENS ........................................67 


\section{CONVERSION FACTORS}

\section{U.S. Customary Units to SI Units}

\begin{tabular}{llll}
\hline \multicolumn{1}{c}{ Quantity } & \multicolumn{1}{c}{ Multiply } & \multicolumn{1}{c}{ By } & \multicolumn{1}{c}{ To obtain } \\
\hline Length & inch (in.) & $2.54 \times 10^{-2}$ & meter $(\mathrm{m})$ \\
Force & Pound $(\mathrm{lb})$ & 4.448 & newton $(\mathrm{N})$ \\
Stress, pressure & pound/inch ${ }^{2}(\mathrm{psi})^{\mathrm{a}}$ & $6.895 \times 10^{3}$ & pascal $(\mathrm{Pa})$ \\
Velocity & foot/second $(\mathrm{ft} / \mathrm{s})$ & 0.3048 & meter $/ \mathrm{second}(\mathrm{m} / \mathrm{s})$ \\
Temperature & Temperature $\left({ }^{\circ} \mathrm{F}-32\right)$ & 0.5556 & temperature $\left({ }^{\circ} \mathrm{C}\right)$ \\
\hline${ }^{\mathrm{a}} \mathrm{ksi}=10^{3} \mathrm{psi} ; \mathrm{Msi}=10^{9} \mathrm{psi}$ & &
\end{tabular}




\title{
RECOMMENDED MINIMUM TEST REQUIREMENTS AND TEST METHODS FOR ASSESSING DURABILITY OF RANDOM-GLASS-FIBER COMPOSITES
}

\author{
J. M. Corum, R. L. Battiste, W. Ren, M. B. Ruggles
}

\begin{abstract}
This report provides recommended minimum test requirements and suggested test methods for establishing the durability properties and characteristics of candidate random-glass-fiber polymeric composites for automotive structural applications. The recommendations and suggestions are based on experience and results developed at Oak Ridge National Laboratory (ORNL) under a U.S. Department of Energy Advanced Automotive Materials project entitled "Durability of Lightweight Composite Structures," which is closely coordinated with the Automotive Composites Consortium. The report is intended as an aid to suppliers offering new structural composites for automotive applications and to testing organizations that are called on to characterize the composites.

Part 1 of the report provides the minimum test requirements deemed necessary to characterize the durability-related properties of a composite sufficiently for incorporating it into durability-based design criteria that have been developed. The recommendations cover tensile, compressive, shear, fatigue, creep, and damage tolerance tests. In addition to room-temperature tests in air, tests of water-soaked specimens and in-air tests over the temperature range from $-40^{\circ} \mathrm{C}$ to $120^{\circ} \mathrm{C}\left(-40^{\circ} \mathrm{F}\right.$ to $\left.248^{\circ} \mathrm{F}\right)$ are specified.

Part 2 of the report provides suggested specimen designs and test methods based on tests successfully carried out at ORNL on two random-fiber composites-one with continuous-strand, swirlmat reinforcement and one with chopped-fiber reinforcement. The emphasis is on describing the simple, economical fixturing and environmental chambers developed for performing the various types of tests.
\end{abstract}

\section{INTRODUCTION}

\subsection{BACKGROUND}

This report is an outgrowth of work done at Oak Ridge National Laboratory (ORNL) under a U.S. Department of Energy project entitled "Durability of Lightweight Composite Structures for Automotive Applications." The primary project goal is to develop experimentally based, durability-driven design guidelines to assure the long-term (15-year) integrity of polymeric composite automotive structures. Durability issues include the potentially degrading effects that both cyclic and sustained loadings, exposure to automotive fluids, temperature extremes, and low-energy impacts from such things as tool drops and roadway kickups can have on structural strength, stiffness, and dimensional stability.

While the focus is now shifting to carbon-fiber composites, the initial project effort addressed random-glass-fiber composites. Two representative reference composites, both structural reaction injection-molded (SRTM) urethanes with random fibers, were extensively studied to characterize and model their durability-related behavior. Both composites were supplied by the Automotive Composites Consortium (ACC) in the form of 3.2-mm-thick (1/8-in.) plaques.

The first reference composite was reinforced with continuous-strand, swirl-mat E-glass. Hundreds of tests, both short- and long-term, were performed on this composite. A two-part durability- 
based design criteria document based on the resulting information was developed and published. ${ }^{1,2}$ Part 1 of the document provides design rules intended to assure adequate long-term (15-year) reliability of polymeric composite automotive structures. Part 2 provides the underlying experimental data and models for the first reference composite. Efforts to validate the applicability of the framework of the design rules to a second reference composite-the P4 chopped-fiber material being used for the ACC Focal Project II pickup truck box-are currently nearing completion.

The purpose of this current report is twofold. The first is to present, based on the experience and understanding developed with the two reference materials, a minimal set of test requirements deemed necessary to incorporate additional similar random-glass-fiber molded composites into the design rule framework. The second purpose is to share the test methods, particularly the fixturing and means for introducing environments, that were developed and utilized in the testing of the reference materials. These were developed with a goal of making them as simple and inexpensive as possible. Thus, the concepts and designs may be of use to others.

Overall, this report is intended as an aid to suppliers offering new structural composites for automotive applications and to testing organizations that are called on to provide durability-based design data for the composites. It is anticipated that ACC will use the guidelines, models, and procedures generated at ORNL as the bases for developing a standardized procedures document, along the lines of SAE Standard J2253, that will specifically cover durability testing of automotive structural composites.

\subsection{OVERVIEW OF PART 1: MINIMUM TEST REQUIREMENTS}

Chapter 2 provides the recommended minimum durability test requirements. The requirements were developed by considering the minimum data judged to be necessary to establish the various allowables, factors, and design curves in the design criteria developed for the first reference material and validated for the second material. In doing this, the assumption was made that much of the basic framework of the rules would remain unchanged. Thus, some tests performed for the reference materials are assumed not to be required for new, but similar, random-glass-fiber composites.

The basic test types recommended are tensile, compression, shear, fatigue, creep, and impact. Generally, tests are recommended to cover the temperature range of automotive design interest, $-40^{\circ} \mathrm{C}$ to $120^{\circ} \mathrm{C}\left(-40^{\circ} \mathrm{F}\right.$ to $\left.248^{\circ} \mathrm{F}\right)$. To quantify fluid environment effects, only one bounding test condition is recommended-specimens soaked in water for $1000 \mathrm{~h}$. The total numbers of recommended tests of each type are tabulated below.

\begin{tabular}{lc} 
Test Type & Total Test \\
\cline { 2 - 2 } Tensile & 45 \\
Compressive & 36 \\
Shear & 24 \\
Fatigue & 32 \\
Creep/creep rupture & 36 \\
Impact & 8
\end{tabular}

Specimens for the recommended test program can be cut from a total of six 610 - by $610-\mathrm{mm}$ (24- by 24 -in.) plaques. 


\subsection{OVERVIEW OF PART 2: TEST METHODS}

Chapters 3 through 8 focus on the test methods developed and used for durability testing of the two reference random-glass-fiber composites. The emphasis is on the unique fixturing developed and on the methods used to introduce temperature and fluid environments. In most cases, standard commercially available servo-hydraulic test machines, controllers, and extensometers or strain gages were used; these are not described in any detail.

The test programs for the two reference composites were significantly broader than those recommended for additional composites in Part 1 of this report. For completeness, Part 2 covers methods not only for the minimum recommended tests but for the additional tests carried out at ORNL for the reference composites.

Chapter 3 briefly describes the specimens used in the ORNL durability test programs. Chapter 4 covers the basic short-time tests-tension, compression, Iosipescu shear, beam bending, and circular plate (biaxial) bending - all of which were tested only in air (although specimens were often preexposed to various fluids). The methods and fixtures for heating and cooling the specimens are described.

Chapter 5 covers two types of fatigue tests-tension-tension and reversed load. The latter were only performed at room temperature in ambient air, whereas the former were performed at various temperatures and in various fluid environments. The various systems used for introducing environments are described. Chapter 6 describes the methods used for conducting both tensile and compressive creep and creep-rupture tests. All of the tests were performed in dead-weight, lever-arm machines, using special grips and fixtures, which are described. The methods of heating, cooling, and introducing fluid environments are also described.

Chapter 7 describes methods used for simulating low-energy impacts. Two facilities, an air gun for simulating small objects impacting at high velocities and a pendulum for simulating large objects at low velocities, were used. Both are described, although only a pendulum or drop-weight test setup is needed for the limited testing recommended in Part 1. The means developed for testing specimens in air at temperatures other than room temperature is also described.

Finally, Chap. 8 describes two types of confirmatory tests carried out on subscale component shapes cut from structural hat sections. Although, these tests were not included in the recommendations of Part 1, they did play an important role in developing and confirming portions of the design criteria. They are included here for that reason. One test involves bending, and the other involves torsion loadings. The fixtures used for these tests are described.

While the International System of Units [SI (metric)] which are now the preferred automotive units, are used in presenting the minimum recommended test requirements of Part 1, U.S. customary units are used in Part 2. This was done to avoid the cumbersome soft conversion from the customary units used in the facilities at ORNL and in the initial ORNL tests. 


\section{PART 1}

MINIMUM TEST REQUIREMENTS 


\section{MINIMUM TEST REQUIREMENTS}

\subsection{INTRODUCTION}

This chapter presents recommended minimum test requirements for characterizing the durability of random-glass-fiber, molded, automotive structural composites. The American Society for Testing and Materials (ASTM) Standard D $4762^{4}$ gives general testing guidance for this class of materials. The recommendations given here do not, alone, meet the sampling requirements of that standard guide. As stated in Sect. 2.2, it is assumed that basic in-air properties of the subject composite have been more thoroughly established in accordance with Ref. 5, and its equivalent, SAE Standard J2253 ${ }^{3}$. If a composite is ultimately chosen for an automotive application, additional durability testing beyond that recommended here may be warranted. In particular, uniaxial and biaxial flexure tests may be desired.

\subsection{PREMISES}

1. The tensile, compression, and shear data specified in the ACC Test Procedures for Automotive Structural Composites Materials ${ }^{5}$ (and SAE Standard $\mathrm{J}_{2253^{3}}$ ), and the fatigue data called for in the ACC Proposed Fatigue Test Specification for Random Fiber Composite Materials ${ }^{6}$ are assumed to be available for the subject material. The requirements here focus just on the durability aspects of material behavior.

2. Specimens for each one of the five types of mechanical properties tests discussed in this chapter-tensile, compression, shear, fatigue, and creep-should come from a single plaque to avoid plaque-to-plaque variation effects in the individual correlations (e.g., fatigue specimens should all come from a single plaque; creep specimens should come from another plaque).

3. Four reference tensile specimens, taken from representative locations around each plaque, should be tested to provide average tensile property values for each plaque. Plaques with multiple strength or stiffness values lying outside the standard deviation of data from all plaques should not be used for the durability tests.

4. All fatigue and tensile creep specimens should have the initial stiffness measured prior to the durability testing. These data will be used for determining an "adjusted stress" for each test to account for strength and stiffness property variability caused by fiber volume variability.

5. Unless otherwise noted, all tests should be conducted in nominal ambient air conditions of $23^{\circ} \mathrm{C}$ $\left(73^{\circ} \mathrm{F}\right) / 50 \%$ relative humidity $(\mathrm{RH})$. Specimen conditioning guidance given in Ref. 4 should be followed for these specimens. For fatigue and tensile tests, control of humidity during each test becomes important.

6. A single bounding fluid environment condition should be examined-specimens preexposed to distilled water at $23^{\circ} \mathrm{C}\left(73^{\circ} \mathrm{F}\right)$ for $1000 \mathrm{~h}$.

\subsection{TENSUE, COMPRESSIVE, AND SHEAR TESTS}

\subsubsection{Tensile Tests}

a. Four tests each at temperatures of $-40,23,50$, and $120^{\circ} \mathrm{C}\left(-40,73,122\right.$, and $\left.248^{\circ} \mathrm{F}\right)$ should be performed. The results will be used to establish multipliers for determining at-temperature tensile properties from the room-temperature averages. 
b. Four tests each of water-soaked specimens should be performed at $23^{\circ} \mathrm{C}\left(73^{\circ} \mathrm{F}\right)$ and $50^{\circ} \mathrm{C}\left(122^{\circ} \mathrm{F}\right)$. The results will be used to establish strength and stiffness reduction factors to bound environmental effects.

\subsubsection{Compression Tests}

a. Variation of properties with temperature: Requirements are the same as for tensile tests.

b. Effects of moisture: Requirements are the same as for tensile tests.

\subsubsection{Iosipescu Shear Tests}

a. Variation of properties with temperature: Requirements are the same as for tensile tests.

b. Effects of moisture: Requirements are the same as for tensile tests.

\subsection{FATIGUE TESTS}

A total of 16 tensile fatigue tests should be performed. The tests should each have a ratio of minimum to maximum stress, $R$, of 0.1 .

a. Eight tests each at temperatures of $-40,23$, and $120^{\circ} \mathrm{C}\left(-40,73\right.$, and $\left.248^{\circ} \mathrm{F}\right)$ should be performed. Duplicate tests should be carried out at each of four stress levels, selected to produce failures equally spaced over the range of 100 to $10^{6}$ cycles. Three tensile tests at each of the above three temperatures should also be performed on specimens from the same plaque. The results will be used to develop stress vs cycles to failure ( $S-N)$ curves for each temperature, with the stress given as a percentage of the at-temperature ultimate tensile strength (UTS). Care should be taken in the room-temperature tests to control the relative humidity to near $50 \%$.

b. Eight tests of water-soaked specimens should be performed in water at $23^{\circ} \mathrm{C}\left(73^{\circ} \mathrm{F}\right)$. The specimens should come from the same plaque as the above fatigue and associated tensile specimens. The results will be used to determine fatigue strength reduction factors to cover moisture and to bound effects of several other fluids.

\subsection{CREEP TESTS}

Both creep-rupture and creep-deformation tests should be performed. While creep-rupture tests provide creep-deformation data as well, the stress levels involved are generally higher than the design stress levels, and they may produce nonlinear response, i.e., the creep deformation is not linear with stress, as it is at lower stress levels. Thus, separate creep-deformation tests are required. These tests can, however, be of short duration, since the creep response in the linear range can generally be represented by a simple power law of the form

$$
\varepsilon_{\text {creep }}=A \sigma t^{n} \text {, }
$$

where $\sigma$ is stress and $t$ is time. Tests of $100 \mathrm{~h}$ duration are sufficient to establish the constants $A$ and $N$.

a. Six creep-rupture tests should be performed at room-temperature $50 \%$ relative humidity. The tests should be duplicates at each of three stress levels, selected to produce failures spaced over the range from approximately $100 \mathrm{~h}$ to $3000 \mathrm{~h}$. These results will be used to establish a power-law creeprupture curve at room temperature. Also, up to eight room-temperature creep-deformation tests, with 
duplicates at each of the following stress levels-20,40,60, and $80 \%$ UTS-should be conducted to $100 \mathrm{~h}$. Some of the creep-rupture tests may partially satisfy these requirements. Particular care must be taken in the deformation tests to carefully control humidity, which can significantly influence results.

b. Two duplicate creep-rupture tests should be performed at $50^{\circ} \mathrm{C}\left(122^{\circ} \mathrm{F}\right)$ and two at $120^{\circ} \mathrm{C}\left(248^{\circ} \mathrm{F}\right)$. The tests should be at stress levels to produce failures in about $1000 \mathrm{~h}$. Also, two duplicate creepdeformation tests to $100 \mathrm{~h}$ should be performed at $50^{\circ} \mathrm{C}$ and two at $120^{\circ} \mathrm{C}$. The stress levels should be $40 \%$ of the at-temperature UTS. Coupled with the assumption of a single multiplier to account for the effect of temperature on creep deformation and the assumption that creep-rupture curves at various temperatures are parallel, the results of these tests will permit the description of creep and creep rupture at higher temperatures based on room-temperature models.

c. Four in-water creep-rupture tests of water-soaked specimens, with duplicates at each of two stress levels chosen to cause failures near 100 and $3000 \mathrm{~h}$, should be performed at $23^{\circ} \mathrm{C}\left(73^{\circ} \mathrm{F}\right)$. Also, two duplicate creep-deformation tests to $100 \mathrm{~h}$ at a stress level of $40 \%$ of the UTS should be performed. The results will allow a creep-rupture curve to be estimated and a creep-rupture reduction factor to be determined, and they will permit the creep of water-soaked specimens to be described as a multiplier on the room-temperature, in-air, creep equation.

d. Four compressive creep-rupture tests at each of two temperatures $-23^{\circ} \mathrm{C}\left(73^{\circ} \mathrm{F}\right)$ and $120^{\circ} \mathrm{C}$ $\left(248^{\circ} \mathrm{F}\right)$ - should be performed. In each case, duplicates should be performed at each of two stress levels, one to produce failures in about $100 \mathrm{~h}$ and one to produce failures in about $3000 \mathrm{~h}$. The results will allow a characterization of the matrix dominated compressive creep-rupture strength relative to the tensile creep-rupture strength.

\subsection{DAMAGE TOLERANCE TESTS}

a. Eight baseline pendulum, or drop-weight, impact tests at room temperature should be performed. The impactor should weigh approximately $11.5 \mathrm{~kg}(25.4 \mathrm{lb})$ and have a 12.7 -mm-diam (0.50-in.) hemispherical steel impactor point. The specimen should be a $229-$ by $229-\mathrm{mm}$ ( 9 - by 9 -in.) square plate, clamped on a 203-mm-diam (8-in.) circle. The tests should be performed in duplicate pairs, and the kinetic energy levels of the impactor should be varied from a low that barely causes detectable damage to a high that results in near penetration, accompanied by significant fiber breakage. Damage areas should be determined by ultrasonic C-scans, and a correlation of damage area vs kinetic energy should be established. In determining the correlation, the sets of tests not involving significant fiber breakage should be given priority.

b. One of each of the four pairs of duplicate impacted specimens should be cut into tensile specimens, and one each should be cut into compression specimens. Three specimens should be cut from each impact specimen-one centered on the damage and a reference specimen at each of the outer, unaffected, edges. The ratio of a property from a damaged specimen to the average of that property from the two unaffected specimens gives a point on a curve of property degradation vs damage area. 


\subsection{SUMMARY OF TEST REQUIREMENTS}

Table 2.1 summarizes the recommended minimum test requirements.

Table 2.1. Summary of minimum requirements

\begin{tabular}{|c|c|c|c|c|c|c|c|}
\hline \multirow{3}{*}{ Test type } & \multicolumn{6}{|c|}{ Number of tests } & \multirow{3}{*}{$\begin{array}{l}\text { Number of } \\
\text { plaques } \\
\text { required }\end{array}$} \\
\hline & \multicolumn{4}{|c|}{ Air/50\% RH } & \multicolumn{2}{|c|}{ Water soaked } & \\
\hline & $\begin{array}{l}-40^{\circ} \mathrm{C} \\
\left(-40^{\circ} \mathrm{F}\right)\end{array}$ & $\begin{array}{l}23^{\circ} \mathrm{C} \\
\left(73^{\circ} \mathrm{F}\right)\end{array}$ & $\begin{array}{c}50^{\circ} \mathrm{C} \\
\left(122^{\circ} \mathrm{F}\right)\end{array}$ & $\begin{array}{c}120^{\circ} \mathrm{C} \\
\left(248^{\circ} \mathrm{F}\right)\end{array}$ & $\begin{array}{l}23^{\circ} \mathrm{C} \\
\left(73^{\circ} \mathrm{F}\right)\end{array}$ & $\begin{array}{c}50^{\circ} \mathrm{C} \\
\left(122^{\circ} \mathrm{F}\right)\end{array}$ & \\
\hline Tensile & 4 & 4 & 4 & 4 & 4 & 4 & 1 \\
\hline Compression & 4 & 4 & 4 & 4 & 4 & 4 & 1 \\
\hline Shear & 4 & 4 & 4 & 4 & 4 & 4 & \\
\hline \begin{tabular}{|c|} 
Fatigue \\
Fatigue \\
Tensile \\
\end{tabular} & $\begin{array}{l}8 \\
3\end{array}$ & $\begin{array}{l}8 \\
3\end{array}$ & & $\begin{array}{l}8 \\
3\end{array}$ & 8 & & 1 \\
\hline \begin{tabular}{|l|} 
Creep \\
Tensile \\
Compression \\
\end{tabular} & & $\begin{array}{c}14 \\
4 \\
\end{array}$ & 4 & $\begin{array}{l}4 \\
4 \\
\end{array}$ & 6 & & 1 \\
\hline \begin{tabular}{|l} 
Damage tolerance \\
Impact \\
Tensile \\
Compression
\end{tabular} & & $\begin{array}{c}8 \\
12 \\
12\end{array}$ & • & & & & 2 \\
\hline
\end{tabular}


PART 2

TEST METHODS 


\section{SPECIMEN CONFIGURATIONS}

\subsection{INTRODUCTION}

Except for the hat-section bend and torsion specimens, all of the specimens used by ORNL in the reference composite testing were cut from flat molded plaques that were nominally $1 / 8$ in. thick. The hat sections tested were also molded parts and were nominally $1 / 8$ in. thick. The dimensions of each specimen type are given in the following sections.

\subsection{TENSLE}

The dogbone-shaped specimen shown in Fig. 3.1 was adopted as the standard configuration for tensile, tensile fatigue, and tensile creep tests at ORNL. The specimen is an adaptation of the 1- by 8.5 -in. straight-sided tensile specimens recommended by ACC in Ref. 5 . Tensile tests of specimens of various widths showed that the 0.8 -in. width was sufficient to yield the same results as 1-in.-wide specimens. Finite-element analysis of the configuration showed the peak axial stress, located at the beginning of the transition to the larger width, to be just $3 \%$ higher than the nominal stress at the specimen midlength.

The advantage of the dogbone specimen is that it eliminates the need for tabs. Straight-sided specimens with tabs tend to frequently fail at the tabs, especially in fatigue. Straight-sided specimens without tabs tend to frequently fail at the grips.

\subsection{COMPRESSION}

The compression tests at ORNL utilized an IITRI test fixture (Procedure B in ASTM D 3410). ${ }^{7}$ The specimen used is shown in Fig. 3.2. The tab material was G-11 composite, an epoxy reinforced with woven fiberglass cloth. Ideally, the modulus of the tab material should be within $10 \%$ of that of the test material. The adhesive recommended for bonding the tabs to the test material is Hysol's EA 93009NA A/B. An experimental version of the adhesive has been successfully used for $250^{\circ} \mathrm{F}$ testing.

\subsection{SHEAR}

The V-notched beam (Iosipescu) shear test method described in ASTM D 5379 was used. The specimen used is shown in Fig. 3.3. The tab material and adhesive used for bonding the tabs are the same as for the compression specimen described above.

\subsection{FLEXURE}

A three-point bend test setup was used to measure out-of-plane bend strength (modulus of rupture) and stiffness. Results from these tests were used to help determine allowable stresses (Chap. 3 of Ref. 2). The specimen used was simply a $1 \times 4 \times 1 / 8$-in.-thick rectangle. The support span was 2 in.

\subsection{BIAXIAL FLEXURE}

Biaxial flexure tests of ring-loaded, simply supported, circular disks were carried out to provide data for choosing a biaxial strength criteria (Chap. 6 of Ref. 2). The specimen used had a 3.71-in. outside diameter (O.D.) and a thickness of $1 / 8$ in. The support ring was 3.50-in. diam, and the load ring was 1.5-in. diam.

\footnotetext{
* Results for the continuous-strand-mat reference material indicated that any width above 0.7 in. was adequate.
} 

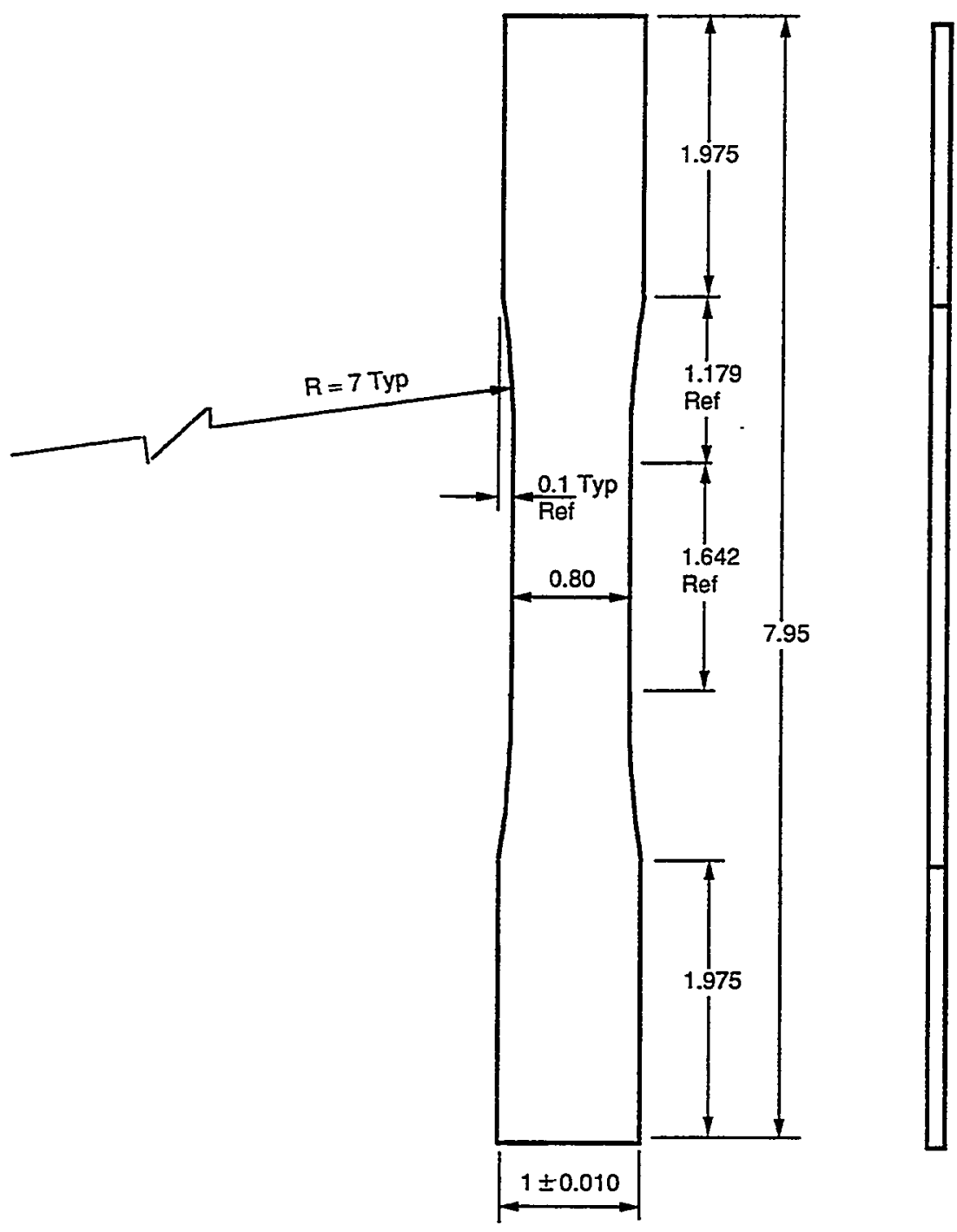

Fig. 3.1. Dogbone tensile specimen used for tensile, creep, and fatigue tests. Dimensions are in inches. 


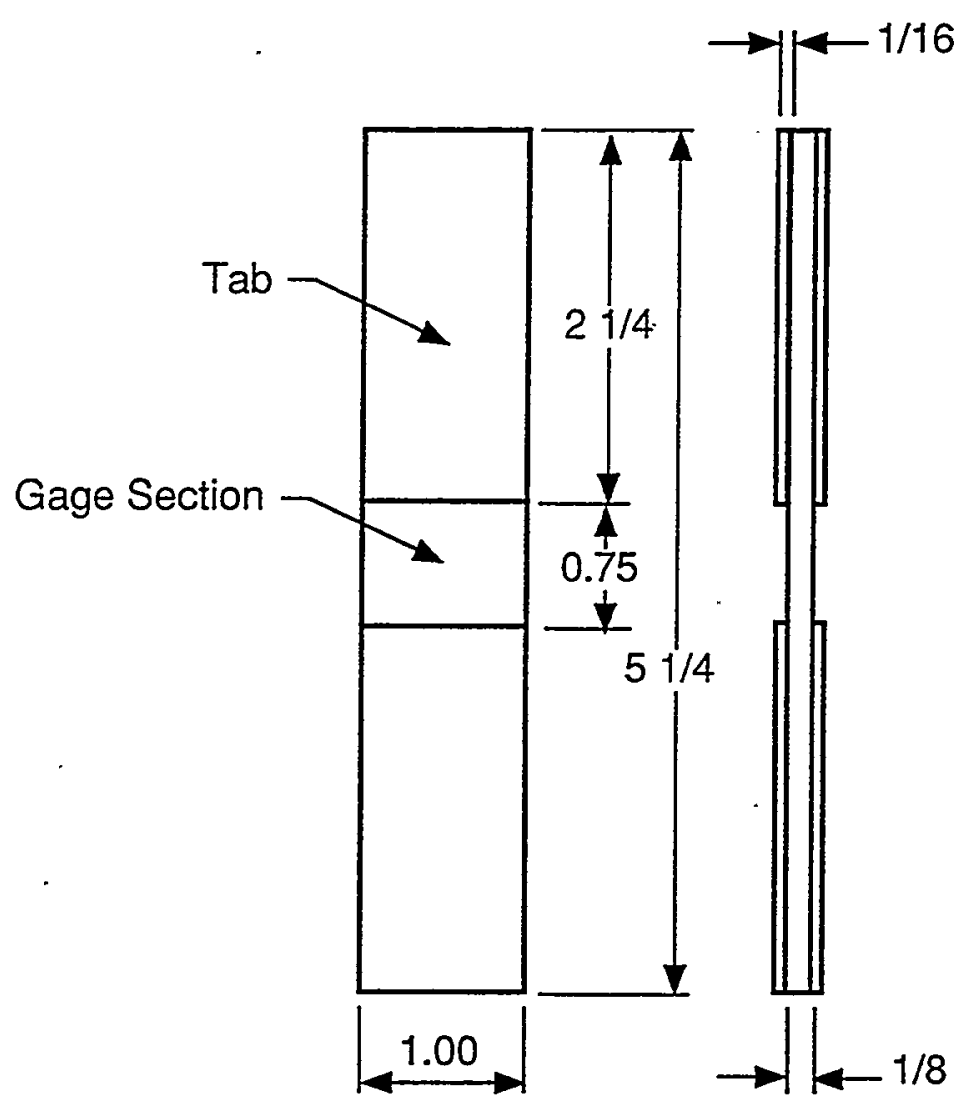

Fig. 3.2. Compression test specimen. Dimensions are in inches. 


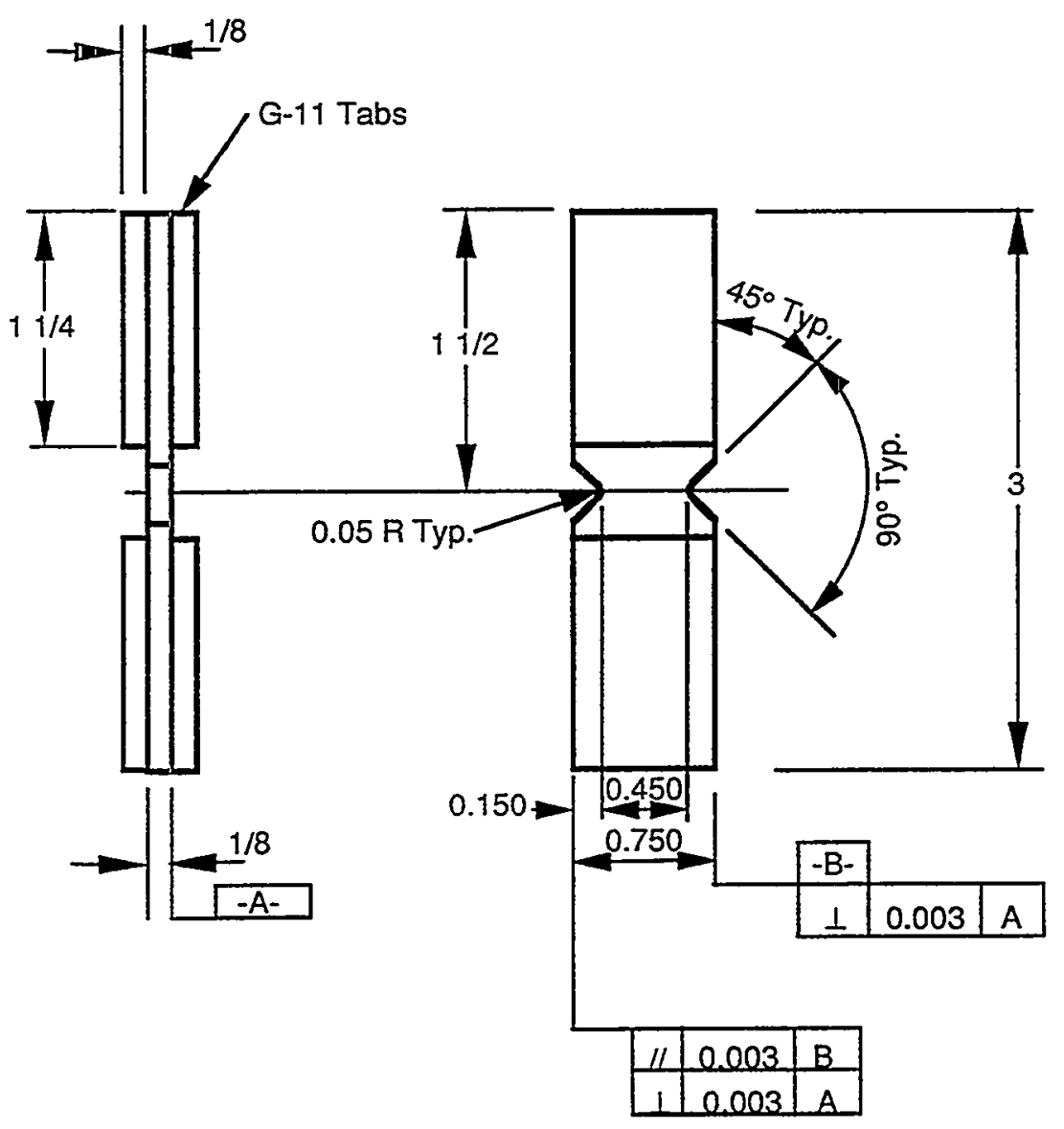

Fig. 3.3. Iosipescu shear test specimen. Dimensions are in inches. 


\subsection{REVERSED FATIGUE}

The tensile specimen described in Sect. 3.2 was used for tensile fatigue tests, which were carried out using a ratio of minimum-to-maximum stress, $\mathrm{R}$, of 0.1 . For reversed fatigue and compression fatigue tests, which were required to provide data for evaluating candidate methods for accounting for mean stresses, ${ }^{2}$ a much more buckling-resistant specimen was required. The specimen used is shown in Fig. 3.4. This hourglass specimen design was adapted from a design successfully used by Owen and Smith for similar fatigue tests of chopped-strand-mat laminates. ${ }^{9}$ Note that no tabs are used, and the specimen is clamped so that the gripped areas extend into the reduced section, as shown in Fig. 3.4. Despite the fact that a finite-element analysis showed a high, but very localized, stress concentration at the edges of the specimen adjacent to the clamped area, the specimens failed in the center. This is understandable in light of the observed insensitivity of the automotive composites to very localized stress concentrations. The calculated maximum axial stress at the midheight of the specimen occurs at the edges and was $3.5 \%$ higher than the average axial stress at midheight.

\subsection{COMPRESSIVE CREEP}

The tensile specimen described in Sect. 3.2 was used for tensile creep tests. For compressive tests, the much shorter 1/8-in.-thick specimen shown in Fig. 3.5 was used. As will be described in Sect. 6.3 , the ends (top and bottom) of the 1-in.-wide specimen were inserted into 0.175-in.-deep slots to provide fixed-end conditions that minimized any tendency to buckle. It is important for this specimen that the ends be machined parallel.

\subsection{IMPACT}

The specimen for both the air-gun and the pendulum impact tests at ORNL was a 9 - by 9- by 1/8in.-thick plate as shown in Fig. 3.6. As will be described in Chap. 7, the specimens were clamped on an 8-in.-diam circle and impacted in the center. The outline of the clamping circle is shown in Fig. 3.6.

In the recommended minimum tests given in Part I, each impacted plate specimen is to be cut into either three tensile specimens or three compressive specimens. The location of these specimens is depicted in Fig. 3.6. The center specimen is to be centered on the damaged area, while the outer two specimens are to be taken from the undamaged edges of the plate. These latter two specimens serve to provide base properties, against which properties from the damaged specimen are compared.

The tensile specimens are 1 in. wide and can be either 8 or 9 in. long. The outer two specimens should be dogboned as in Fig. 3.1 and tested without tabs. The center specimen should remain straightsided and can be tested without tabs." In the case of compression specimens, all three should be of the design shown in Fig. 3.2.

\footnotetext{
* Note that when the damage area is negligible, the center specimen may still yield slightly lower properties than the outer specimens, due to the inevitable stress concentrations at the grips. This situation may be improved by the use of tabs, which should be $1 \times 2 \times 1 / 8$-in.-thick G-11 composite with $15^{\circ}$ tapers.
} 


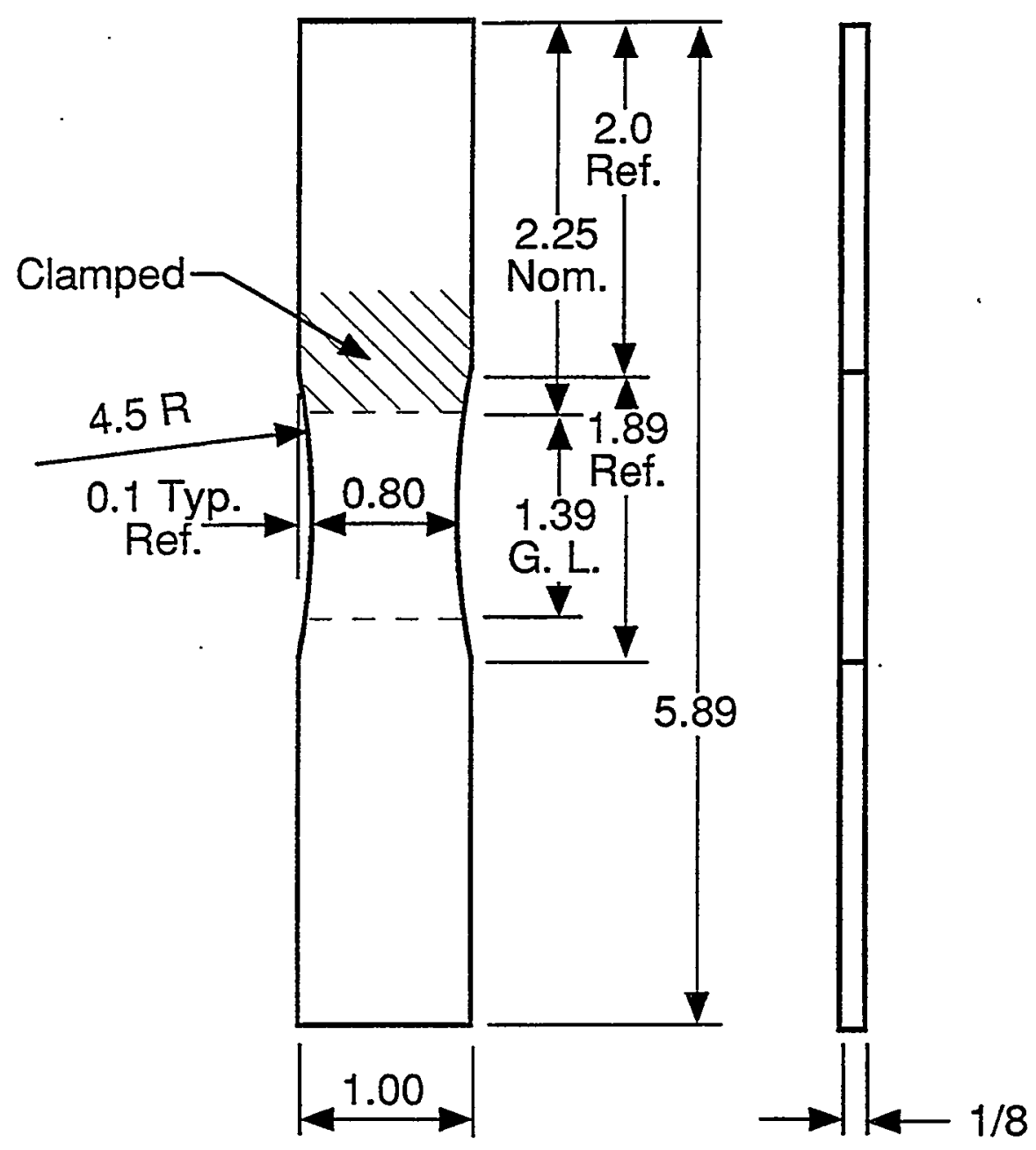

Fig. 3.4. Reversed or compressive fatigue test specimen. Dimensions are in inches. 


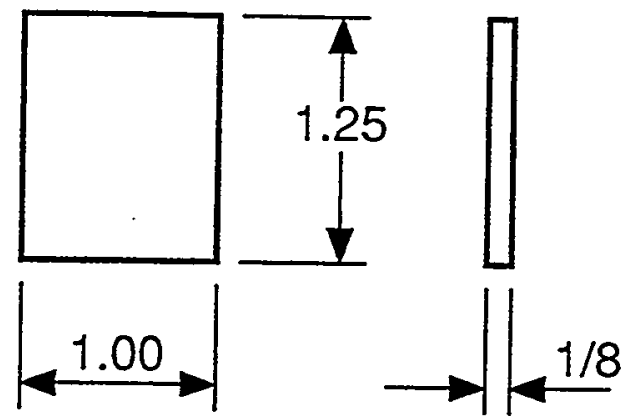

Fig. 3.5. Compressive creep test specimen. Dimensions are in inches.
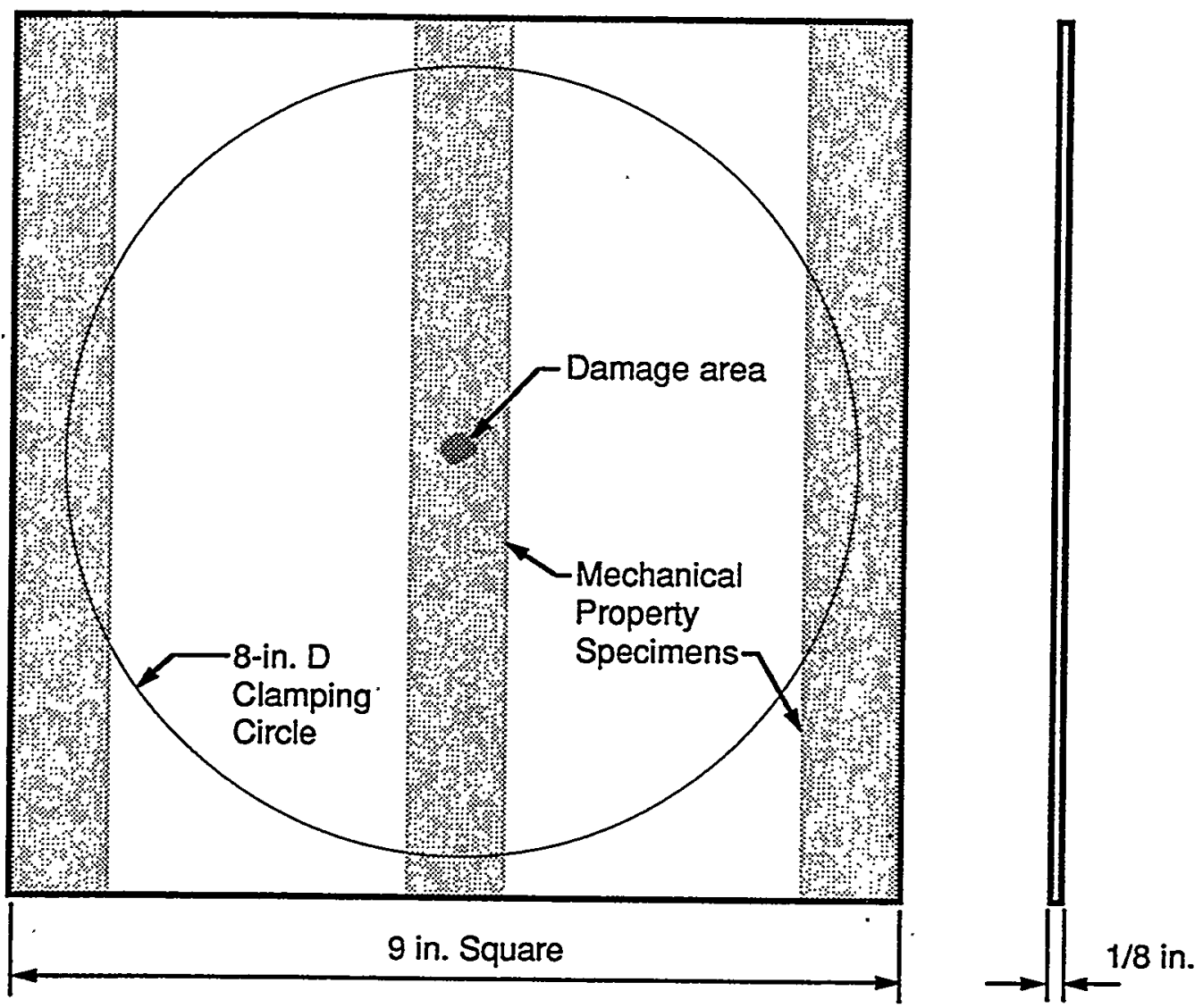

Fig. 3.6. Impact test specimen. Locations of subsequent mechanical property specimens are shown shaded. 


\subsection{SPECIMENS FROM HAT SECTIONS}

Molded hat-section parts, having the configuration and dimensions shown in Fig. 3.7, were used as the source of two types of specimens-the 1-in.-wide bend specimen shown in Fig. 3.7 and the torsion specimen shown in Fig. 3.8 (see Chap. 15 of Ref. 2). For testing, the untabbed ends of the bend specimens were mounted in ordinary test machine grips and were either pulled (tension) or pushed (compression). Both cases produced bending in the representative three-dimensional geometries. The ends of the torsion specimens were gripped in a special fixture that was mounted in a torsional test machine.

ORNL. 98-1296 EFG

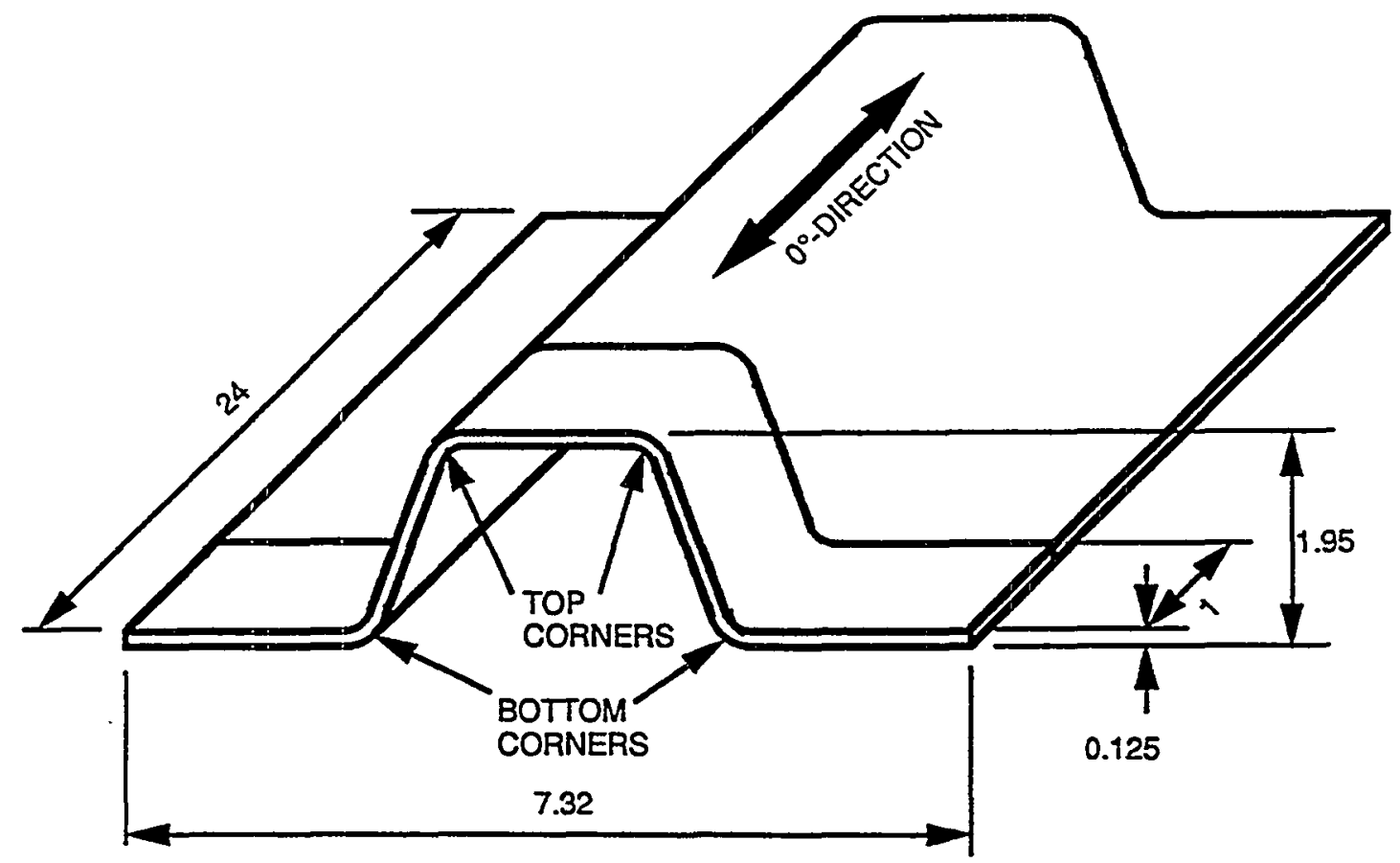

Fig. 3.7. Bend specimen cut from hat-section part. Dimensions are in inches.

ORNL 98-1298 EFG

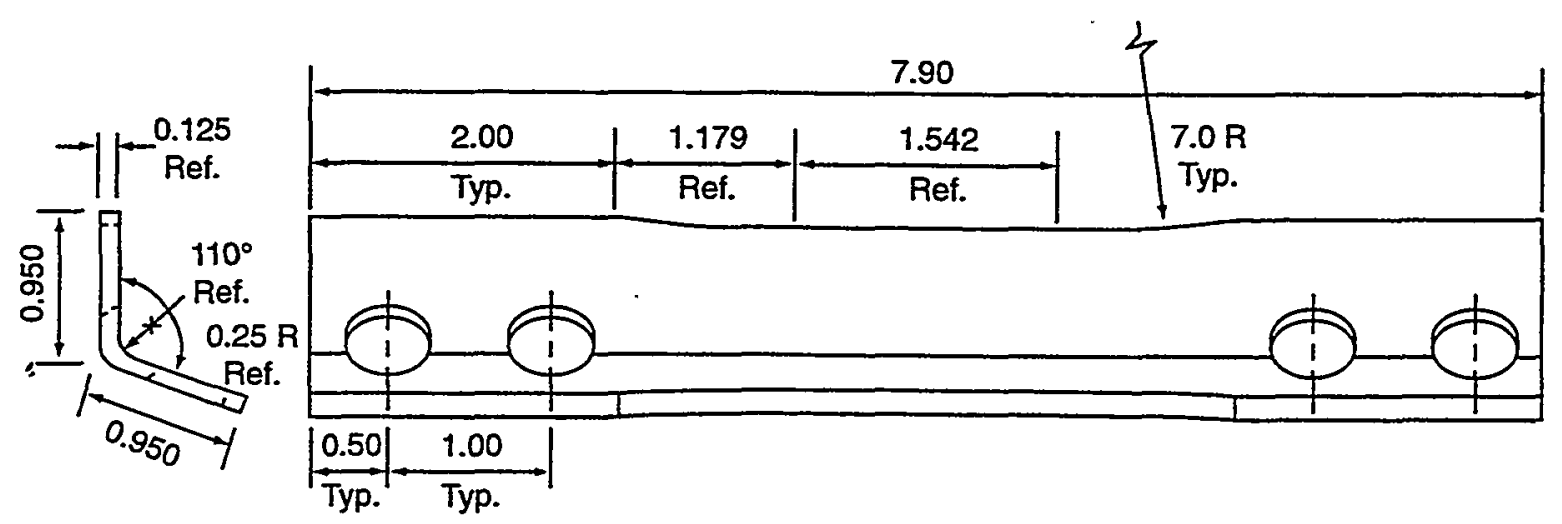

Fig. 3.8. Torsion specimen cut from hat-section part. Dimensions are in inches. 


\section{BASIC SHORT-TIME TESTS IN AIR}

\subsection{INTRODUCTION}

Five types of tests are covered in this chapter: tensile, compression, shear, flexure, and biaxial flexure. The first three were included in the minimum test requirements of Part 1 . The last two were performed at ORNL to provide data for establishing the design criteria framework. ${ }^{1,2}$ All of these tests were performed in standard servo-hydraulic material test machines. Those machines and their controllers are not described here. Rather, the emphasis is on the methods of heating/cooling and, in special cases, the fixturing used.

\subsection{TENSIE}

The specimen for tensile tests was shown in Fig. 3.1. The specimens were mounted either in mechanical or hydraulic wedge grips. Axial strain measurement was accomplished either with an MTS 632.11B-20 extensometer, which has a 1-in. gage length and which was mounted on a flat face, or with an MTS 632.17E-20 extensometer, which is an averaging extensometer with a 1-in. gage length and which was mounted to measure the average strain on the specimen edges. In those cases where Poisson's ration measurements were desired, a transverse strain gage was employed. The recommended 0.250 in. gagelength gage is the same as described in Sect. 4.3 for compression tests. To accurately measure elastic modulus, tensile tests were preceded with three load-controlled cycles between stress levels of 1000 and $4000 \mathrm{psi}$ (less than $25 \%$ of the UTS). The recorded elastic modulus was established as the average value obtained during cycling. Tensile tests to failure were conducted in displacement control at a rate of $0.001 \mathrm{in} . / \mathrm{s}$.

For heating/cooling, a special container was used around the specimens, and either hot air or liquid-nitrogen vapor $\left(\mathrm{LN}_{2}\right)$ was passed through the container. The container is shown in Fig. 4.1 and in the photographs of Figs. 4.2 and 4.3. The averaging extensometer is shown mounted on the specimen. This setup was also used for hot and cold tensile fatigue tests as well as for fatigue tests in high (>95\%) and low (<5\%) RH air.

The container system shown in Figs. 4.1 through 4.3 is fabricated entirely from simple, readily available, commercial products. The main body is a 6-in.-O.D. by 1/8-in.-thick Lexan tube, split in half. The end plugs are cast from pourable room temperature vulcanizing (RTV) silicone rubber. They too are split in half and contain a slit for the specimen. The hot or cold gas, or wet or dry air, comes in and out through standard compression tube fittings mounted in the Lexan tube. The extensometer leads pass through the split in the end plugs.

For heating up to $250^{\circ} \mathrm{F}$, plant instrument air is passed through an Omega in-line air heating unit, which is simply a cartridge heater encapsulated in a hollow tube with an annular air space between the heater and outside tube. Two thermocouples are taped to the specimen, one for controlling and one for recording temperature. An analog proportional temperature controller is used.

For cooling to $-40^{\circ} \mathrm{F}, \mathrm{LN}_{2}$ is used. A cryogenic solenoid valve is used for on/off control. A metering valve is adjusted to minimize thermal cycling caused by the on/off control. Also, a three-bottle manifold for the $\mathrm{LN}_{2}$ cylinders is used to allow unattended long-term operation. A 1-in.-thick layer of closed-cell foam insulation is wrapped around the container to minimize $\mathrm{LN}_{2}$ usage. The same thermocouple arrangement and controller is used as in the heating case. 


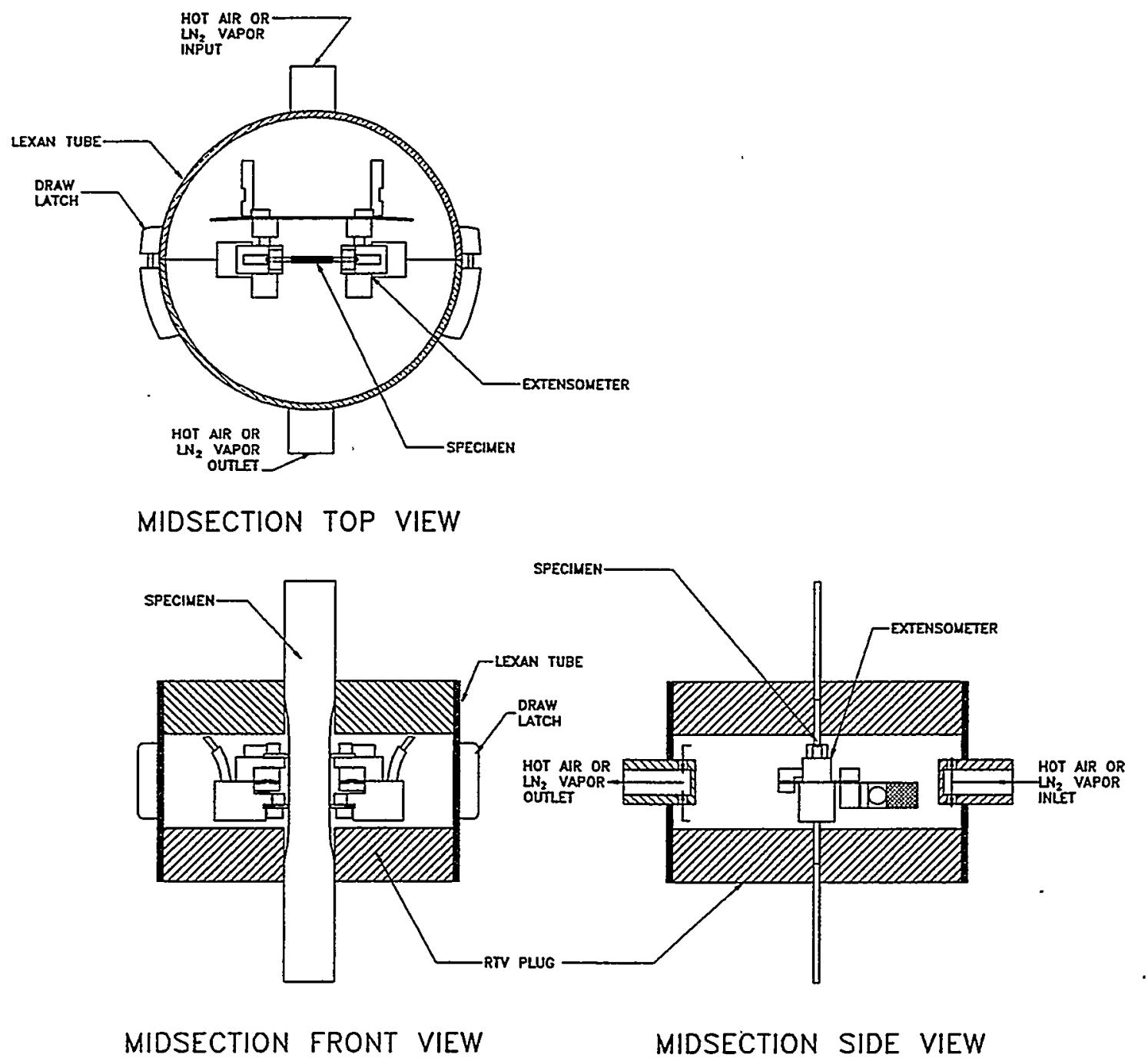

Fig. 4.1. Drawing of test chamber for hot and cold testing of tensile specimens. 


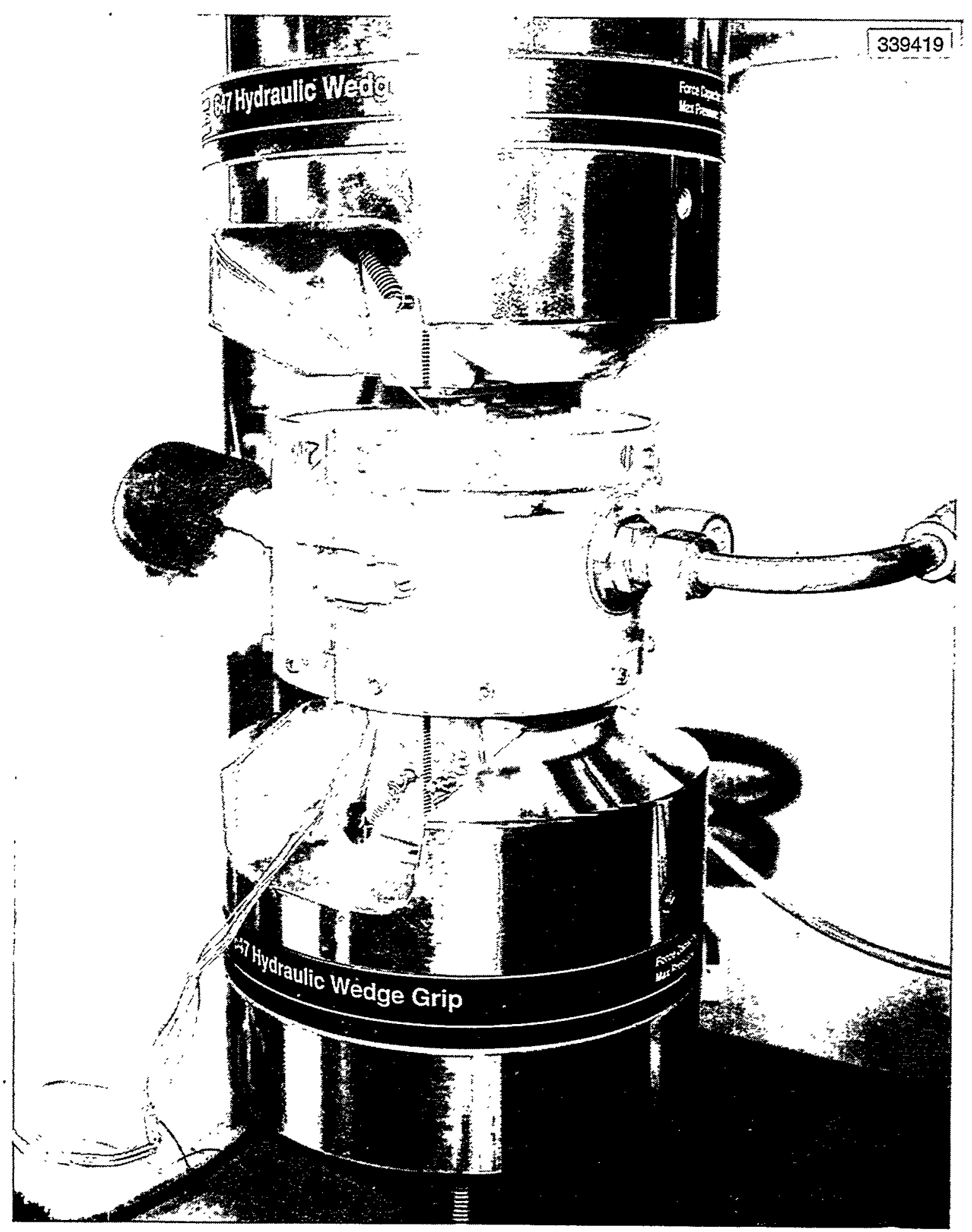

Fig. 4.2. Test chamber for hot and cold testing, with a $-40^{\circ} \mathrm{F}$ test in progress. 


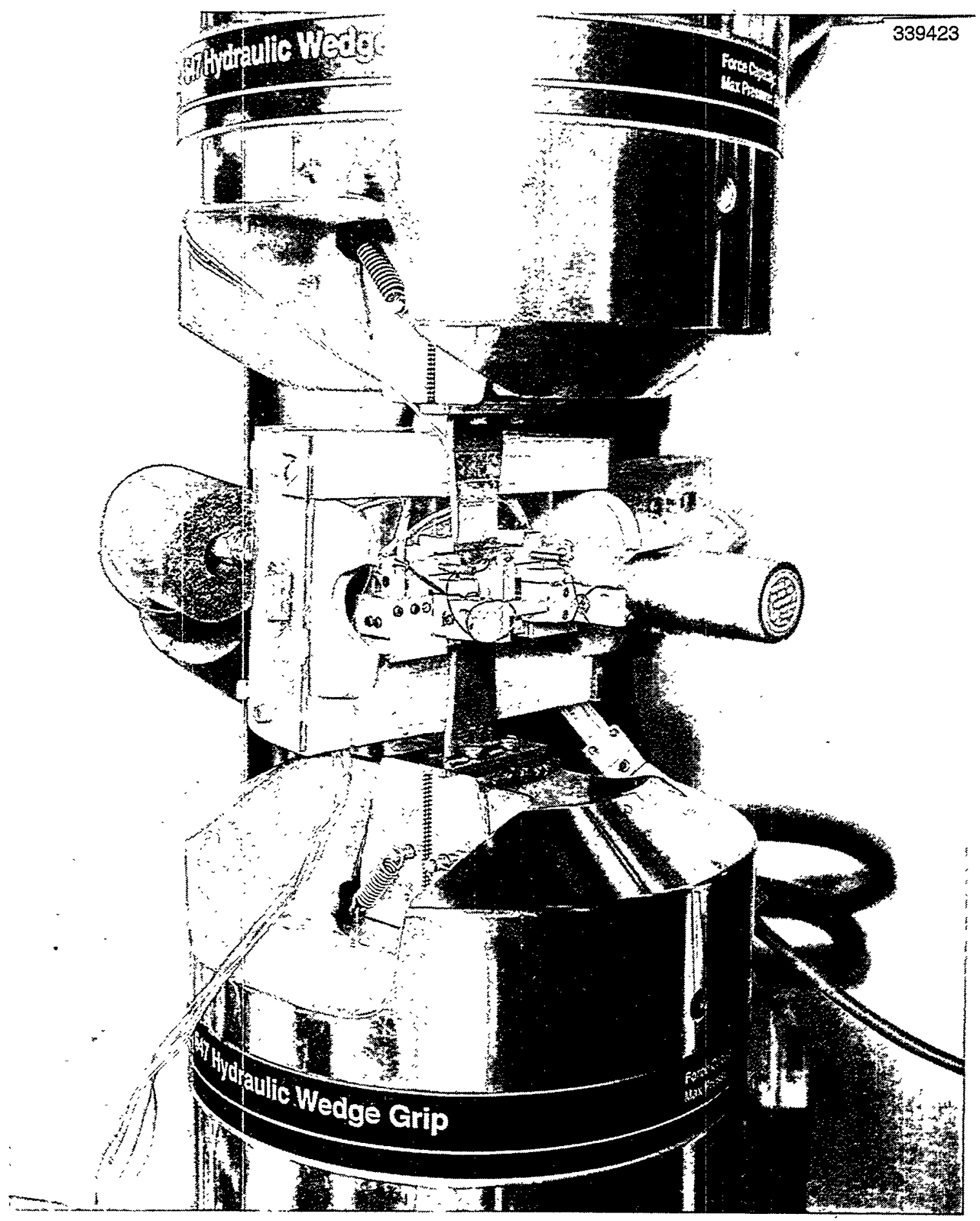

Fig. 4.3. Interior of chamber showing averaging extensometer mounted on specimen. 
For low humidity, normal plant instrument air, which contains almost no water or oil, is used. The instrument air is bled into the chamber through a metering valve to produce the less than 5\% RH air environment. For greater than 95\% RH, an ultrasonic humidifier and Omega on/off controller is used. Either system is connected to the chamber with Tygon tubing.

\subsection{COMPRESSION}

The compression test specimen, which is for use with an IITRI-type compression test fixture, was shown in Fig. 3.2. Figure 4.4 shows the specimen mounted in the fixture. Compression tests to failure were conducted in displacement control at a rate of $0.001 \mathrm{in} . / \mathrm{s}$.

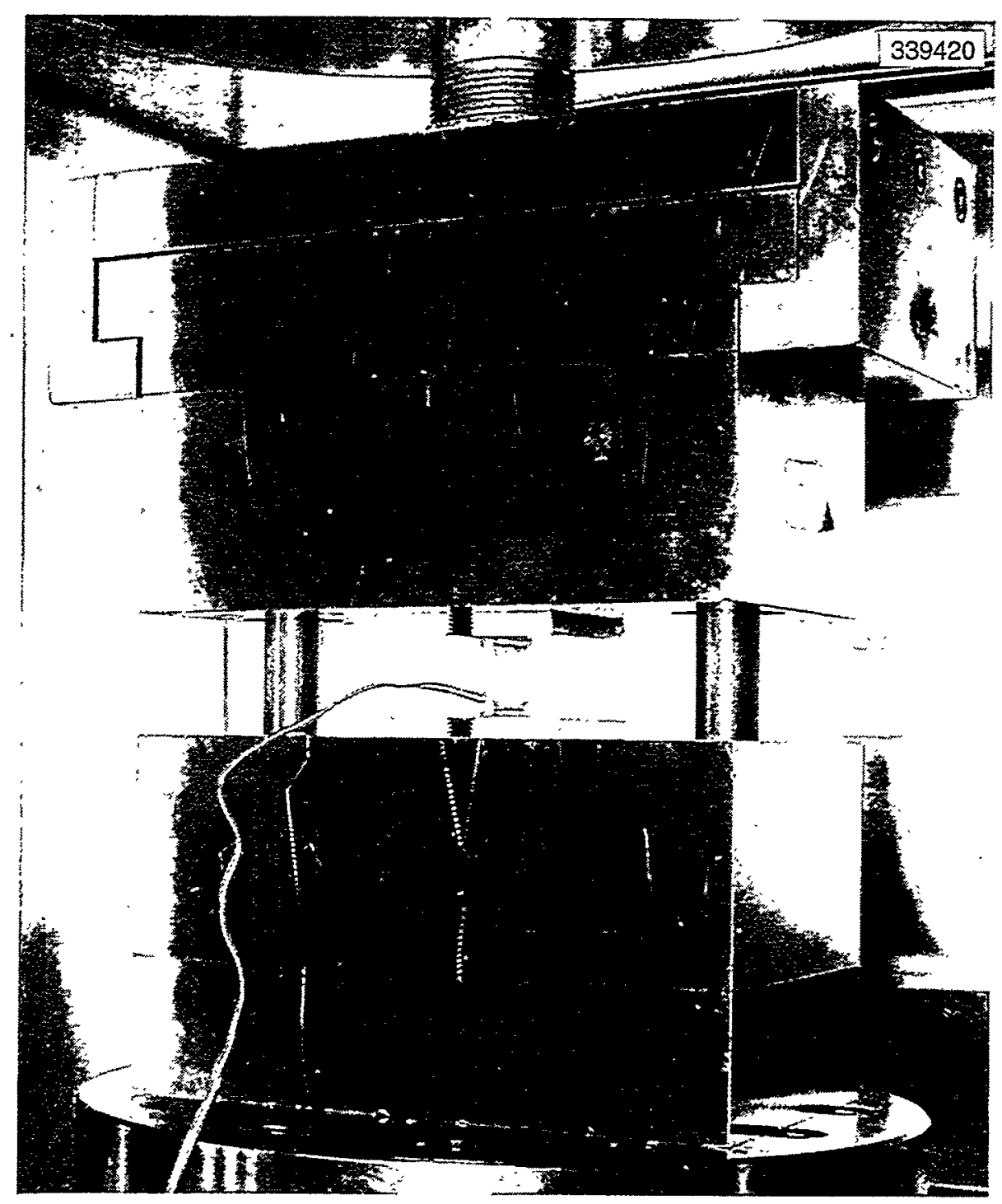

Fig. 4.4. Close-up of specimen in compression test fixture. 
Strain measurement was accomplished with two strain gages, which were mounted on each face of the specimen at midheight. The two gage readings were averaged. Compressive stiffness was calculated using linear regression for the initial stress-strain slope from 800 to 4000 psi. The strain gages used were Micro-Measurements ${ }^{*}$ EA-13-250 AE-350, which have a 0.250-in. gage length. For temperatures of $120^{\circ} \mathrm{F}$ and below, Micro-Measurements M-Bond 200 adhesive was used to bond the gages. Above $120^{\circ} \mathrm{F}, \mathrm{M}$-Bond 600 is recommended. Whereas M-Bond 200 cures at room temperature, $\mathrm{M}$-Bond 600 requires a cure of $4 \mathrm{~h}$ at $250^{\circ} \mathrm{F}$. Micro-Measurements recommends a $1 \mathrm{~h}$ postcure for the $\mathrm{M}$-Bond 600 adhesive at $50^{\circ} \mathrm{F}$ above the intended use temperature.

For tests other than at room temperature, the compression fixture was used inside an ATS environmental chamber, as shown in Fig. 4.5. For hot testing, the chamber has an oven, which is controlled in the same manner as described above for tensile testing. For cold tests, the $\mathrm{LN}_{2}$ system described for tensile testing is used, with the vapor simply passed through the chamber.

\subsection{SHEAR}

The V-notched Iosipescu shear specimen, which is used in a special test fixture, was shown in Fig. 3.3. Figure 4.6 shows the specimen in the shear test fixture. ASTM Standard D $5379^{8}$ covers the test. Tests at ORNL were conducted in displacement control at a rate of $0.001 \mathrm{in.} / \mathrm{s}$.

Shear strain measurement was accomplished with two special strain gages, specifically designed for the Iosipescu specimen. The Micro-Measurement gages are designated as N2A-00-C032A-500. One was located between the notches on each face of the specimen. Adhesives used for mounting the gages were the same as used in the compression case (Sect. 4.3).

Just as in the compression case, tests at other than room temperature were performed inside an ATS environmental chamber. The methods of heating and cooling used were exactly the same as used for compression testing.

\subsection{FLEXURE}

The flexure specimen used was described in Sect. 3.5. A three-point bend test with a support span of 2 in. was used. The specimens were mounted in an MTS 642.10 bend fixture as shown in Fig. 4.7. Displacement control, at a rate of 0.003 in./s, was used.

Strain measurement was accomplished with a single strain gage mounted at the center of the beam on the tension side. The gage was the same as used for compression tests (see Sect. 4.3).

These tests, which were used to determine the relation between tensile strength and elastically calculated bending strength (modulus of rupture), were only performed in ambient room-temperature air.

\subsection{BIAXIAL FLEXURE}

Biaxial flexure tests were used to obtain failure data under biaxial tensile stresses for use in establishing a biaxial strength criterion. Ideally, a tubular specimen would be used to obtain the needed data, but the molding/preforming process used for automotive composites does not lend itself to making satisfactory tubes. Flat cruciform specimens were an option, but they are extremely difficult and

\footnotetext{
* Micro-Measurements is a division of the Measruements Group, Inc., of Vishay.
} 


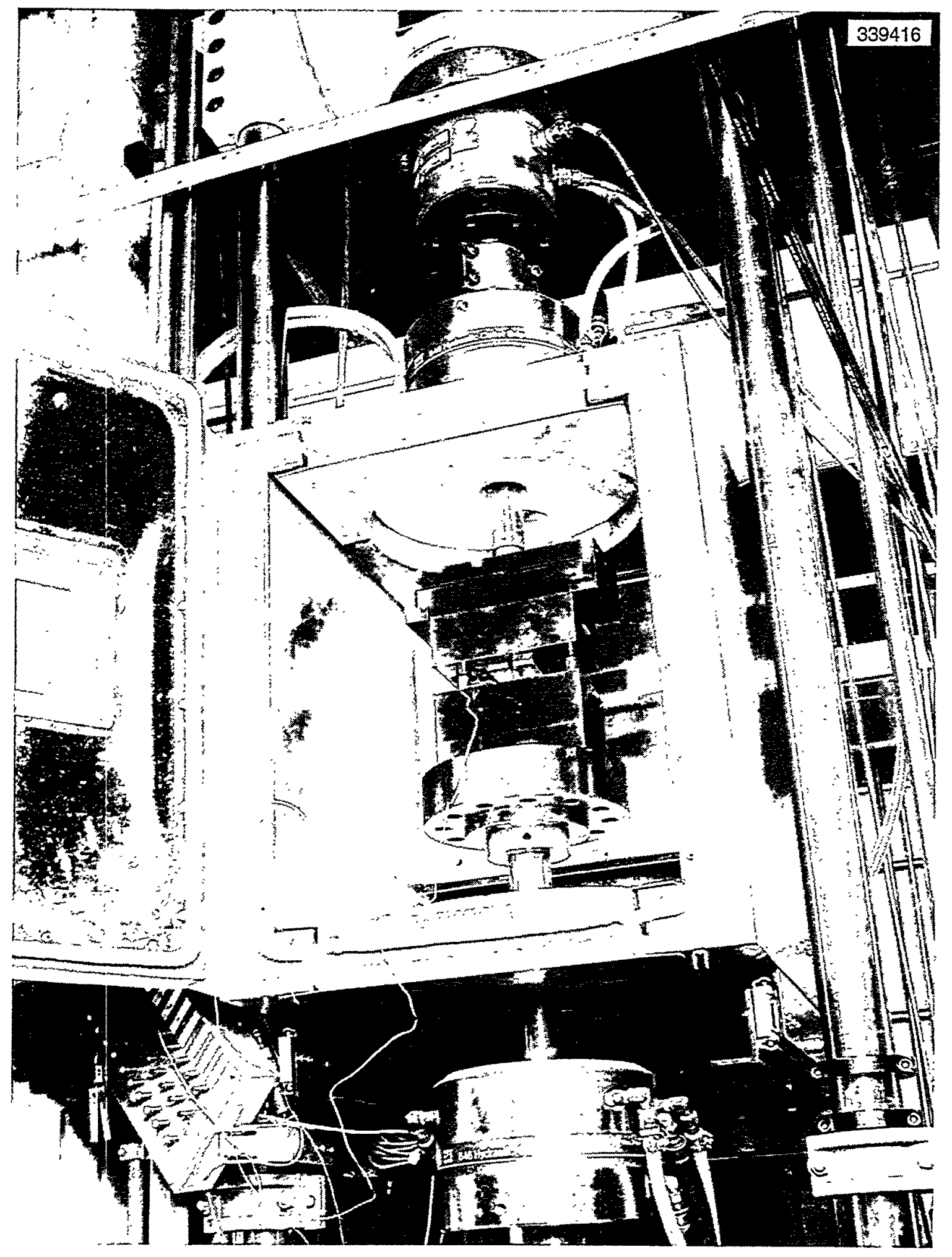

Fig. 4.5. ATS environmental chamber with ITRI fixture installed for compression testing. 


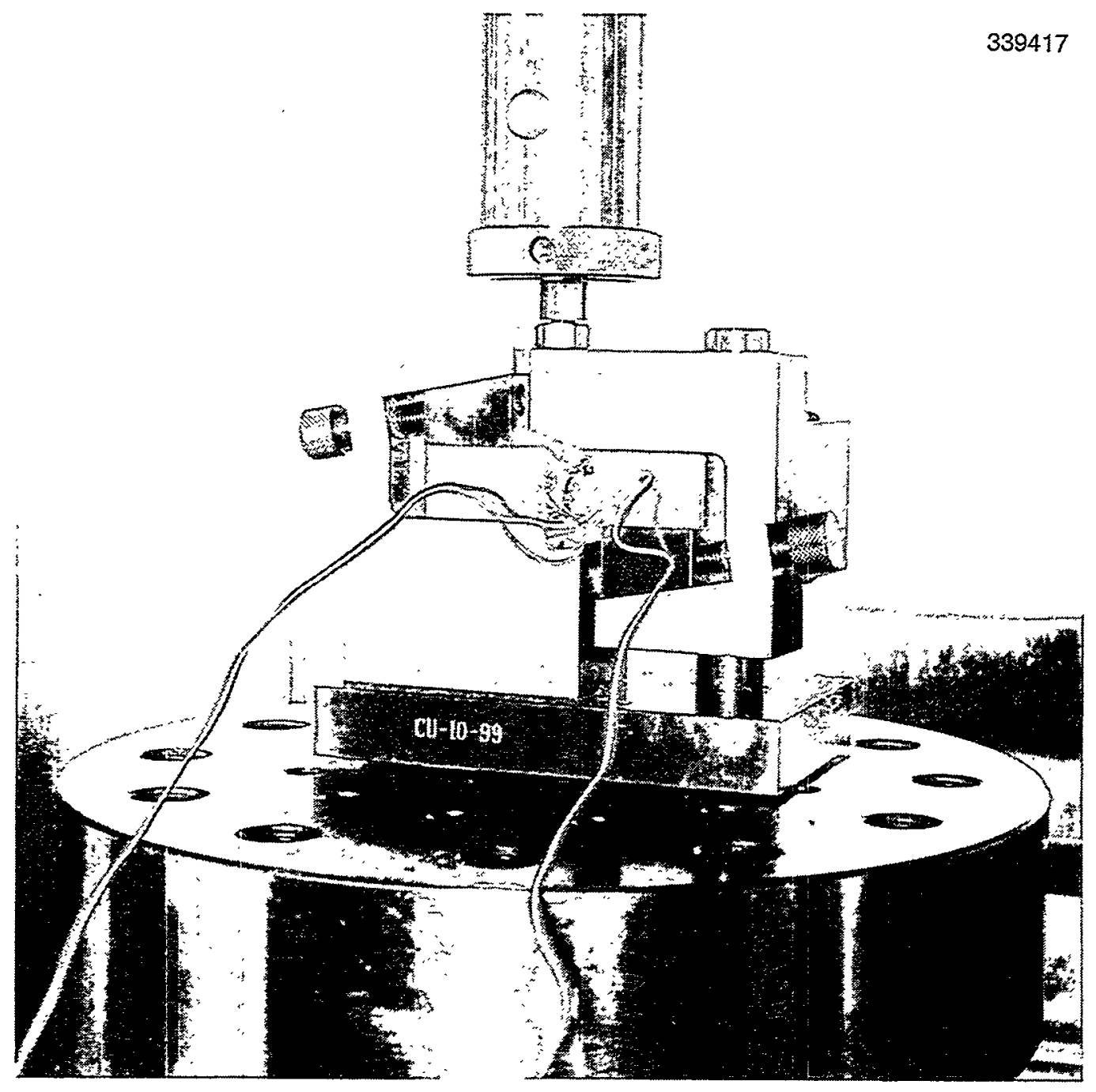

Fig. 4.6. Shear specimen in Iosipescu test fixture. 


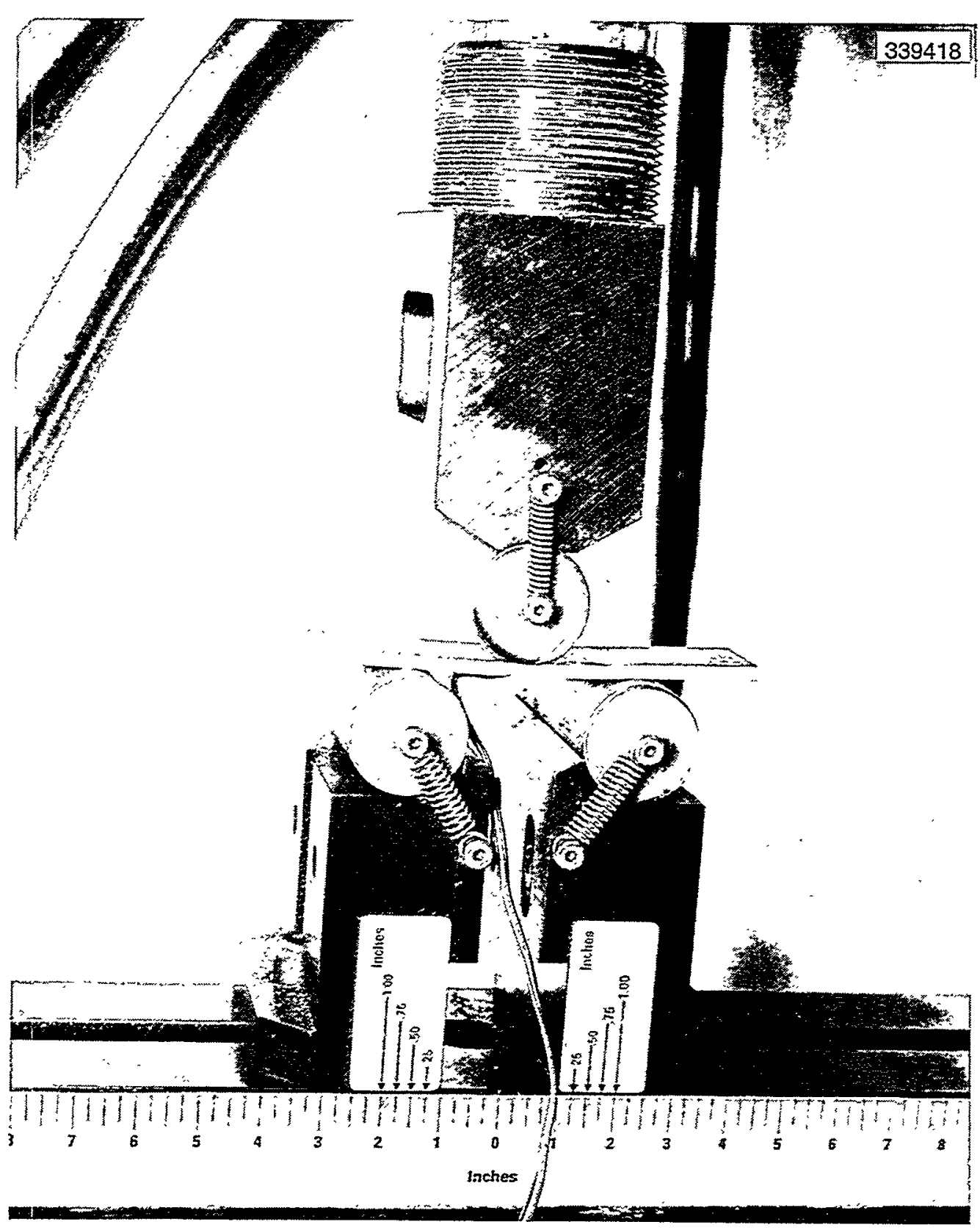

Fig. 4.7. Out-of-plane flexure test. 
expensive to test. The biaxial flexure test was thus a compromise. The way in which the results were used is described in Chap. 6 of Ref. 2.

The loading fixture for the biaxial tests is depicted in Fig. 4.8. A photograph is shown in Fig. 4.9. The circular specimen was simply supported and loaded by a concentric circular ring load. Plate theory predicts that on the surface opposite the ring load, the stress state is equibiaxial tension everywhere inside the ring load. Nonlinear finite-element analysis showed this to be true only for plate deflections that are less than one-half the thickness of the disk. At larger deflections, the maximum biaxial tensile stresses are on a circle opposite the ring load. Thus, a nonlinear, inelastic, large-deflection, finite-element analysis is required to determine the maximum stresses at failure in this test. A loading rate of $0.003 \mathrm{in} . / \mathrm{s}$ is recommended.

Various strain gage layouts were used in conducting the biaxial tests. As shown in Fig. 4.8, lead wires for the top (compression) side of the specimen could be brought out through the drilled hole in the load plunger. The bottom of the specimen is readily accessible for strain gages. Three-gage rosettes were used at the center of the specimens, while single

radially and tangentially oriented gages were used on the bottom (tension) side of the specimen under the ring load. The single gages, which provided the most useful information, were the same 0.250 -in.-long gages as described for compression tests. The measured strains were compared with finite-element predictions to validate the analysis results, thus providing confidence in the predicted stresses.

All of the biaxial tests were performed in ambient room-temperature air. 


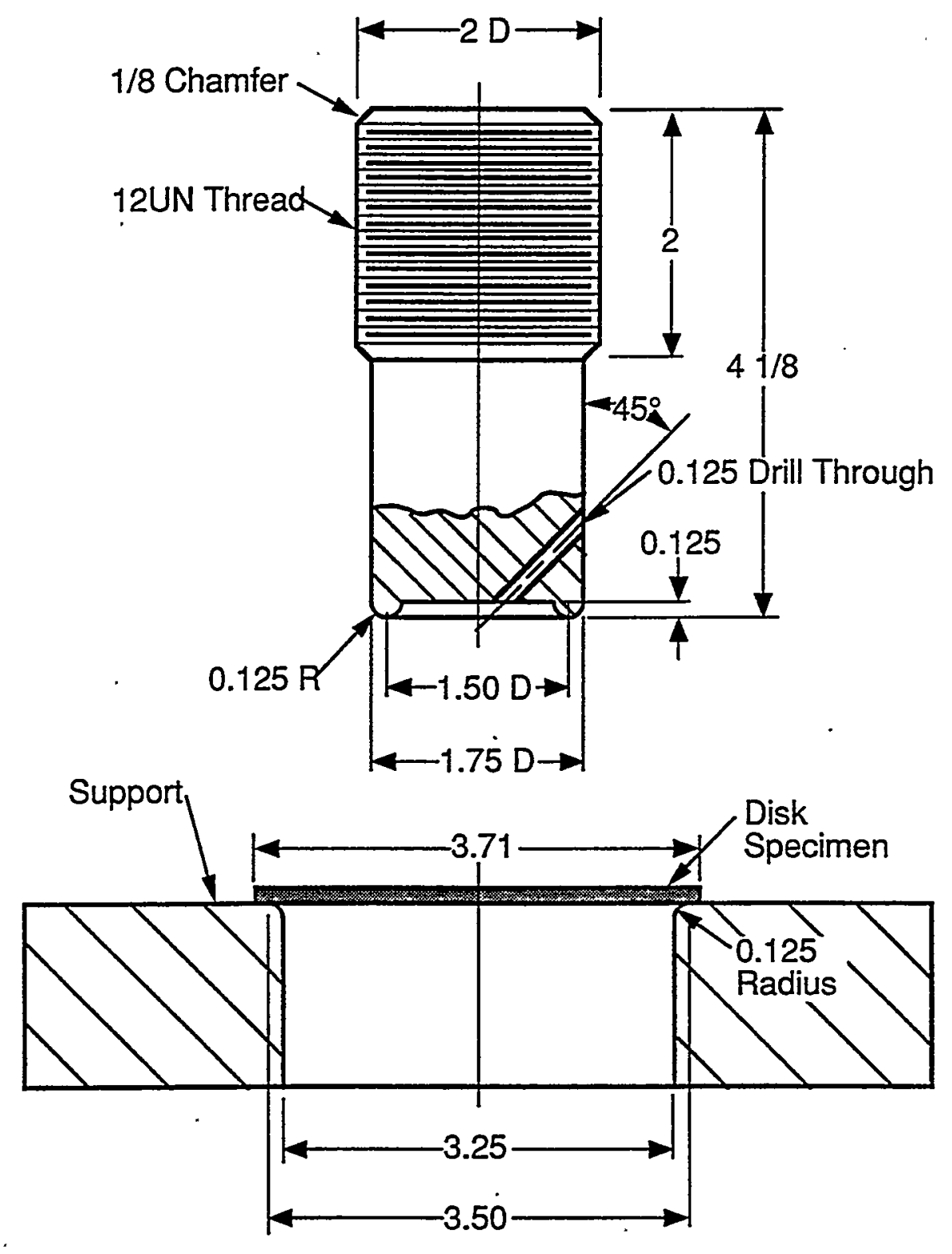

4.8. Drawing of out-of-plane biaxial flexure test loading fixture. Dimensions are in inches. 


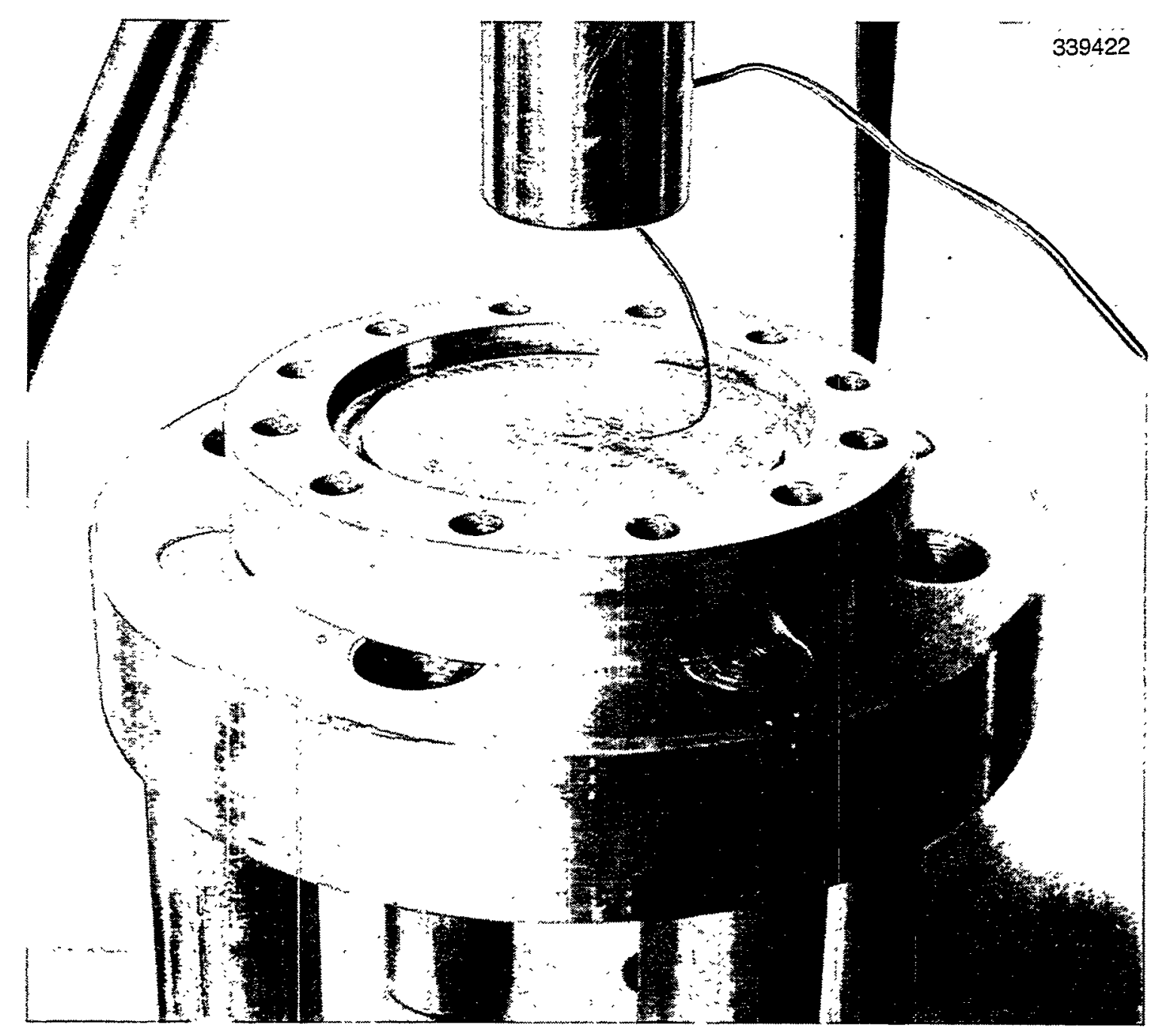

Fig. 4.9. Biaxial flexure test. 


\section{FATIGUE TESTS}

\subsection{INTRODUCTION}

Two kinds of fatigue tests were performed at ORNL-tension-tension fatigue and reversed, or compression-compression, fatigue. They are described in the following two sections.

The tension-tension tests were performed under a full range of temperatures $\left(-40^{\circ} \mathrm{F}\right.$ to $\left.250^{\circ} \mathrm{F}\right)$ and environmental conditions. The latter included tests in wet and dry air, distilled water, saltwater, engine coolant, windshield washer fluid, brake fluid, motor oil, and battery acid. The reversed fatigue and compression-compression fatigue tests were performed only in ambient room-temperature air.

\subsection{TENSION-TENSION FATIGUE}

The tension-tension fatigue tests were performed either in standard MTS test machines or in servo-controlled hydraulic machines designed and built at ORNL. An example of the latter are the three small machines shown in Fig. 5.1. These machines were built specifically for fatigue testing of automotive composites. The dogbone tensile specimen shown in Fig. 3.1 was used, with either mechanical or hydraulic wedge grips.

A haversine waveform was used, with a ratio, $R$, of minimum to maximum stress of 0.1 . The frequency used varied with stress in accordance with the following relation, recommended by $\mathrm{ACC}:{ }^{10}$

$$
\mathrm{f}=\left(\mathrm{k} \mathrm{S}_{\mathrm{ult}}\right) /\left(\mathrm{S}_{\max }-\mathrm{S}_{\min }\right)
$$

where $\mathrm{k}$ is a constant ( $3 \mathrm{~Hz}$ recommended), $\mathrm{S}_{\mathrm{ult}}$ is the UTS of the composite, $\mathrm{S}_{\max }$ is the maximum stress in the cycle, and $S_{\min }$ is the minimum cyclic stress $\left(S_{\min }=0.1 S_{\max }\right)$.

Hot and cold fatigue tests, as well as those in wet or dry air, used exactly the same chamber, and heating and cooling, or drying and humidifying, arrangements as described in Sect. 4.2 for tensile tests. One or the other of the extensometers mentioned there was used for the in-air fatigue tests.

Three different fluid container designs were used, depending on whether the fluid being evaluated evaporated rapidly and whether an extensometer was used. Like the chamber used for heating and cooling, all three fluid containers were fabricated from simple, readily available, commercial products.

All of the tests in fluids were on specimens that had been presoaked in the fluid for at least $100 \mathrm{~h}$ prior to the start of testing.

All of the fluid container designs described here take advantage of the "actuator on top" configuration of the test machines. The simplest container used is the open one shown in Fig. 5.2. It is made of a piece of polyvinylchloride (PVC) pipe and a pipe-reducing couple. The plug at the bottom is cast from pourable RTV silicone rubber, with a slit to accommodate the specimen. This container does not accommodate an extensometer, and it can be used only for short tests with fluids having components that evaporate quickly. It is attractive for fluids like oil, however, because of its ease of use and of cleanup. 


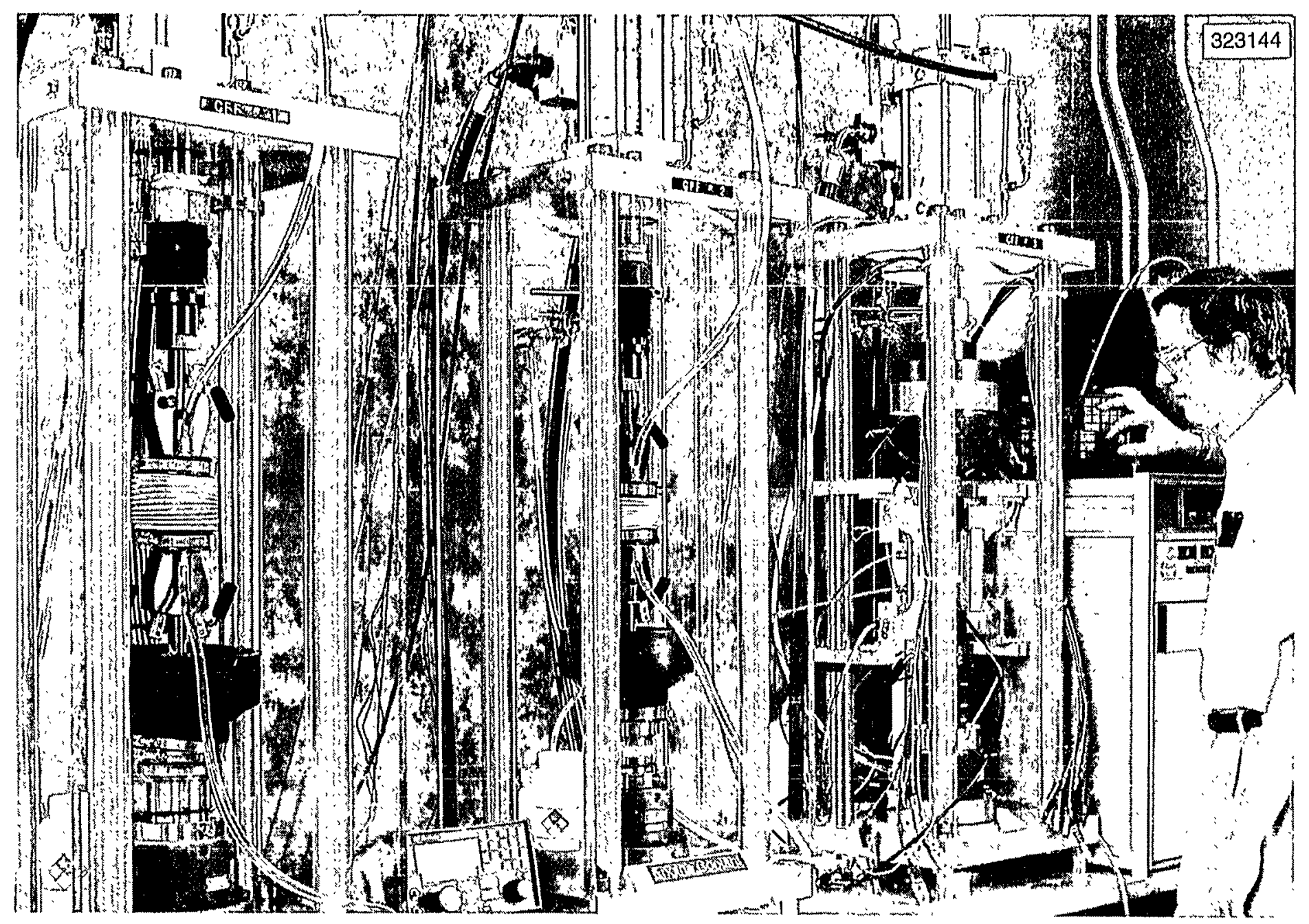

Fig. 5.1. Small fatigue test machines built at ORNL for testing automotive composites. 


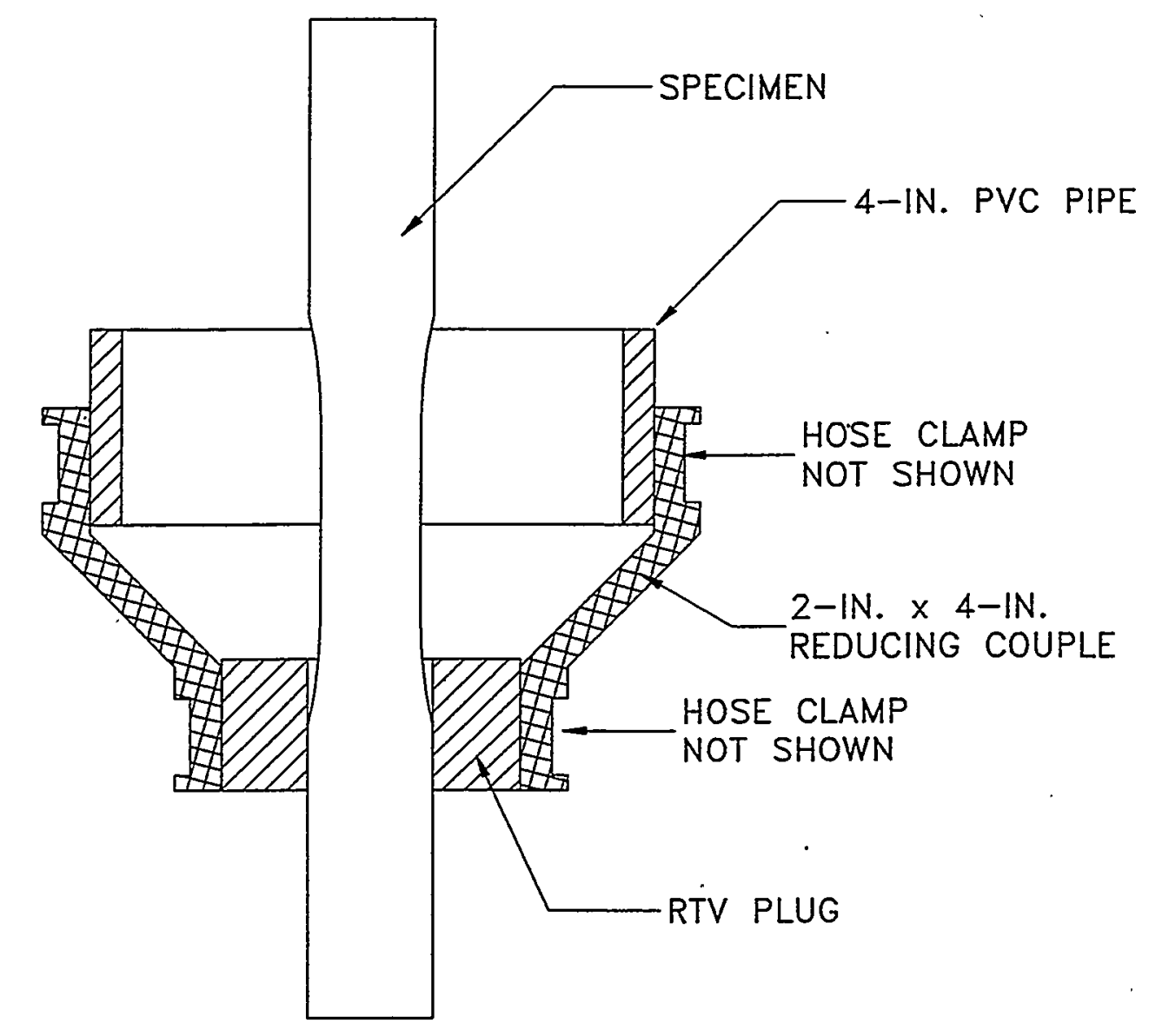

Fig 5.2. Cross-section of simple open fluid container for fatigue tests. 
For fluids that evaporate quickly and for tests where an extensometer is not required, the container shown in Fig. 5.3 and in the photograph of Fig. 5.4 was used. The container is based on a bellows purchased from McMaster-Carr Supply Company. The bellows is a modified version of part No. 95635K65. The 4.5-in. O.D., the 3-in. I.D., and the 0.060-in.-wall thickness were retained, but the compressed length was changed to 1.5 in., the extended length was changed to 8 in., and the cuffs (straight ends) were changed to 0.75 in. The bellows is a white neoprene-coated nylon fabric. The inside shields were glued in place to protect the black neoprene couple material from harsh fluids such as battery acid.

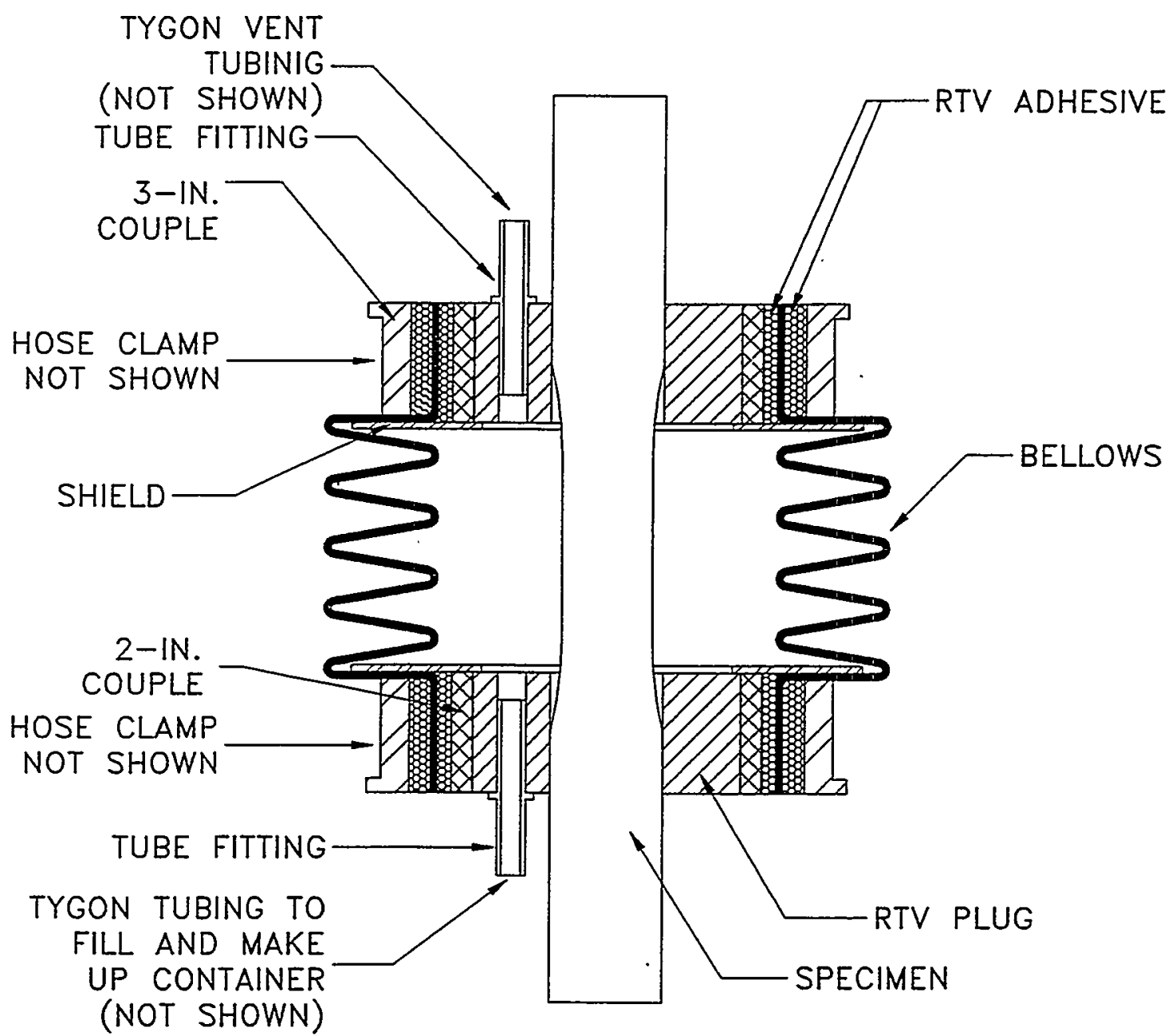

Fig. 5.3. Cross-section of closed fluid container for fatigue tests. 


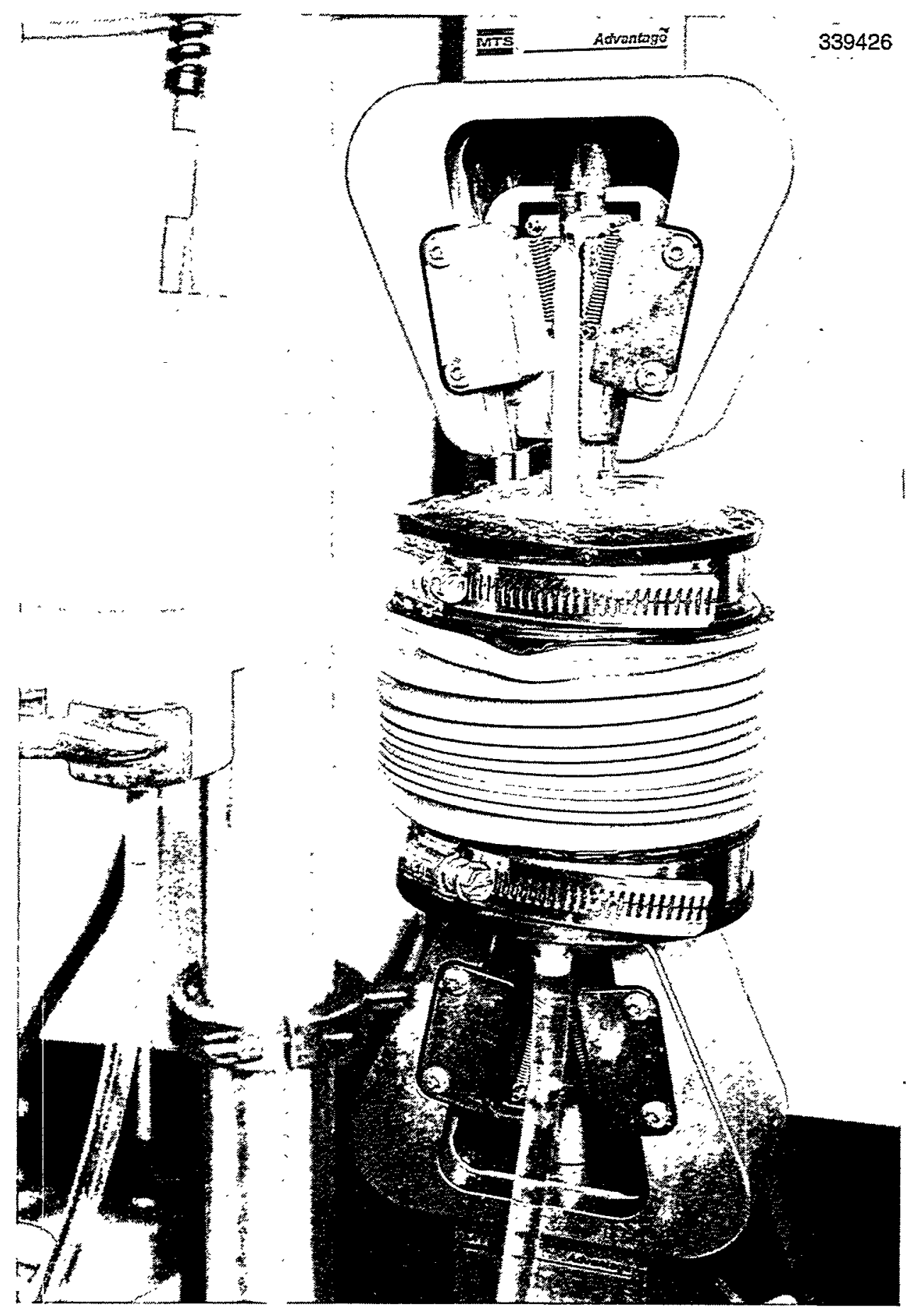

Fig. 5.4. Photograph of closed container and makeup fluid system. 
A closed plastic container was connected to the bottom tube fitting of the main bellows container with Tygon hose and used for the initial filling and for fluid makeup during a test. The hose was connected to the bottom of the small makeup container, and the top of the container was vented. The venting allowed air into the container but minimized contaminates coming in and evaporation out. This arrangement can be seen in Fig. 5.4. This system worked very well. Only small amounts of the worst evaporating fluid, windshield wash with $70 \%$ methanol, had to be added weekly.

The top of the main container was vented by using a hypodermic needle glued into a 5-in. length of Tygon tubing attached to the upper tube fitting of the container.

In those cases where strain measurements were required during fatigue cycling in a fluid, the closed container shown in Fig. 5.5 and in the photograph of Fig. 5.6 was used. This design is built around the use of a high-temperature MTS extensometer (632.51B-01) having quartz rods to transfer strain to the sensor head. The main component of the container is a $11 / 2$-in. O.D. $\times 1 / 8$-in.-wall Lexan tube. Cast RTV silicone plugs are used at top and bottom, with the top one acting as a flexible diaphragm. Its contact surfaces were lubricated with Apiezon grease in an effort to further reduce extraneous loads on the specimen. Fluid is added through the 1/4-in. tube mounted on the side opposite the extensometer.

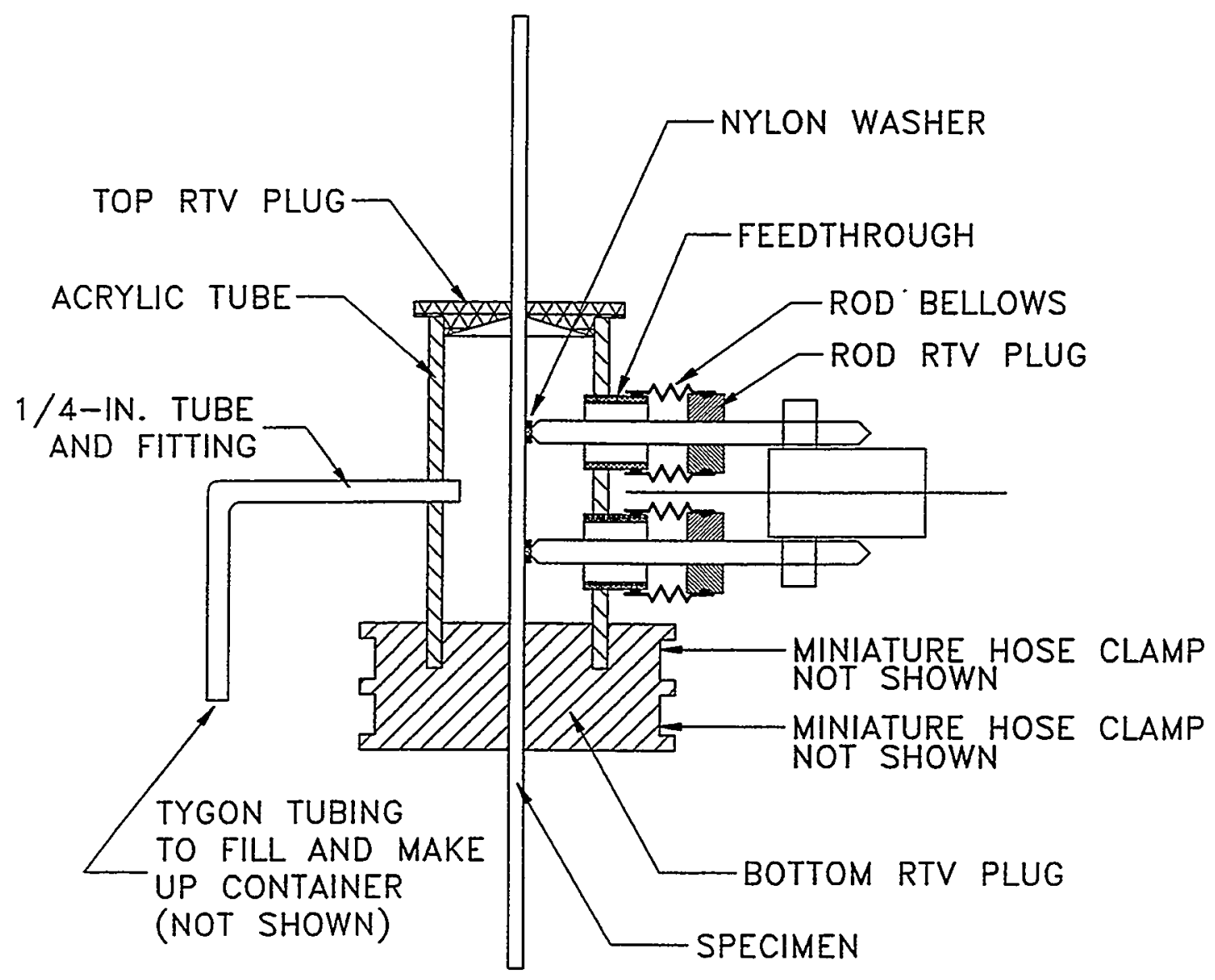

Fig. 5.5. Cross-section of closed container accommodating extensometer. 


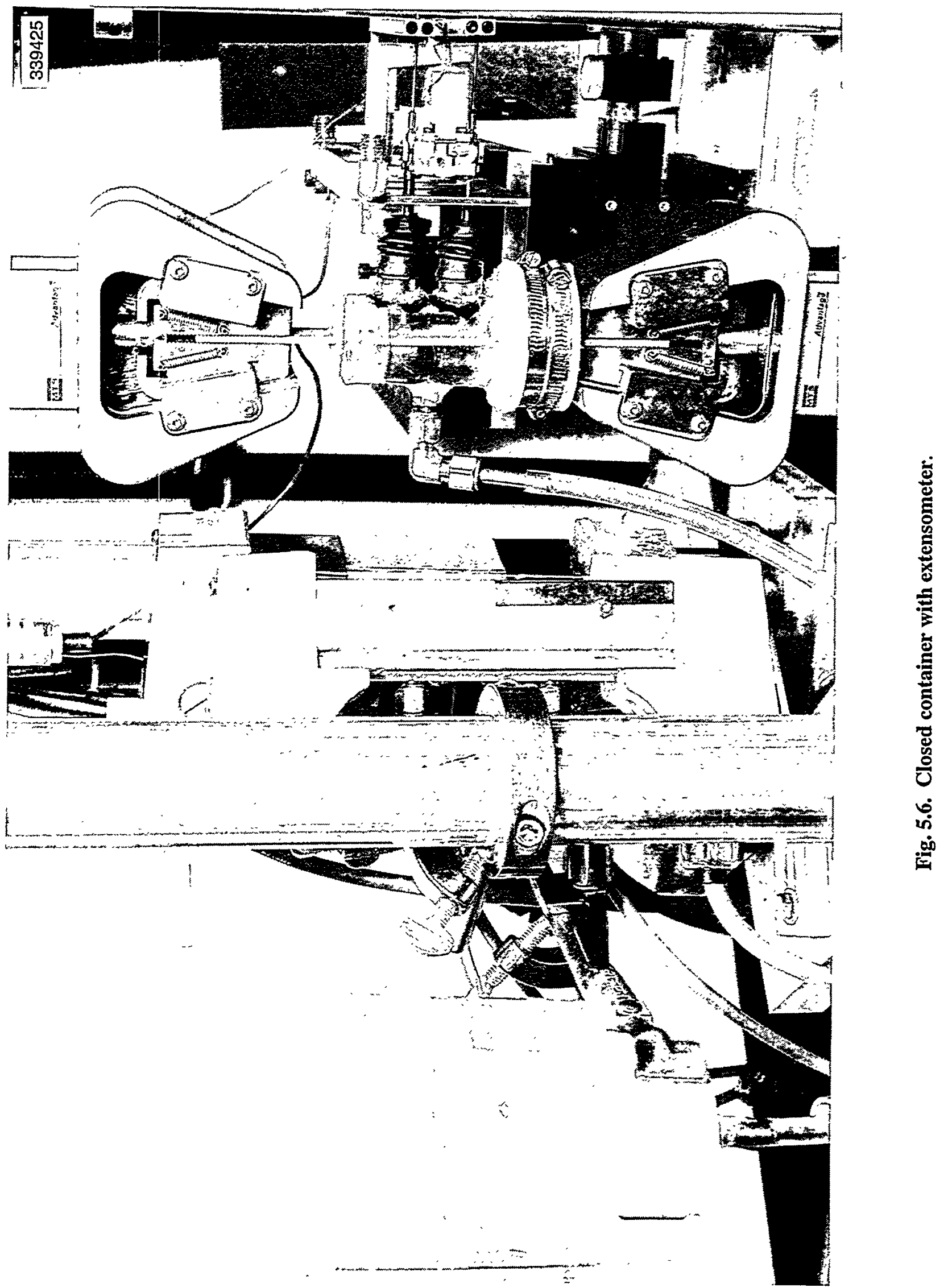


The extensometer rod feedthroughs were machined from 5/8-in. stainless steel tubing. One end was threaded, and a partial O-ring groove was machined in the other end. The threaded ends were epoxy glued to matching threaded holes in the Lexan tube. Dust covers for a 1998 Lincoln Town Car brake caliper were used as the rod bellows. ${ }^{*}$ These bellows have an inside half O-ring bead in each end that matches the grooves in the metal feedthroughs. Silicon tubing was used for the rod plugs.

Because the original quartz extensometer rods tended to break with each specimen failure, they were replaced with stainless steel rods. The extensometer rods are held to the specimen by nylon washers glued to the specimen. This eliminates the need for indentations in the composite specimen. The washers also help protect the extensometer head because the glue joint fails before damage to the extensometer occurs. As another line of defense against extensometer damage, the feedthroughs were sized to prevent excessive motion of the stainless steel rods.

In addition to room-temperature fatigue tests in fluids, this third container has been successfully used for $120^{\circ} \mathrm{F}$ tests in distilled water. Quartz light heaters were placed opposite the extensometer for this purpose. A piece of gasket material was placed in the water between the heaters and the specimen to even the side-to-side temperature profile. The top plug minimized evaporation and heat loss during these hot tests.

\subsection{REVERSED FATIGUE}

The reversed fatigue and compression-compression fatigue tests were performed on the hourglass specimen shown in Fig. 3.4. Only room-temperature ambient air tests were performed. Strain measurement was accomplished with an MTS 632.11B-20 extensometer having a 1.0-in. gage length. The fact that the specimen width was not uniform over the gage length led to a small error in the measured strain. Elastic finite-element analysis indicated that the measured axial strain over the 1-in. gage length was $96.9 \%$ of the actual axial strain at the middle of the hourglass.

Tests were conducted in load control with a sawtooth waveform. The frequency used was $5 \mathrm{~Hz}$ for lower stress tests and $2 \mathrm{~Hz}$ for the higher stresses. For the P4 chopped-fiber composite, the break point between the two frequencies was a stress of $12.8 \mathrm{ksi}$.

\footnotetext{
* Purchased as a hardware repair kit (Brake Headquarters H5841) from AutoZone.
} 


\section{CREEP AND CREEP-RUPTURE TESTS}

\subsection{INTRODUCTION}

Both tension and compression creep tests were carried out at ORNL. The tensile tests made use of the untabbed dogbone tensile specimen that was shown in Fig. 3.1, while the compressive tests used the much shorter specimen that was shown in Fig. 3.5. All tests were conducted in dead-weight, leverarm creep frames. Strain gages were used for strain measurement in both cases. These two types of tests are described in the following sections.

\subsection{TENSLE CREEP}

\subsubsection{Test Details}

Details of the tensile grips and the assembly with the specimen are shown in Fig. 6.1. The specimen was held by two 1.5 -in.-long segments of a common curved-tooth file, which were backed by pieces of stainless steel plate with slots to limit travel of the file segments. Four screws were torqued to a set value to hold these components together firmly. The stainless steel pieces were attached to the rest of the pull stringer with steel pins.

Several of the lever-arm creep machine load trains with specimens under tensile testing in $50 \%$ $\mathrm{RH}$ air at room temperature are shown in Fig. 6.2. The loading process was controlled to obtain a constant loading strain rate of $0.04 \mathrm{in}$./in. per minute by using a speed-controllable elevator to lower the weight pan of the lever-arm creep machine at the desired speed. Note that because of the nature of the lever arm, displacement in the specimen is not equal to that of the weight pan. A calculation must be done to determine the correct displacement rate of the weight pan to obtain the desired loading strain rate.

Stains were measured using a Micro-Measurements type CEA-13-500UW-350 strain gage, with a 0.5 -in. gage length, bonded to the specimen surface. Two methods were employed to record the strain gage signal. In method one, the signal was input into a high-precision, laboratory-type digital display strain indicator that was connected to a strip chart recorder. The loading strain as a function of time was recorded continuously on the strip chart recorder, and the long-term strain was recorded manually from the strain indicator display. In method two, the strain gage signal was input into a LabVIEWTM* data acquisition system and recorded as a computer file.

\subsubsection{Simulated Automotive Service Environments}

\subsubsection{50\% RH Air at Room Temperature}

The strain gage was bonded to the middle of the specimen gage length with M-Bond 200 supplied by Micro-Measurements.

\subsubsection{50\% RH Air at Elevated Temperatures ( 120 and $\left.250^{\circ} \mathrm{F}\right)$}

Although a temperature of $120^{\circ} \mathrm{F}$ is lower than the upper recommended operating temperature limit of the M-Bond 200 adhesive $\left(200^{\circ} \mathrm{F}\right.$ for short term and $150^{\circ} \mathrm{F}$ for long term), it was found that some creep of the adhesive bond occurred at this temperature. Therefore, for tests at both $120^{\circ} \mathrm{F}$ and $250^{\circ} \mathrm{F}$, M-Bond 600 is recommended. As previously mentioned, M-Bond 600 must be cured at elevated

${ }^{*}$ LabVIEWrM is a registered trademark of National Instruments. 


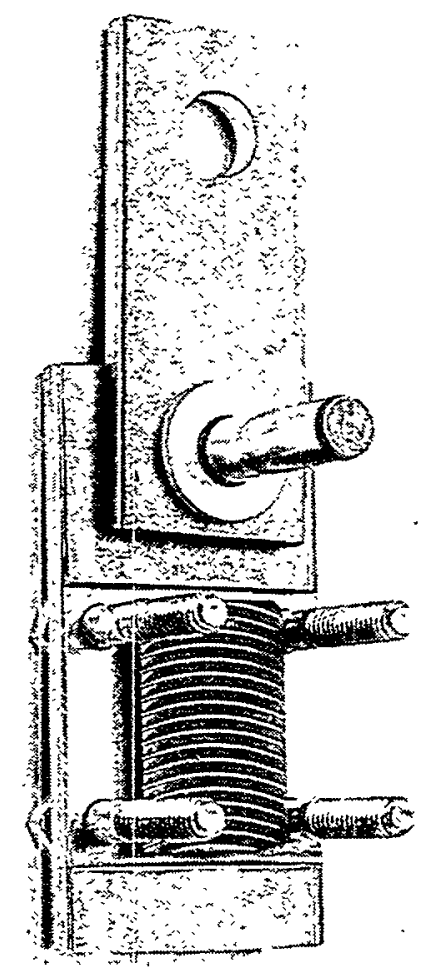

ORNL-Photo-3843-95

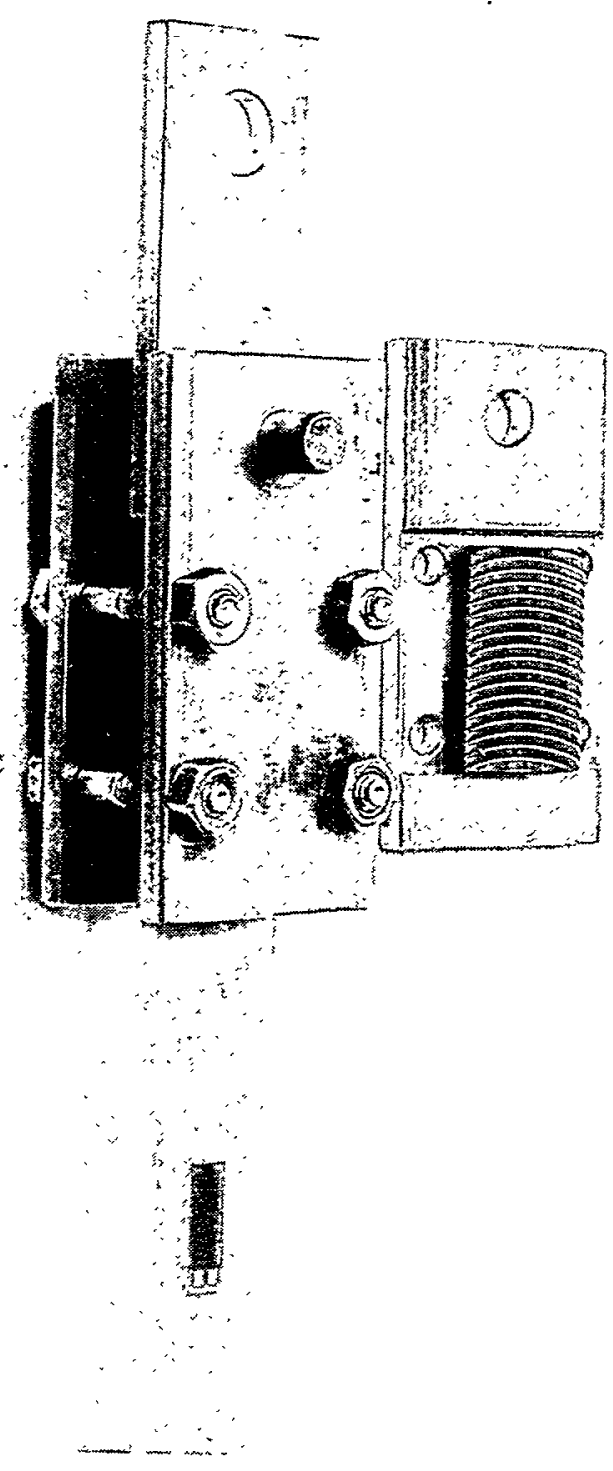

Fig. 6.1. Economical grips developed for use in tensile creep tests. 


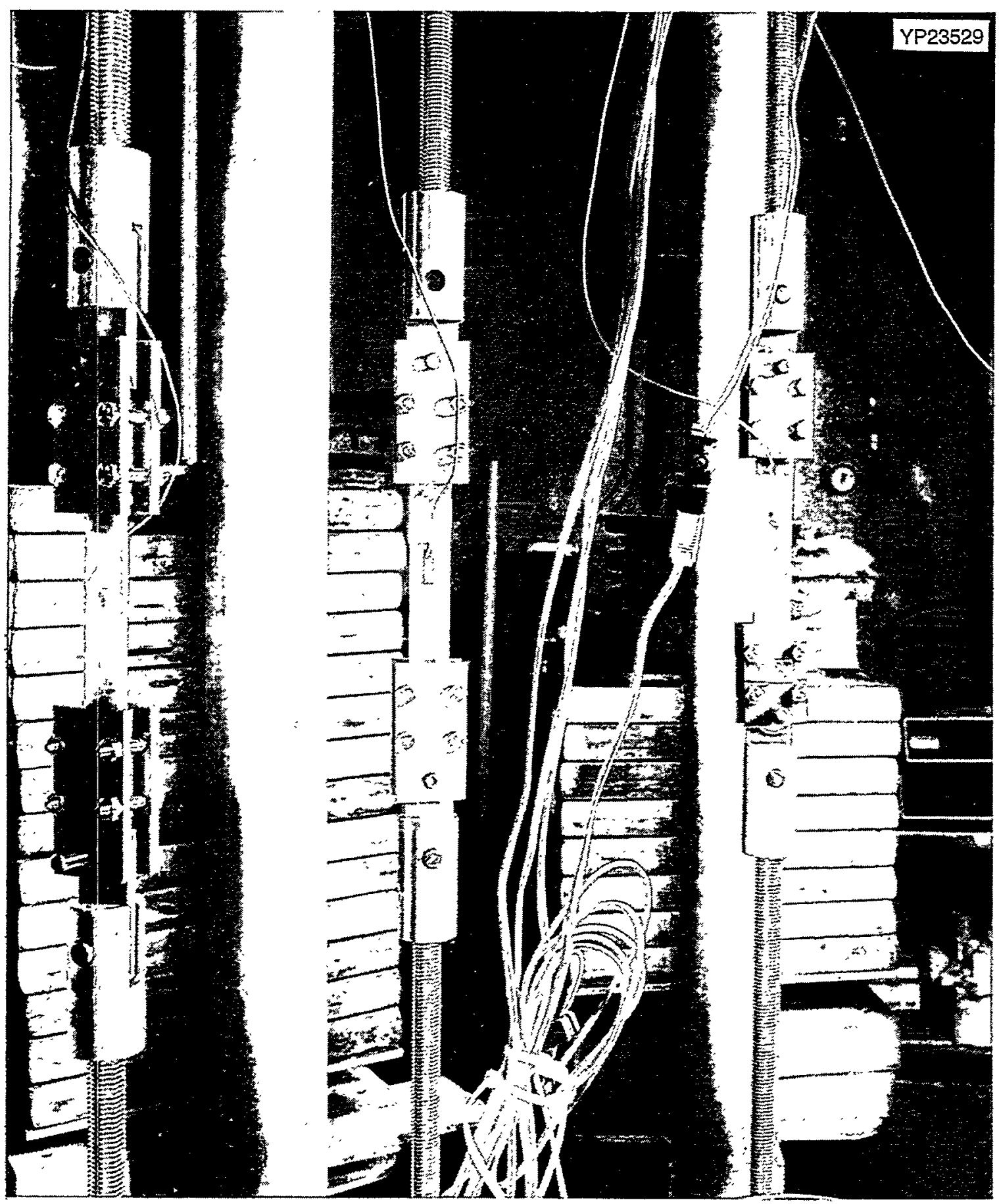

Fig. 6.2. Load trains of several lever-arm creep frames. The strain gages and their lead wires can be seen on each specimen in these room-temperature ambient air tests. 
temperature to form a creep-resistant bond between the strain gage and the specimen. Details of the application procedures of the M-Bonds are described in instructions provided with the products.

Heating the specimen was accomplished with heating tape. Pieces of copper or aluminum $(1 \times 4 \times 1 / 8$ in.) were placed on each side of the specimen gage section as conduction plates to ensure uniform heating. An insulation tape was put between the conduction plate and the strain gage to prevent short circuiting of the strain gage signal. Thermocouples were attached to the specimen gage section using glass tape. The heating tape was wound over these materials and then insulated with insulation cloth. The heating tape and the thermocouples were connected to a digital temperature controller that allows the desired temperatures to be set and monitored. A specimen being tested at elevated temperature in $50 \% \mathrm{RH}$ air is shown in Fig. 6.3.

\subsubsection{Air at Low Temperature $\left(-40^{\circ} \mathrm{F}\right)$}

The strain gage was bonded to the specimen gage section with M-Bond AE-10 supplied by Micro-Measurements. The specimen, with thermocouples, was contained in an insulated chamber connected to a liquid nitrogen dewar. A closed-loop temperature controller was employed to monitor and maintain the set temperature by controlling the nitrogen flow into the specimen chamber via a normally closed valve. A schematic of the control system is shown Fig. 6.4. The resulting atmosphere was essentially nitrogen, with very little air/moisture.

\subsubsection{Water at Room Temperature}

The strain gage was bonded to the middle of the specimen gage length with M-Bond 200 and covered with a protective coating of microcrystalline wax, M-Coat W-1, supplied by MicroMeasurements. The specimen was immersed in distilled water in a chamber for loading.

\subsubsection{Water at Elevated Temperature $\left(250^{\circ} \mathrm{F}\right)$}

The same protective coating and chamber was employed as for testing in water at room temperature. The desired temperature was kept constant and uniform throughout the chamber using an immersion heater, an electrical stirrer, and thermocouples. A water level adjusting system was employed to compensate for water evaporation. The system consisted of a plastic jar with a hermetically sealed lid on top and a flexible tube in the bottom. The jar was filled with water and placed above the specimen chamber with its lid sealed air-tight and tube outlet immersed below the water level in the specimen chamber. When the water level decreased to expose the tube outlet, air came into the jar through the tube and released water from the jar into the chamber until the water level rose to seal the outlet again and no air could enter the jar. In addition to the water compensation system, evaporation was reduced by putting a layer of melted wax on the water surface before starting the test. The wax cools to form a solid seal on the chamber opening with the thermocouples, immersion heater, stirrer, strain gage wire, and the water compensation tube. A picture of the water chamber setup is given in Fig. 6.5. A schematic of the watercompensation system is given in Fig. 6.6.

\subsubsection{Methanol (70 vol \%) plus Distilled Water (30 vol \%) at Room Temperature}

The same protective coating and chamber were employed as for testing in water at room temperature. To prevent evaporation, the opening of the chamber was sealed with a transparent plastic film using glass tape. The transparency of the film allowed visibility of the liquid level in the chamber, thus permitting compensation when necessary. 


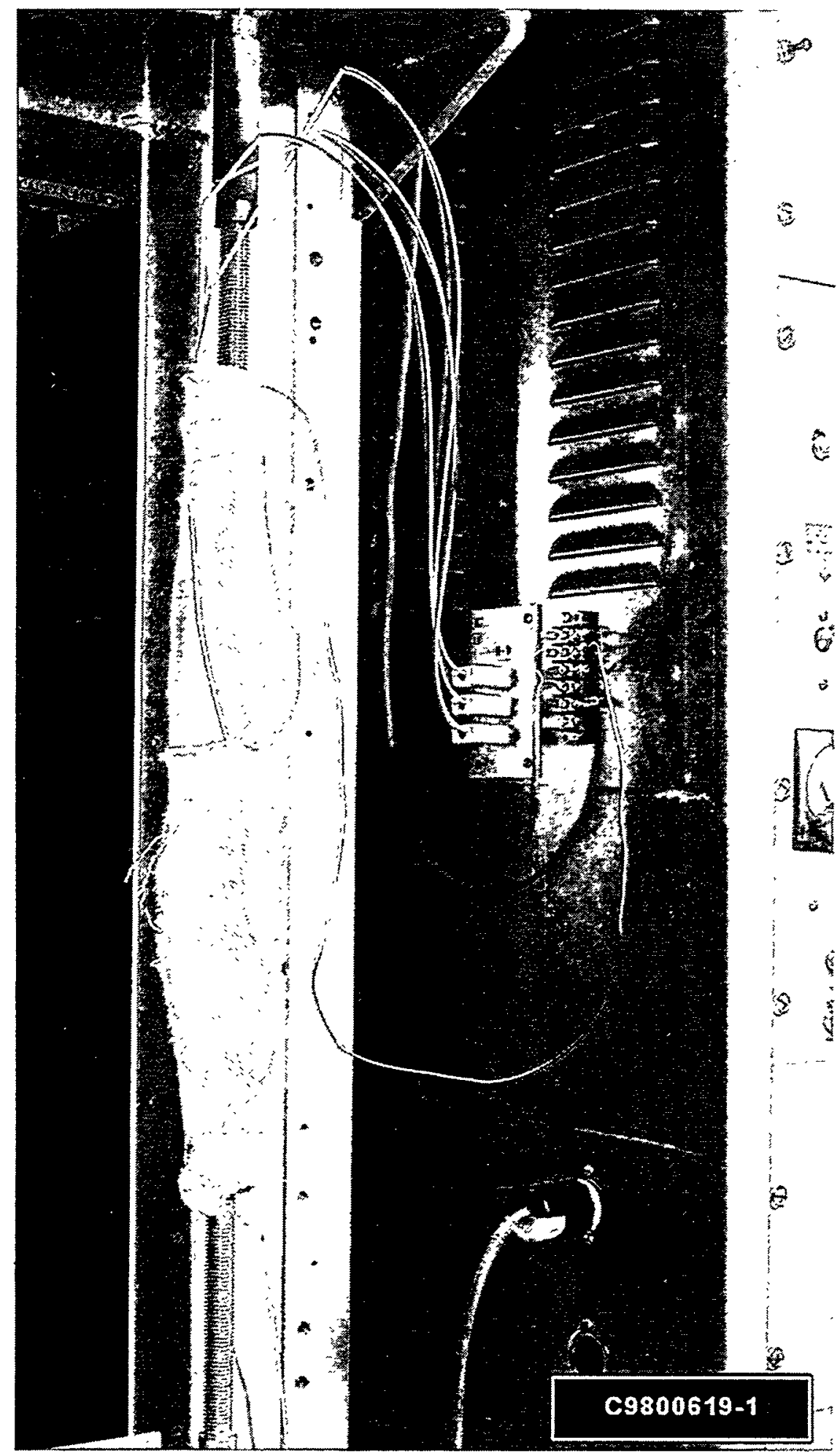

Fig. 6.3. In-air creep test at elevated temperature. Specimen is heated by heat tape and wrapped in an insulating cloth. 


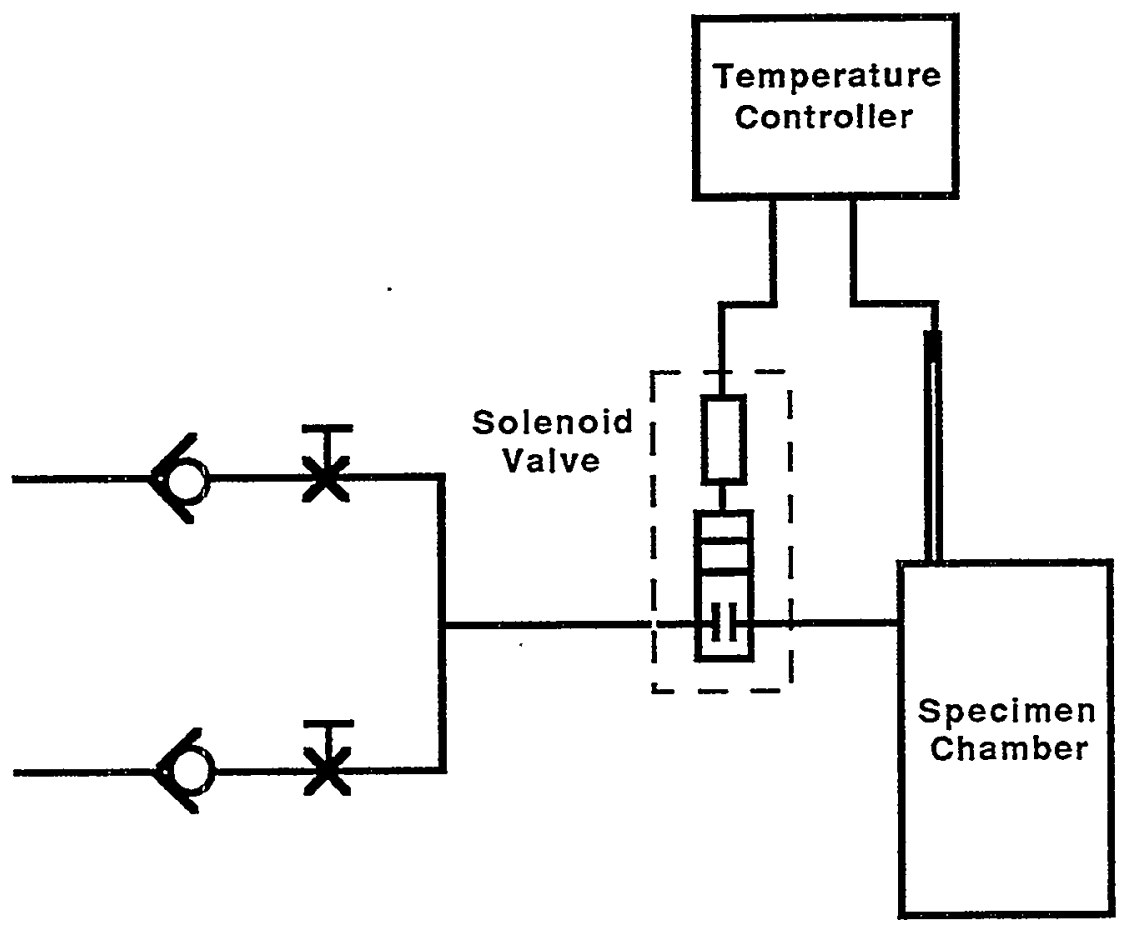

Fig. 6.4. Schematic of control system for creep testing at $-40^{\circ} \mathrm{F}$ in air. 


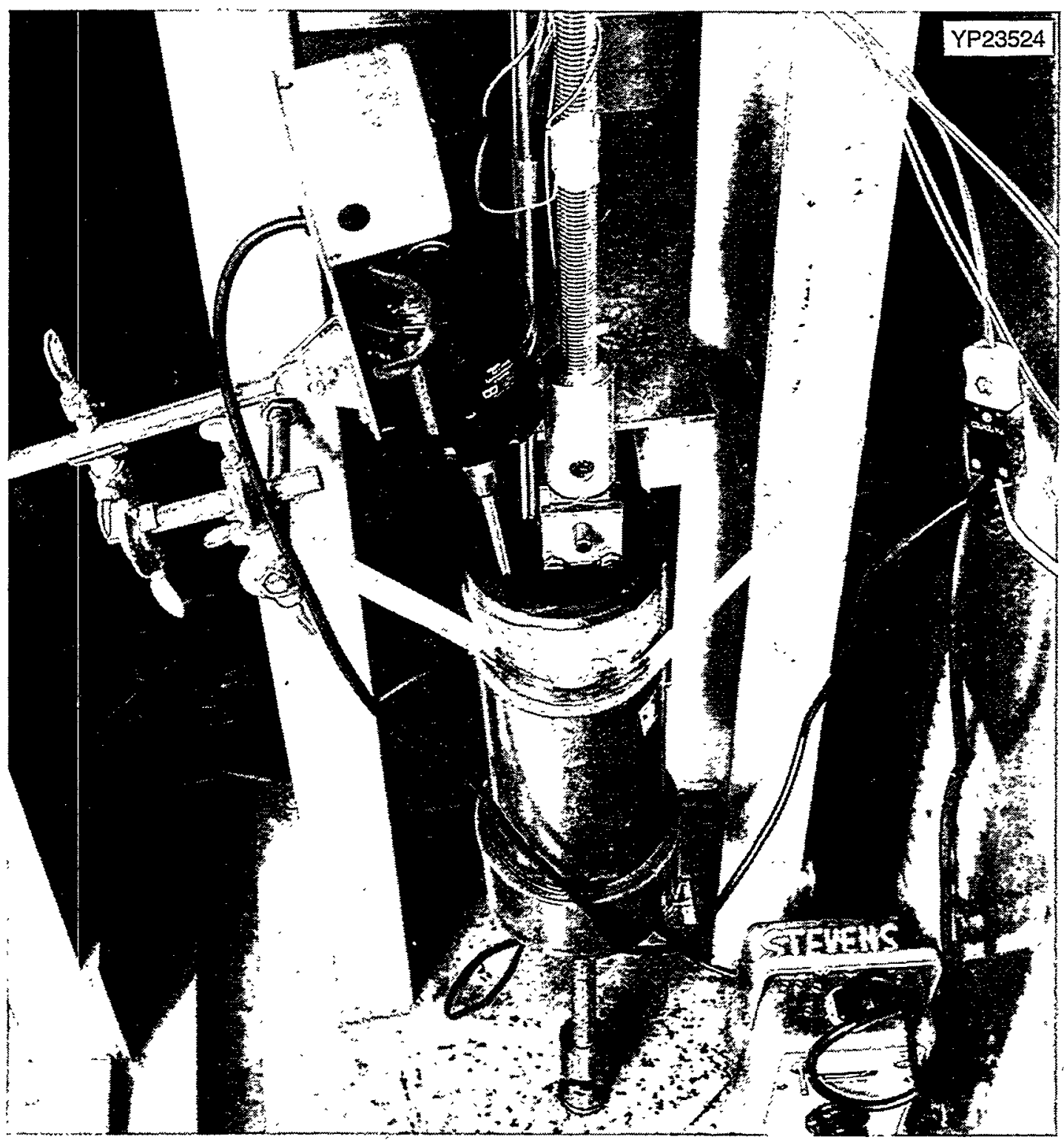

Fig. 6.5. Photograph of fluid chamber and electric stirrer, with tensile creep test in progress. 


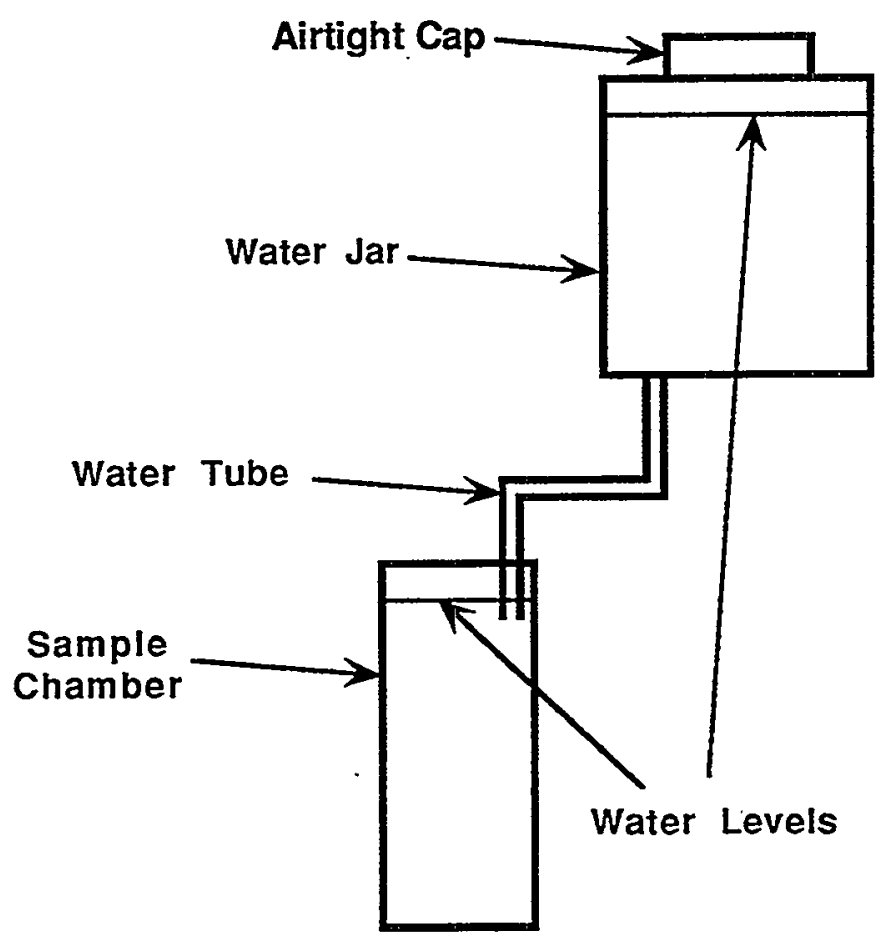

Fig. 6.6. Schematic of water-compensation system. 


\subsubsection{Sulfuric Acid (35 wt \%) Splatter at Room Temperature}

About 0.2 in. ${ }^{3}$ of sulfuric acid solution was placed on the surface of the specimen. The specimen was then heated for $24 \mathrm{~h}$ at $150^{\circ} \mathrm{F}$ so that wetting and absorption occurred. It is very important that in preparing the solution, $35 \mathrm{wt} \%$ of full-strength sulfuric acid be SLOWLY added to $65 \mathrm{wt} \%$ of distilled water. The reversed order, adding water to sulfuric acid, can cause an explosive reaction, resulting in significant injury.

\subsubsection{Low-Frequency Load Cycling in 50\% RH Air at Room Temperature}

The low-frequency load cycling was produced by an air-driven piston that added a pulsing load to the fixed load on the weight pan of a lever-arm creep frame. A frequency of 30 cycles per minute was used. Two kinds of dynamic-static load combinations can be employed: (1) a fixed dynamic-to-static load ratio for various loads and (2) a fixed static load plus various dynamic loads. A schematic of the airdriven piston setup for a lever-arm creep machine is shown in Fig. 6.7.

The strain gage signal was recorded using a thermal type strip chart recorder so that no ink runout problem occurred. However, because of the fatigue effect of the load, the strain gage usually debonded and stopped functioning after a period of testing time. A dial gage was employed as a backup by measuring the displacement of the lever arm. The dial gage was calibrated with the strain gage signals obtained before the strain gage ceased to function.

\subsubsection{Motor Vibration in 50\% RH Air at Room Temperature}

The motor vibration tests were conducted using a motor with a eccentric load to supply the vibratory stress component superimposed on the fixed stress. The motor was mounted on the weight pan of a creep machine as a part of the weight. An eccentric weight was fixed on the axis of the motor to generate vibration. The vibratory component had a frequency of about 2000 cycles per minute (to simulate vibrations from an automobile engine) and induced a cyclic stress range of about 300 psi. Figure 6.8 is a photograph of the motor and weight mounted on the dead weights of a lever-arm creep machine.

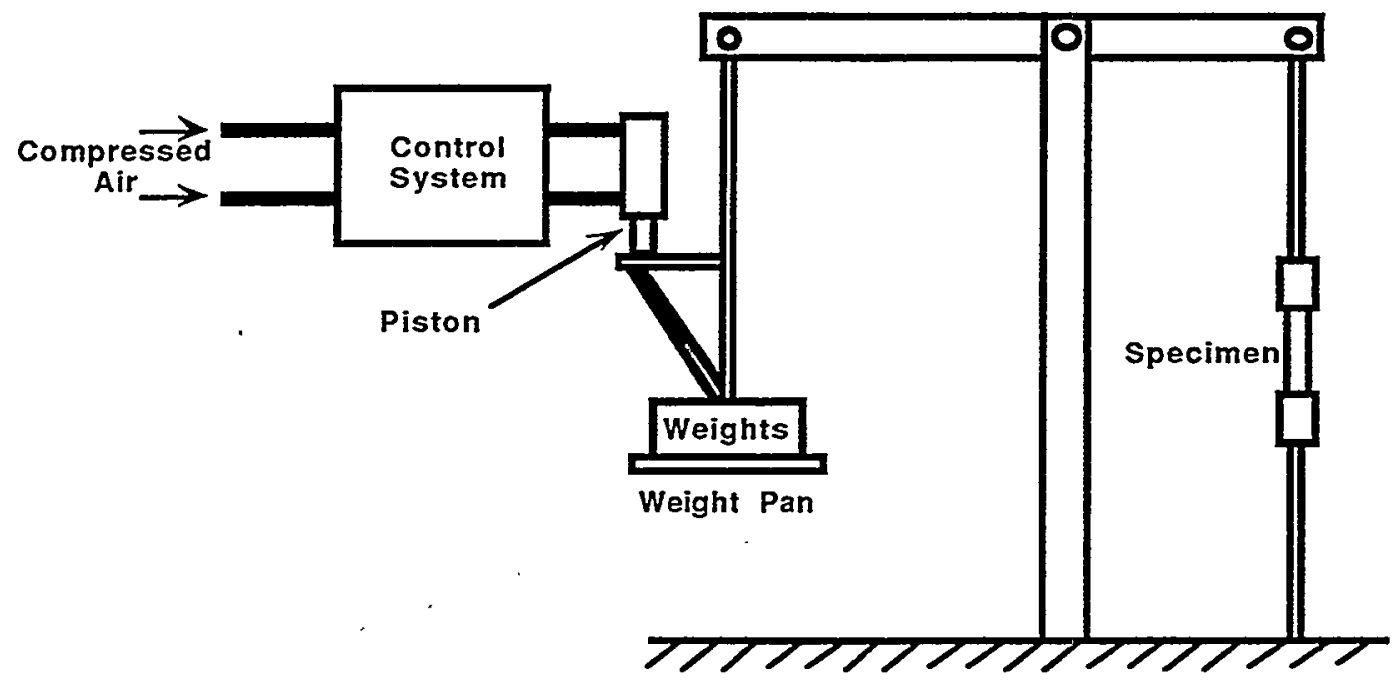

Fig. 6.7. Schematic of air-driven piston setup on a lever-arm creep machine. 


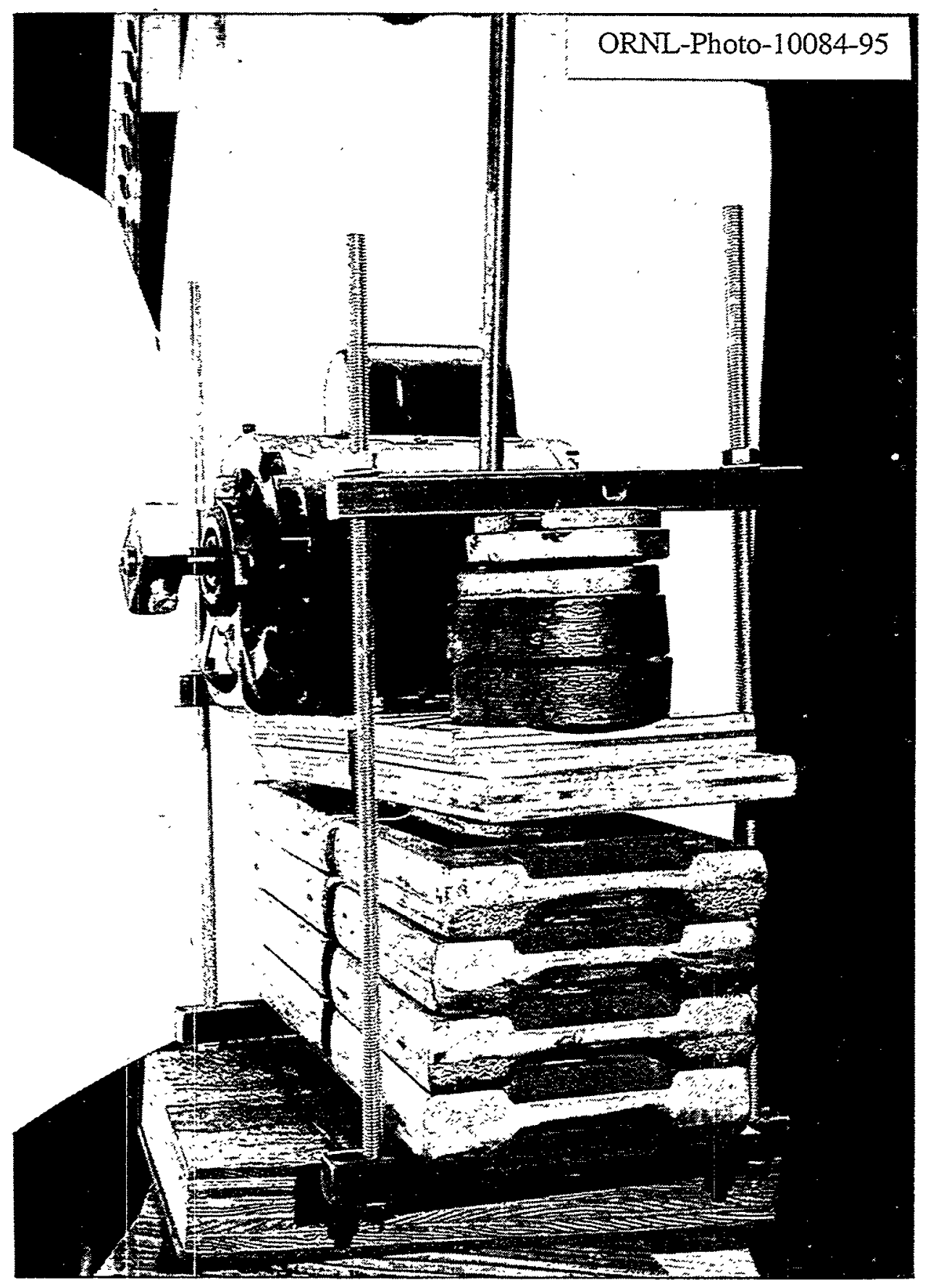

Fig. 6.8. Vibrating motor attached to dead weights of lever-arm creep machine. 


\subsection{COMPRESSIVE CREEP}

Compression creep tests were performed in the same lever-arm creep machines as used for the tensile creep tests. The compressive loading fixture is shown in Fig. 6.9. Each end of the 1.25-in.-long specimen was inserted into a 0.175 -in.-deep slot in a $1 \times 1 \times 0.4$ in. stainless steel block that fits the sample snugly. The two stainless steel pieces fit against upper and lower blocks that are pulled downward and upward, respectively, by the linkages shown in Fig. 6.9.

Compressive creep tests in fluids utilized the same chamber setup as described above for tensile tests. However, heating was different, because the shortened specimen length made it difficult to employ heating tape. A resistance furnace, which surrounded the loading fixture, was employed.

Strain measurements for the compressive tests utilized the same strain gage systems as used for tensile testing.

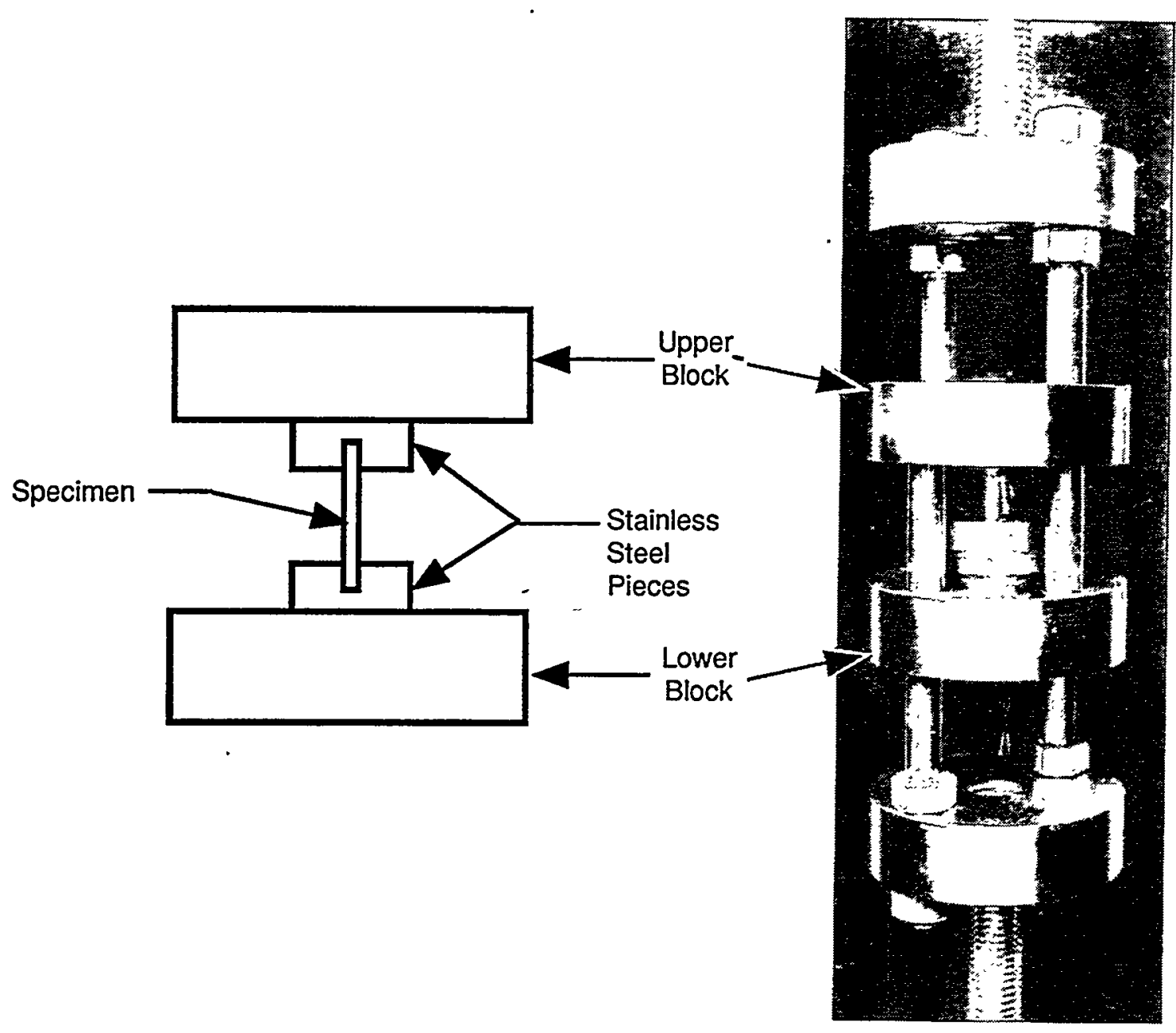

Fig. 6.9. Compression creep test fixture mounted in pull rods of a lever-arm creep machine. 


\section{LOW-ENERGY IMPACT TESTS FOR DAMAGE TOLERANCE CHARACTERIZATION}

\subsection{INTRODUCTION}

Among the durability issues of concern in the use of composites in automobile structures are the damaging effects that low-energy impacts (e.g., tool drops and roadway kickups) might have on strength and stiffness. These two examples represent two extreme cases-heavy objects impacting at low velocities and small, light objects impacting at higher velocities. To bound this range, two impact facilities were designed and built-a pendulum device and an air gun. The test specimen is the same in both facilities-a $9 \times 9 \times 1 / 8$-in.-thick plate clamped on an 8-in.-thick outer circle, as was shown in Fig. 3.6. The specimens are impacted at the center, normally with hardened steel 0.5-in.-diam hemispherical impactors. The goal is to develop a correlation between impactor mass and velocity and the resulting impact damage area. Mechanical property degradation can then be related to the damage area and ultimately back to mass and velocity.

\subsection{SPECIMEN SUPPORT STRUCTURE}

The 8-in.-diam test dimension was chosen to be large enough to be representative of a plate impacted away from the vicinity of a support or stiffener, but not so large that a disproportional amount of the impact energy would go into flexure of the plate. An impacted plate specimen with its steel support structure is shown in the pendulum facility in Fig. 7.1. The details of the support structure are shown in Fig. 7.2. The plates clamping the specimen are 1-in. thick. The backside of the support structure is visible in Fig. 7.3.

Figure 7.2 depicts how the 9- by 9-in.-square specimen fits in a square recess, which is slightly more shallow than the plate thickness. The front support plate is then bolted on with eight bolts, lightly tightened, to provide the clamped edge condition.

The lid, which is not present in Fig. 7.1 but is shown in Figs. 7.2 and 7.3, serves a dual purpose. First, for the air gun, it serves as a safety closure in case the projectile should completely penetrate through the specimen. Second, it allows for cooling or heating the specimen for tests at other than room temperature. In that case, the resulting back enclosure is insulated, as shown in Fig. 7.2. For tests to $-40^{\circ} \mathrm{F}$, vapor from a liquid nitrogen tank is piped into the enclosure and vented through an outlet hole. A thermocouple attached to the specimen is used with a temperature controller to open an on/off cryogenic solenoid valve as needed to maintain the set temperature. A circle of insulation is used over the front face of the specimen while the desired temperature is being achieved. That insulation is removed immediately before the specimen is impacted.

\subsection{IMPACT FACILITIES}

Figures 7.3 and 7.4 are different views of the pendulum and air-gun facilities. A pendulum impact test of a specimen at $-40^{\circ} \mathrm{F}$ is being performed in Fig. 7.3 (nitrogen vapor can be seen venting from the specimen support enclosure). The pendulum bob or weight, which is suspended by cables from the ceiling, is a 25.4-lb bar. The baseline hemispherical impactor point seen on the front of the weight is $0.5 \mathrm{in}$. in diameter and is made of a hardened tool steel. A miniature dynamic load cell behind the impactor point measures contact force during the impact event. Drop heights of less than 10 in. are generally adequate. 


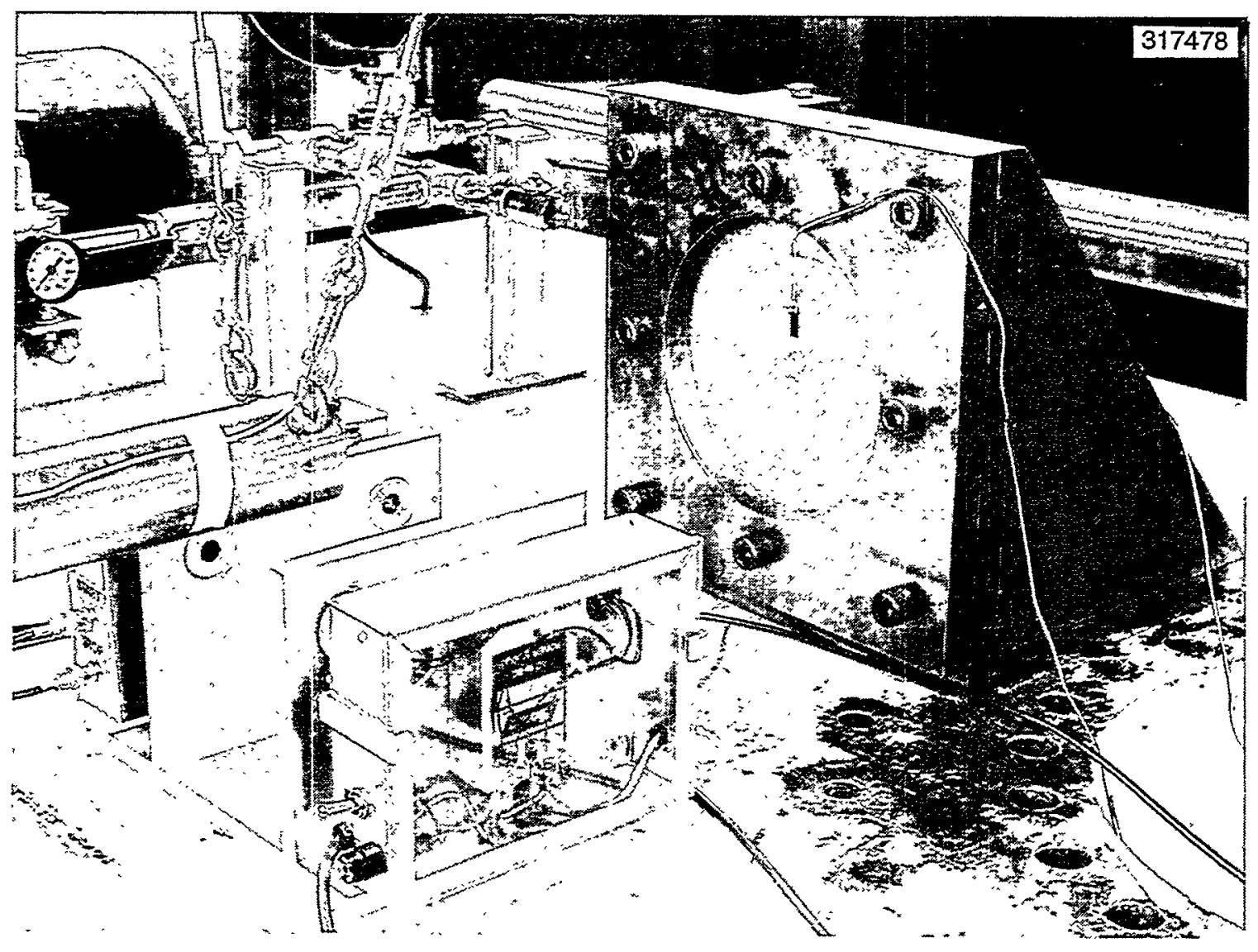

Fig. 7.1. Impacted specimen and support structure in pendulum facility. 


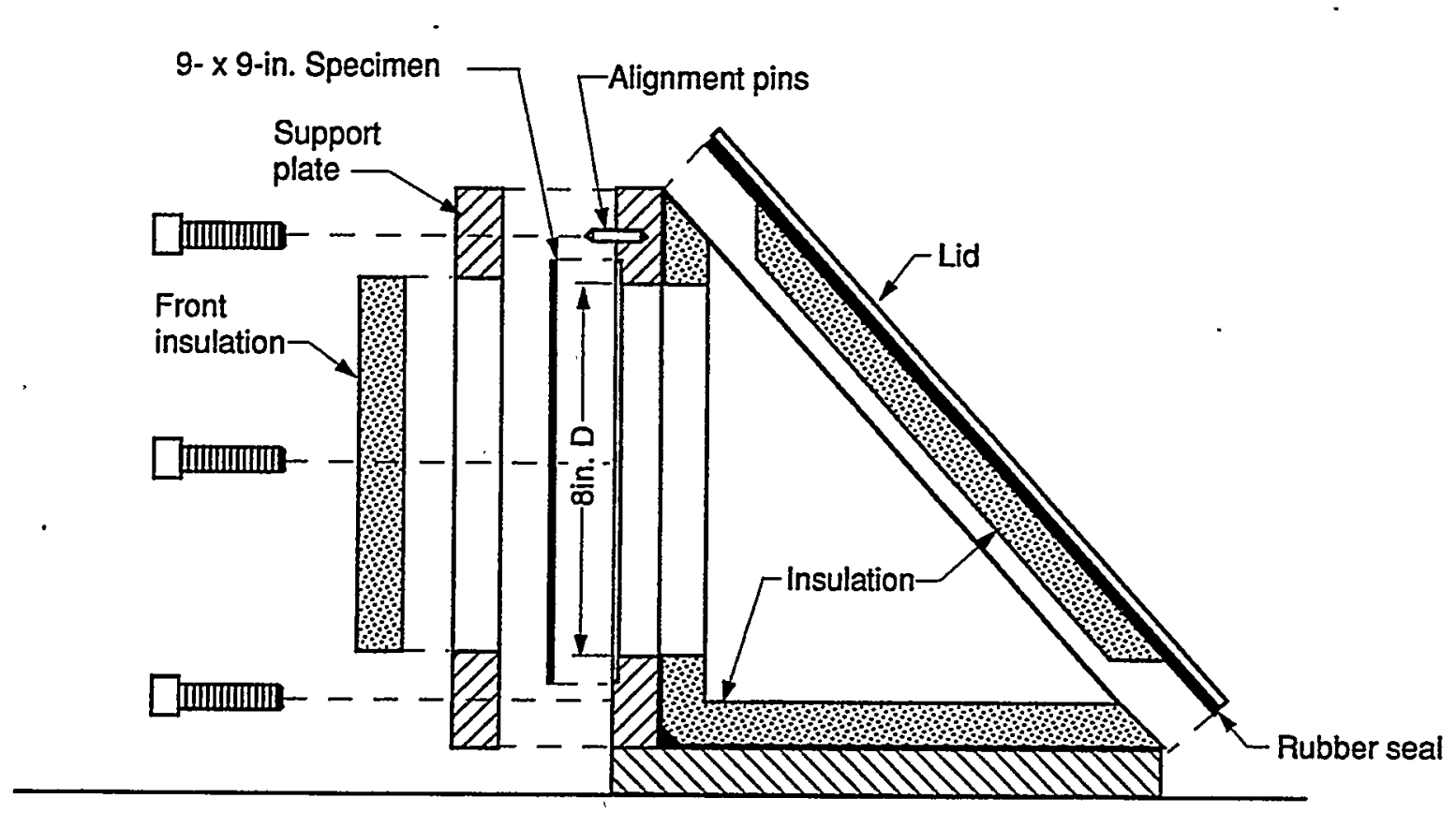

Fig. 7.2. Exploded view of impact specimen support structure. 


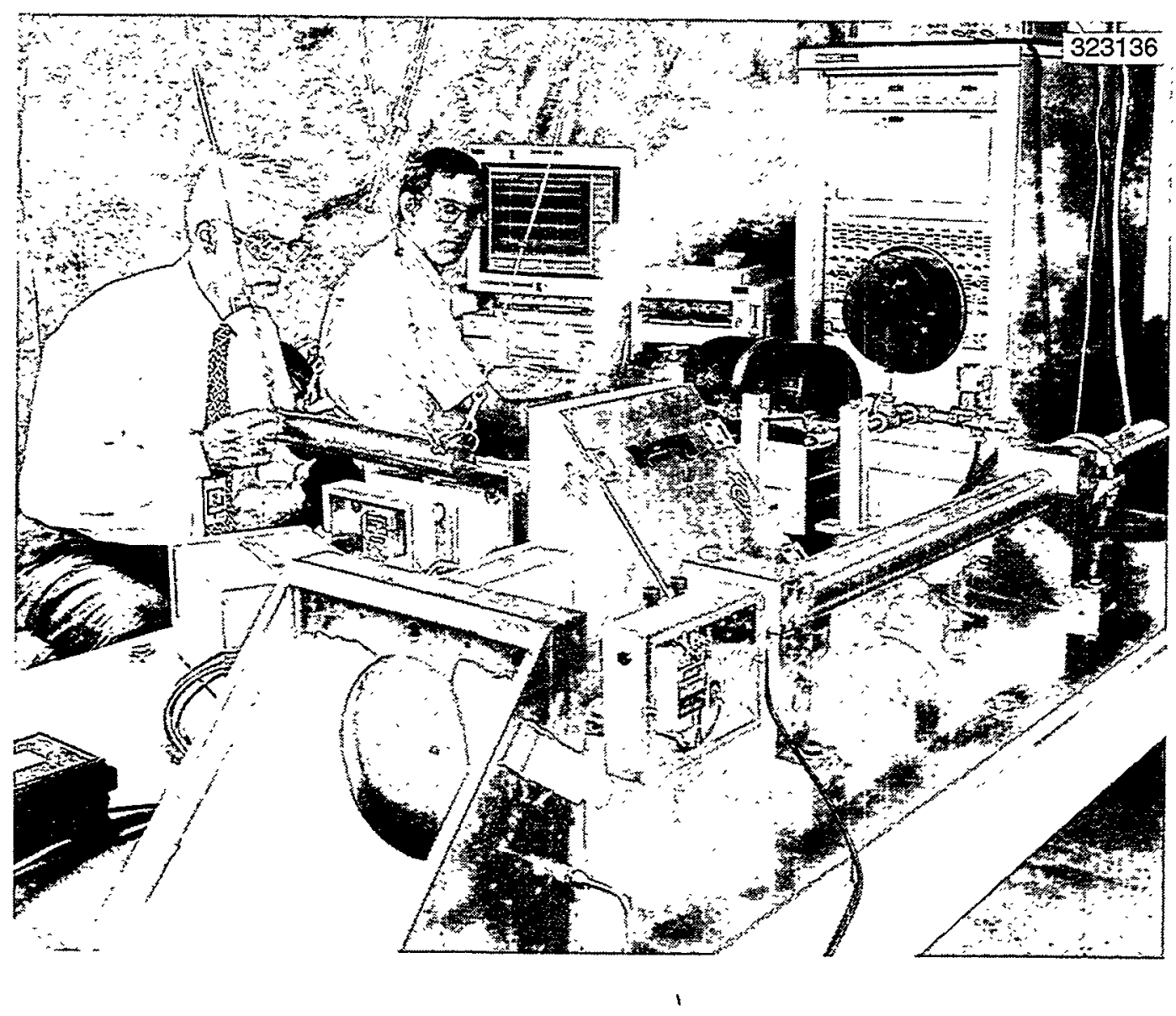

Fig. 7.3. Overall view of pendulum and air-gun impact test facilities. The air gun is in the foreground, and the pendulum is in back on the left. 


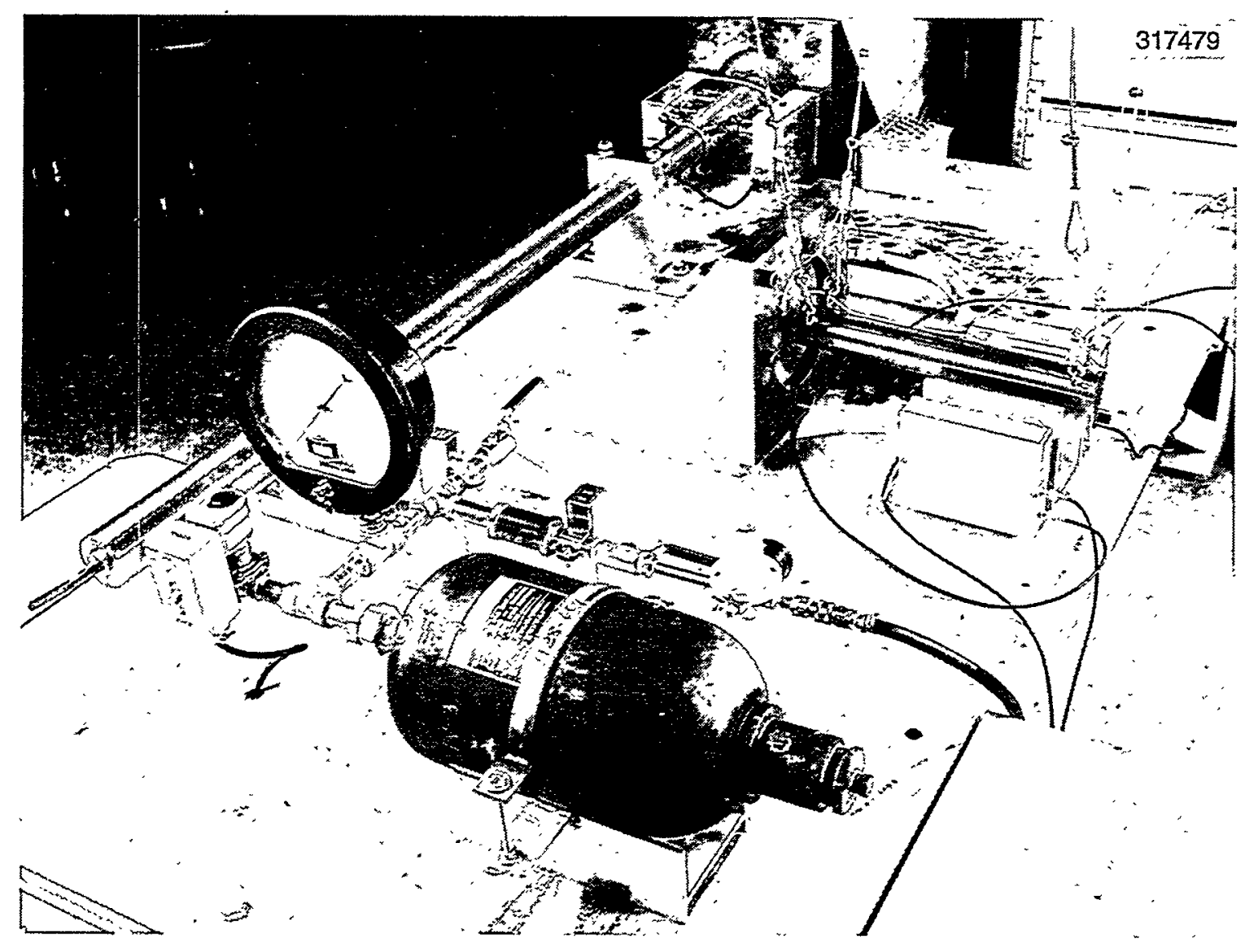

Fig. 7.4. Backview of impact test facilities. The pendulum is on the right, and the air gun is on the left and in the foreground. 
In the case of the air gun, the baseline impactor or projectile is a 0.5 -in.-diam cylinder with a hemispherical point (overall length of $1 \mathrm{in}$.) and weighing $0.05 \mathrm{lb}$. The material is hardened tool steel. The gun barrel is $215 / 16$ in. O.D. $\times 0.5$ in. I.D. $\times 65$ in. long and is made of Type 304 stainless steel. Ordinary plant compressed air, having a maximum pressure of $100 \mathrm{psi}$, is used to charge the accumulator tank, shown in the foreground of Fig. 7.4. A series of test shots established the relation between pressure and velocity that is shown in Fig. 7.5. Once the tank is properly pressurized, a quick-acting solenoid valve is used to release the compressed air into the breech of the barrel. The projectile is pushed into the barrel through the breech to a position ahead of the compressed air inlet. A screw-in breech plug is then inserted.

In addition to the load cell at the front of the pendulum weight, both facilities are fitted with laserbased devices for measuring velocity just prior to impact. The devices, which were designed and built inhouse at ORNL, can be seen in each of the previous photographs. Two beams of light, separated by a known distance ( 5 in.), are used in each case, and the time is measured from when the first beam is interrupted until the second beam is interrupted. The projectile, in the case of the air gun, breaks the two beams, while a flag suspended below the pendulum weight is used in the case of the pendulum. Lowpower visible lasers are used for the light sources, and infrared sensitive photo-transistors are used to sense the laser beams. The transistors are normally in a conducting state when the light beams are impinging on them. When the first light beam is interrupted by the projectile or pendulum, the transistor for that beam is turned off and creates a positive rising voltage that is connected to the start trigger of a time interval counter. When the second light beam is interrupted, the transistor of that beam is turned off and activates the stop trigger of the time interval counter.

The enlarged cylinder that can be seen clamped to the muzzle of the air-gun barrel in Fig. 7.4 is simply a shell used to catch and contain the rebounding projectiles. The air-gun barrel is positioned so that there is about a 1/8-in. gap between the shell and specimen when the gun is fired. The laser devices are attached to the shell, and the beams pass through holes in the shell.

A dynamic data acquisition system is shown in the background of Fig. 7.3. Several specimens were instrumented with strain gages, and the output of these gages as well as the load cell output from the pendulum tests were recorded with time and analyzed. For basic tests, however, only the impact velocity is required.

Ultrasonic C-scans have proven to be good tools for detecting local damage due to impacts. Figure 7.6 shows a specimen being scanned. Each tested impact specimen was scanned, and a hard copy of the scanned image was obtained for measuring the impact damage area. A mechanical planimeter was adequate for measuring the area. Specimen-to-specimen consistency in performing the C-scans and measuring the areas is essential.

\subsection{MECHANICAL PROPERTY TESTS}

The ultimate goal in evaluating the damage tolerance of a composite is to relate damage area to mechanical property degradation (tension, compression, and fatigue). One reason for using square impact specimens is so that mechanical property specimens can be conveniently cut from the impacted specimens. The recommended cutting layout for specimens was shown in Fig. 3.6. The center specimen is centered at the impact damage area. Experience has shown that the outer specimen on each side is unaffected by the damage. Hence, the average of a given property (e.g., tensile strength) from tests of those two specimens can be used as the reference for quantifying the degradation exhibited by the center specimen. The design of the mechanical property specimens was covered in Sect. 3.9. 


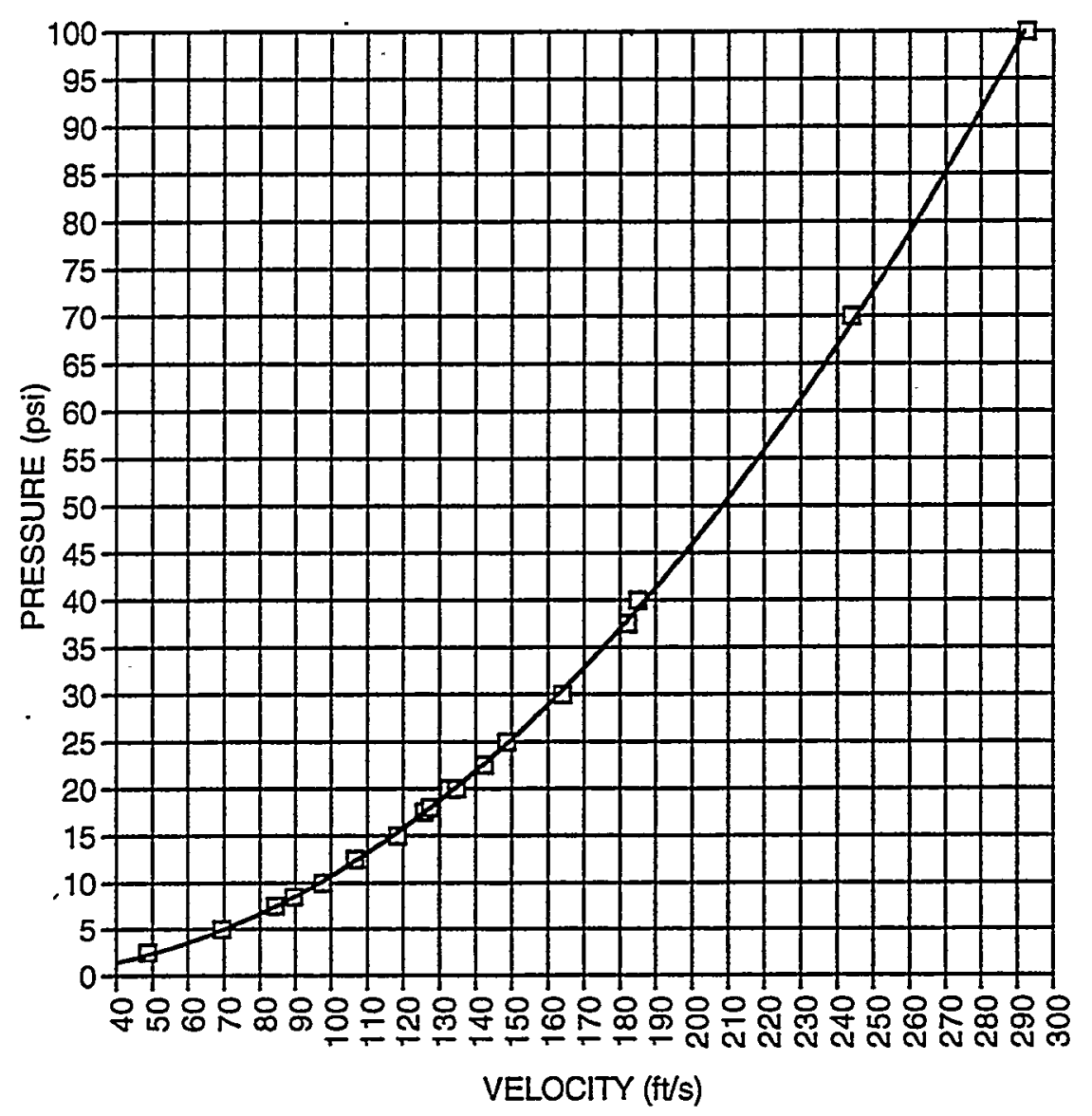

Fig. 7.5. Experimentally determined pressure vs projectile velocity correlation for air gun. 


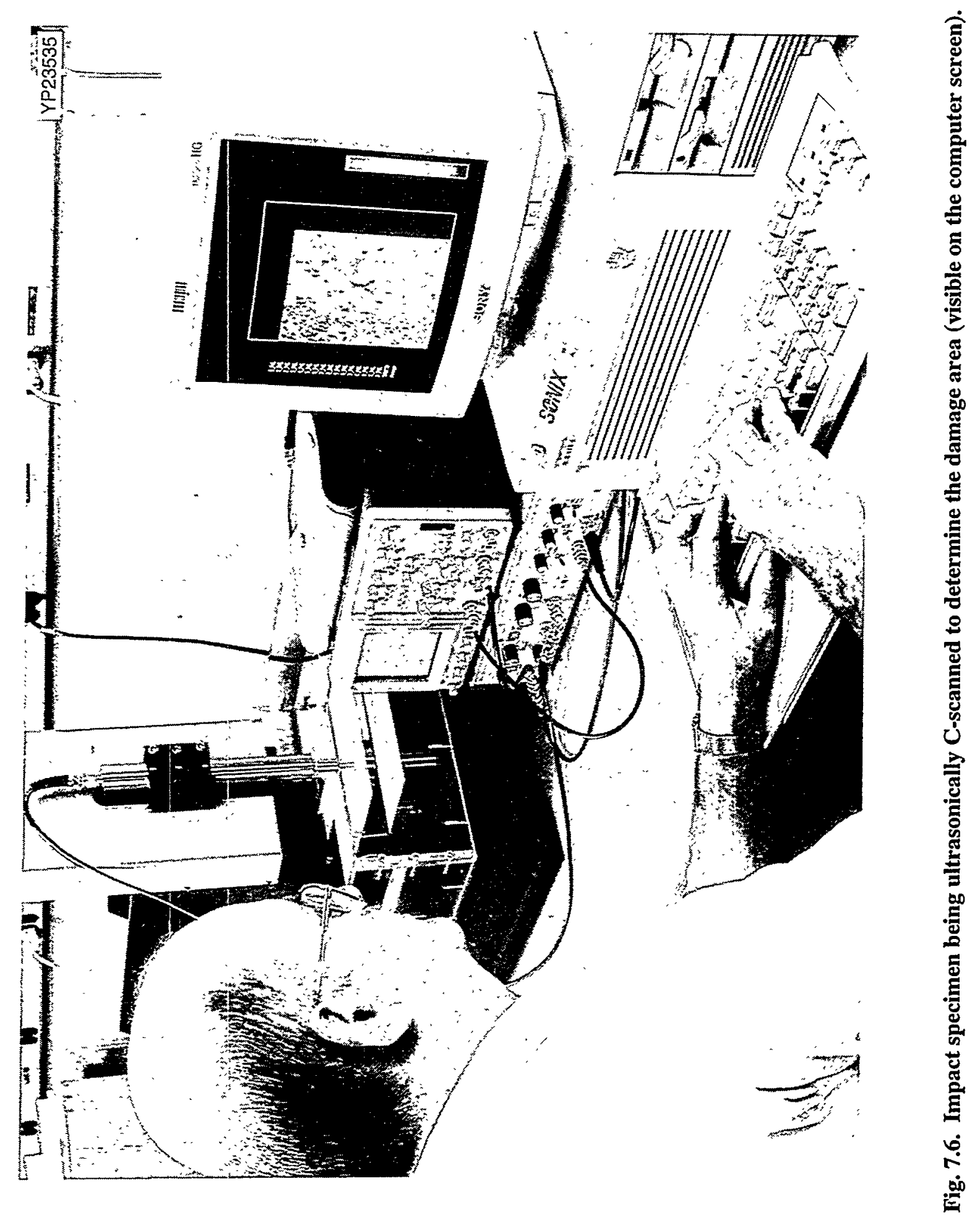




\section{TESTS OF SPECIMENS FROM HAT SECTIONS}

\subsection{INTRODUCTION}

All of the tests described in the previous four chapters utilize specimens cut from plaques, which were specifically molded for evaluation of material properties. In developing durability-based design criteria, ${ }^{1}$ there was a need to assess how well the potential criteria would apply to more realistic parts, or components, having geometric discontinuities (bends). Hat sections, often used for structural stiffeners, were available from ACC. Therefore, special specimens, which were described in Sect. 3.10 and which contained bends, were cut from hat sections and tested. One test, described in Sect. 8.2, involved flexure of the bends. The results dictated that allowable bending stresses at geometric bends be lower than those in flat components. The second test, described in Sect. 8.3, involved torsional loading of bends. These tests and the results obtained from them are described in Chap. 15 of Ref. 2.

All of the hat-section tests at ORNL were performed in room-temperature ambient air.

\subsection{BENDING TESTS}

As was depicted in Fig. 3.7, the bend specimen was a 1-in.-wide transverse slice of the basic hat section. The specimens were clamped in the grips of a standard uniaxial test machine and subjected to either tension or compression loading, as depicted in Fig. 8.1. The tension loading put the inside, reentrant, surface of the outer corners in tension, while the compression loading put the outside surface of the outer corners in tension. The failure modes and failure stresses were very different in these two cases. Note that finite-element analyses were required to predict the bending stresses accurately.

ORNL 98-1297 EFG

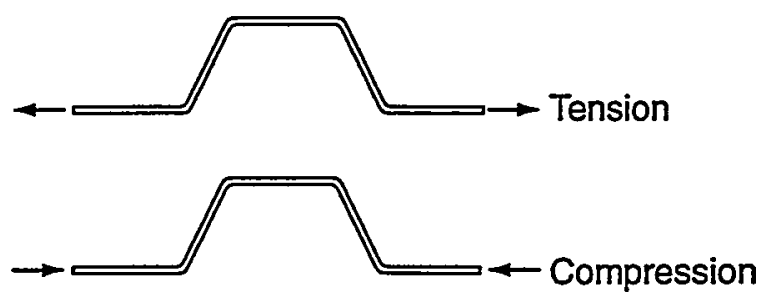

Fig. 8.1. Application of tension and compression loadings to hat-section bend specimens.

Figure 8.2 depicts a bend specimen mounted in the grips of a test machine. No strain measurements were made, but stroke, which was relatively large ( $2 \mathrm{in}$.$) , was measured and correlated$ with analysis predictions.

\subsection{TORSION TESTS}

The hat-section torsion specimen, which was shown in Fig. 3.8, is cut axially along a bend of the hat section. The specimen is dogboned so that failure occurs in the reduced section. The specimen is mounted in special grips in an axial-torsion test machine so that the shear center of the cross section (the intersection of the two flanges) is at the vertical axis of the test machine load train. 


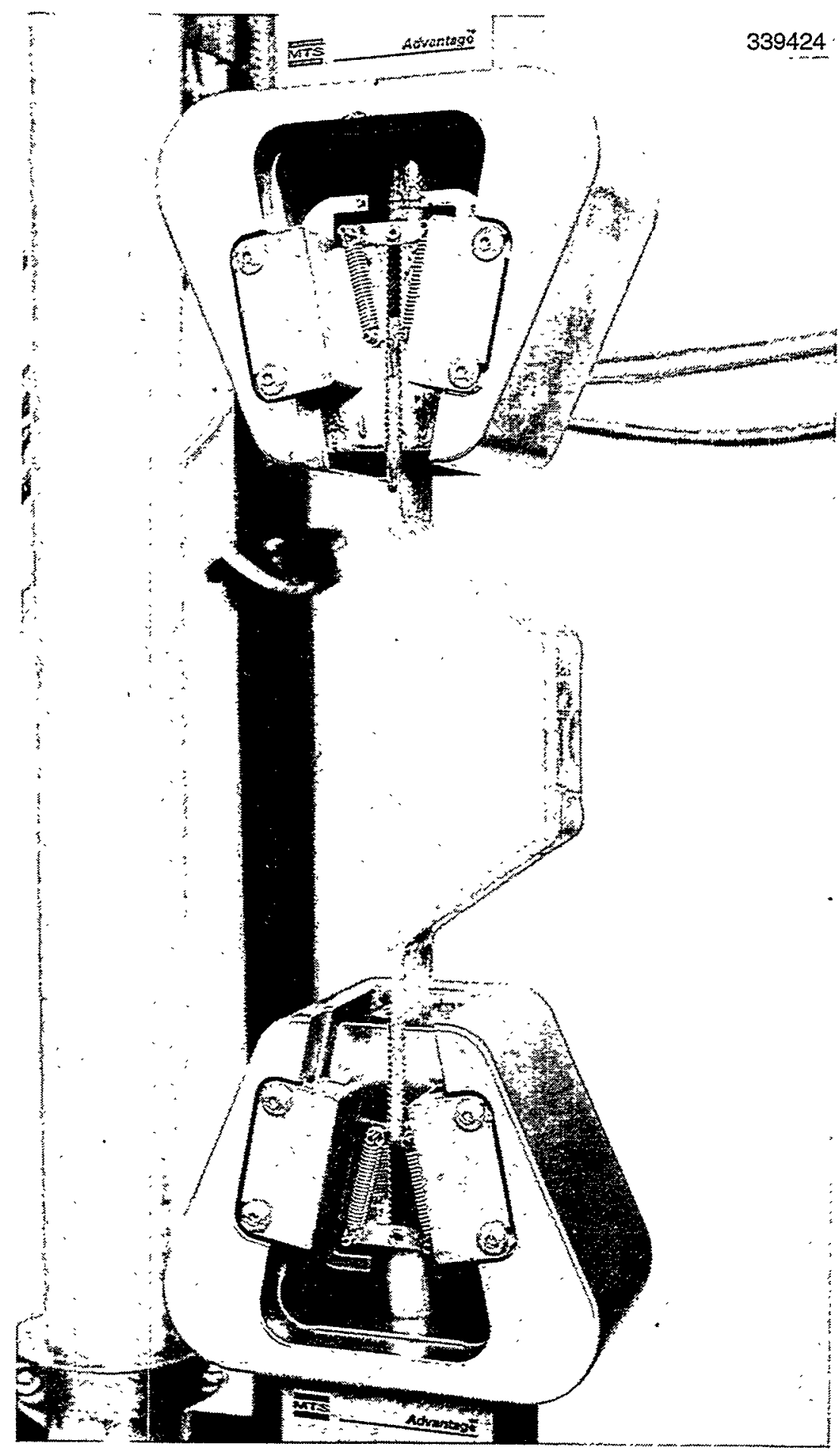

Fig. 8.2. Hat-section bend specimen in test machine. 
A torsion specimen is shown in Fig. 8.3 mounted in its special grips, which are, in turn, mounted in the hydraulic collet grips of an MTS axial-torsion test machine. Rubber pads, 1/8 in. thick, were used to cushion the metal grips, thereby preventing premature failure of the specimens at the edges of the grips. Not shown at the top is a miniature torque transducer (Sensotec Model QSFK-9/3469-05-02) having a capacity of $600 \mathrm{in.-1b}$. This transducer was required because the torsional load transducer on the test machine was much too large to accurately measure the load to failure of the composite specimens.

The sketches used to fabricate the special grips shown in Fig. 8.3 are included in an appendix to this report. These details are provided because they are needed to match the end design of the specimen, as shown in Fig. 3.8.

Strains were not measured in the torsion tests; rather rotation was measured and correlated with analysis predictions. Specifying accurate boundary conditions for the analysis was made difficult in this case by the use of rubber pads to cushion the grips. The rubber cushions contributed significantly to the more than $90^{\circ}$ of total angular rotation that occurred in these tests prior to failure. 


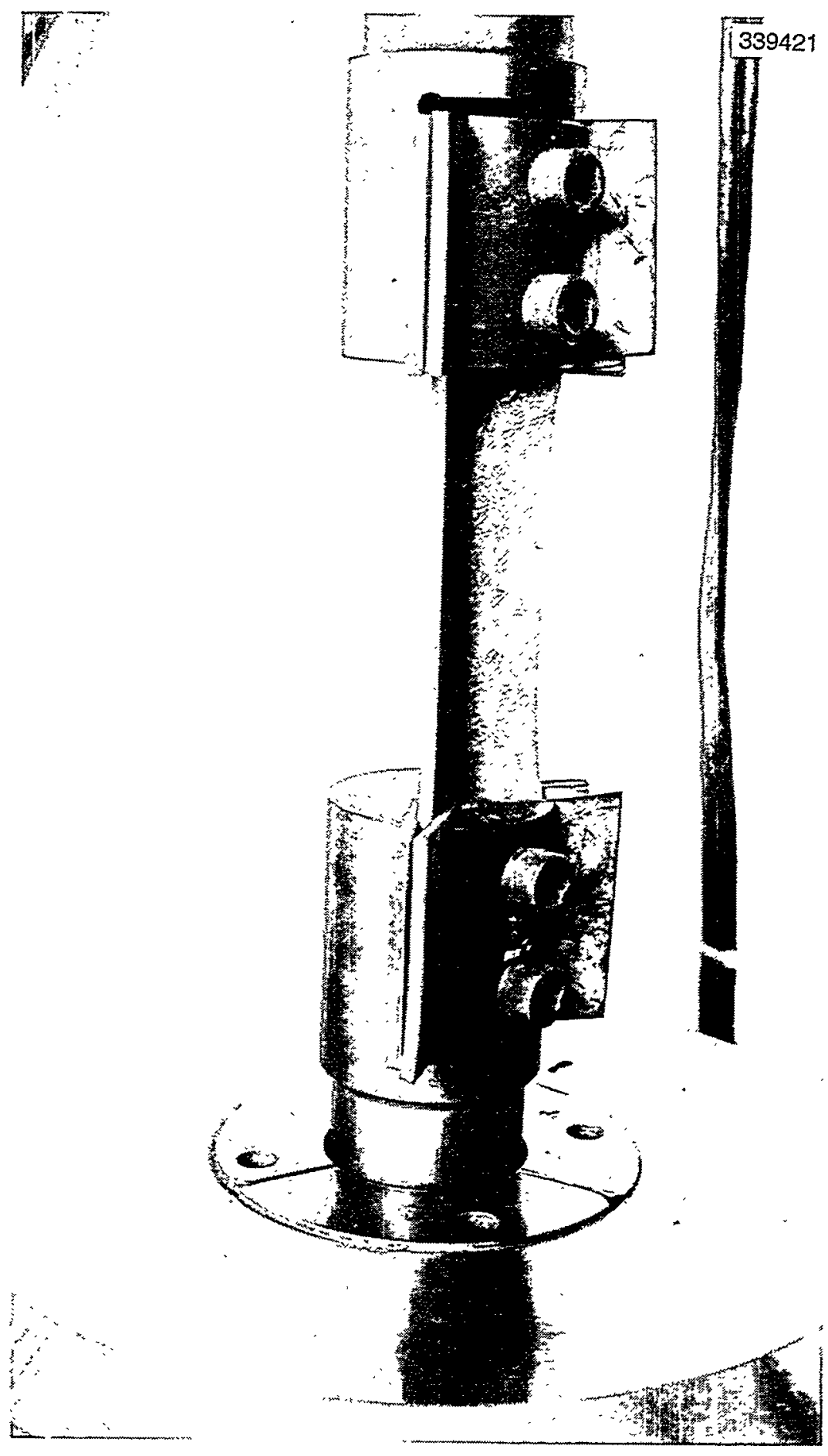

Fig. 8.3. Hat-section torsion specimen in special gripping fixture mounted in hydraulic collet grips. 


\section{REFERENCES}

1. J. M. Corum et al., Durability-Based Design Criteria for an Automotive Structural Composite:

Part 1. Design Rules, ORNL-6930, Lockheed Martin Energy Research Corp., Oak Ridge National Laboratory, February 1998.

2. J. M. Corum et al., Durability-Based Design Criteria for an Automotive Structural Composite: Part 2. Background Data and Models, ORNL-6931, Lockheed Martin Energy Research Corp., Oak Ridge National Laboratory, February 1998.

3. SAE Standard J2253, Test Procedures for Automotive Structural Composite Materials, Society of Automotive Engineers, December 1995.

4. ASTM Standard D 4762-88, Standard Guide for Testing Automotive/Industrial Composite Materials, American Society for Testing and Materials.

5. Test Procedures for Automotive Structural Composite Materials, 2nd Edition, ACCM-T-02, Automotive Composites Consortium, Troy, Michigan, September 1994.

6. Proposed Fatigue Test Specification for Random Fiber Composite Materials, Automotive Composites Consortium, Troy, Michigan, January 1996.

7. ASTM Standard D 3410-87, Standard Test Method for Compressive Properties of Unidirectional or Crossply Fiber-Resin Composites, American Society for Testing and Materials.

8. ASTM Standard D 5379/D 5379M-93, Standard Test Method for Shear Properties of Composite Materials by the V-Notched Beam Method, American Society for Testing and Materials.

9. M. J. Owen and T. R. Smith, "Some fatigue properties of chopped-strand-mat/polyester-resin laminates," Plastics and Polymers, 33-44 (February 1869).

10. T. J. Dearlove et al., "Development of Standardized Tests for an Automotive Structural Composite Database," pp. 555-566 in Proceedings of the 10th Annual ASM/ESD Advanced Composites Conference, Detroit, Michigan, November 1994. 


\section{APPENDIX.}

\section{TEST FIXTURE FOR HAT-SECTION TORSION SPECIMENS}

The test specimen for the hat-section torsion tests that were described in Sect. 8.3 was shown in Fig. 3.8. Figure 8.3 showed the specimen mounted in special grips that fit into the collet grips of an axialtorsion test machine.

The sketches used to fabricate the special torsion test grips are shown in Figs. A.1 and A.2. The grips themselves (two required) are shown in Fig. A.1. One grip (part 1) does not have the hole and keyway. It fits directly into a collet grip, as shown in Fig. 8.3. The other grip has a hole and keyway to accommodate the miniature torque transducer. The transducer has a 1-in. diam shaft and keyway at both ends. One end fits into the hole in the grip; the other end fits into the split collar of Fig. A.2, that in turn, fits into the other collet grip.

As stated in Sect. 8.3, it was necessary to use 1/8-in.-thick rubber pads between the specimen and parts 1 and 2 to avoid failure-causing stress concentrations in the specimens at the edge of the grips. This shifted the shear center slightly away from the axis of the fixture, thus introducing some bending into the loading. This was not thought to have any significant influence on the results. 


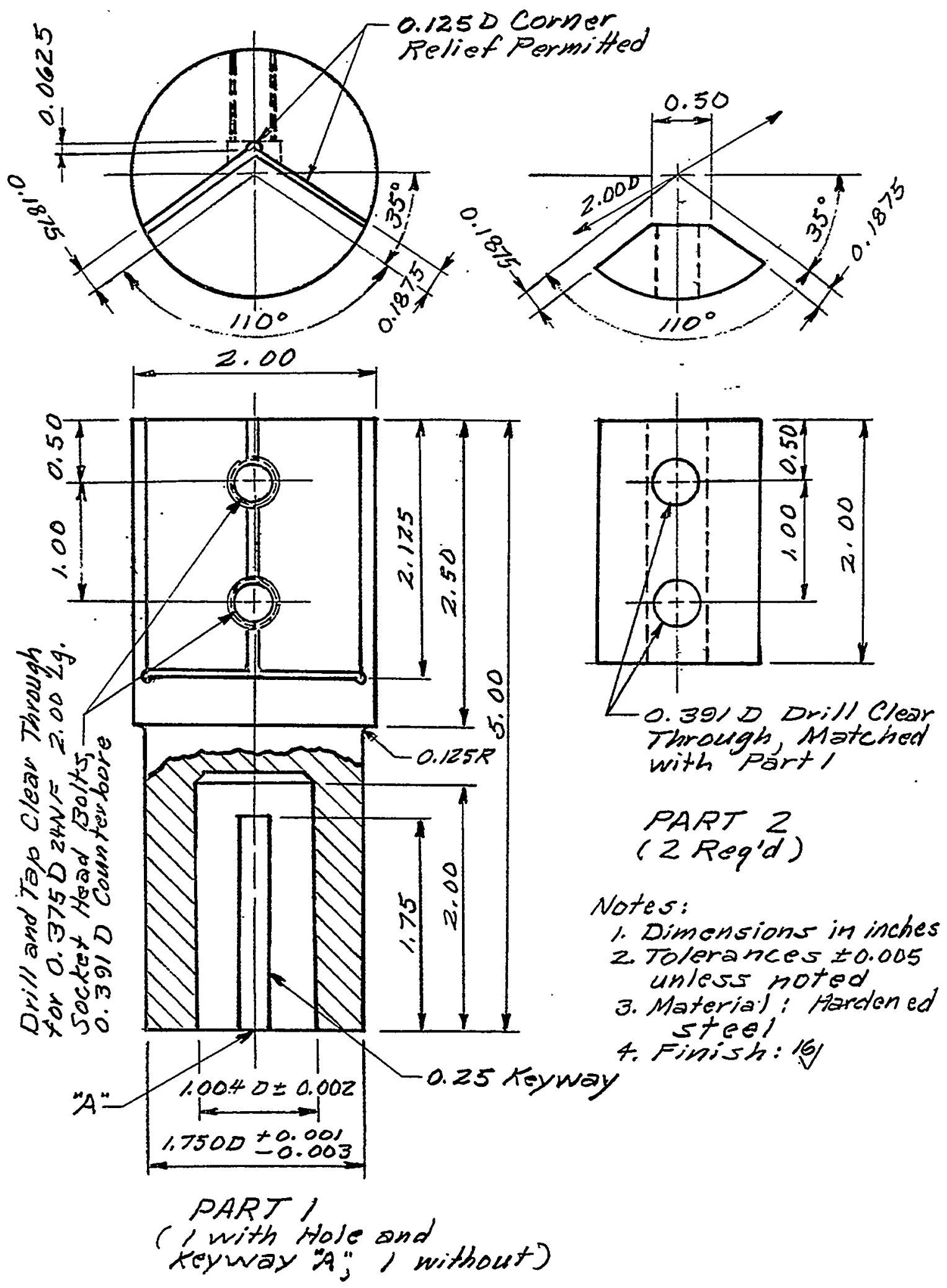

Fig. A.1. Sketch of special grips used to test hat section torsion specimen. Refer to Fig. 8.3 for assembly. 

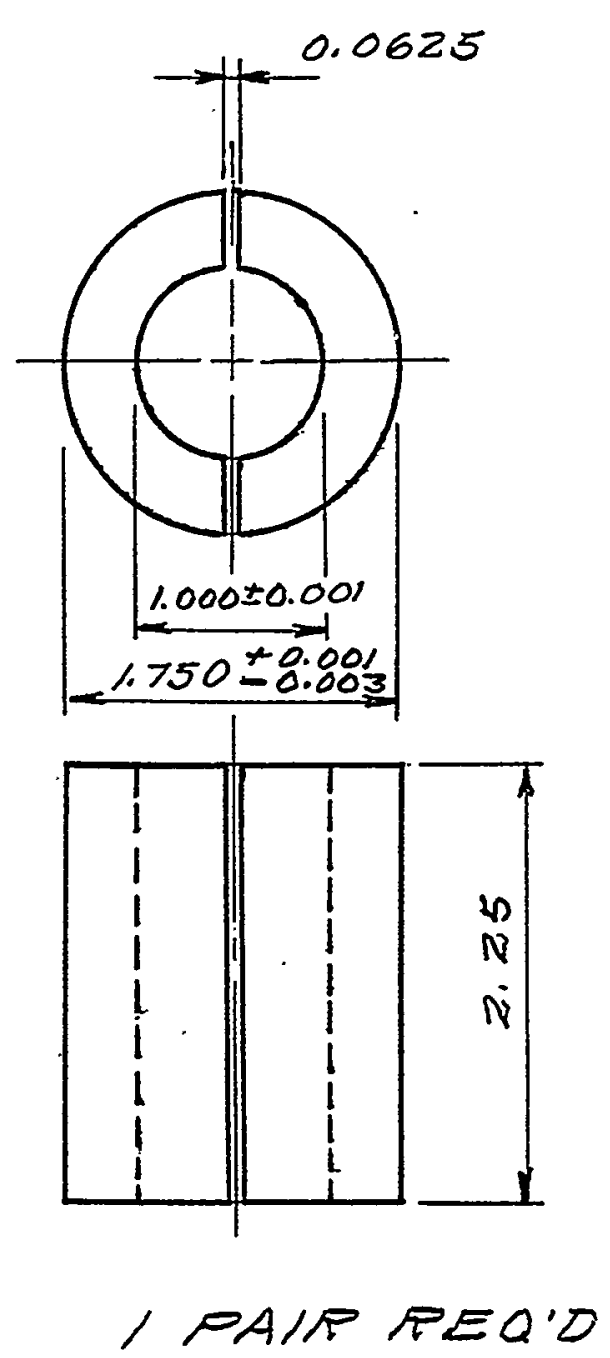

Notes:

1. Dimensions in inches

2. Material: Hardened steel

3. Finish :

Fig. A.2. Sketch of split collar used to mount torque transducer in collet grips of test machine. 


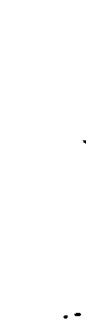


ORNL-6953

\section{INTERNAL DISTRIBUTION}

1. R. L. Battiste

2. H.W. Blake

3. R. G. Bowman

4. C. R. Brinkman

5-14. J. M. Corum

15. W. G. Craddick

16. M. Elahi

17. D. L. Erdman

18. J. G. Hansen

19. L. D. Klett

20. R. E. Norris
21. W. Ren

22. M. B. Ruggles

23. J. M. Starbuck

24. P. A. Sklad

25. C. D. Warren

26. Y.J. Weitsman

27. G. T. Yahr

28. S. Simunovic

29. R. E. Ziegler

30. ORNL Patent Section

31. Laboratory Records, ORNL-RC

\section{EXTERNAL DISTRIBUTION}

32. R. A. Bergen, MSX International, 255 Rex Boulevard, Auburn Hills, Michigan 48326.

33. K. Fielder, The Dow Chemical Company, 2301 N. Brazosport Blvd., B1608, Freeport, Texas 77541-3257.

34. R. B. Freeman, The Budd Company, 1515 Atlantic Boulevard, Auburn Hills, Michigan 48326

35. R. Gjerde, Textron Automotive Company, 100 Brady Road, Americus, Georgia 31709.

36-64. E. M. Hagerman, Automotive Composite Consortium, General Motors, 30500 Mound Road, I-6, Box 9055, Warren, Michigan 48090-9055.

65. J. M. Henshaw, Department of Mechanical Engineering, The University of Tulsa, $600 \mathrm{~S}$. College Avenue, Tulsa, Oklahoma 74104-3189.

66. G. A. Holmes, National Institute of Standards and Technology, Bldg. 224, Room B116, MS: Room B108, Gaithersburg, Maryland 20899.

67. D. Kossak, Cambridge Industries, 29333 Stephenson Highway, Madison Heights, Michigan 48071.

68. F. G. Krautz, Vetrotex Certainteed, 4515 Allendale Road, Wichita Falls, Texas 763102199.

69. K. Liechti, Engineering Mechanics Research Laboratory, Department of Aerospace Engineering and Engineering Mechanics, The University of Texas at Austin, Austin, Texas 78712.

70. G. R. Miesel, Ashland Chemical Company, 900 Wilshire Drive, Suite 100, Troy, Michigan 48084.

71. L. M. Ojanen, Decona International, 50 Casmir Court, Concord, Ontario, Canada L4K $4 \mathrm{~J} 5$.

72. D. Oplinger, AAR-431, FAA William J. Hughes Technical Center, Atlantic City International Airport, New Jersey 08405.

73. T. A. Reinhart, The University of Dayton Research Institute, 300 College Park Drive, Dayton, Ohio 45469-0130.

74. G. Sandgren, Owens Corning Science \& Technology Centre, 2790 Columbus Road, Route 16, Granville, Ohio 43023-1200.

75. C. R. Schultheisg, National Institute of Standards and Technology, Building 224, Room A209, Gaithersburg, Maryland 20899.

76. T. D. Seagrave, Bayer Corporation, 100 Bayer Road, Pittsburgh, Pennsylvania 15205.

77. L. V. Smith, Washington State University, School of Mechanics and Materials Engineering, Pullman, Washington 99164-2920.

78-81. J. A. Carpenter, U.S. Department of Energy, 1000 Independence Avenue, SW, Washington, DC 20588. 
82. P. G. Patil, U.S. Department of Energy, 1000 Independence Avenue, SW, Washington, DC 20588

83. M. Rowlins, U.S. Department of Energy, Oak Ridge Site Office, Oak Ridge, Tennessee 37831.

84. J. Russell, U.S. Department of Energy, 1000 Independence Avenue, SW, Washington, DC 20588. 